\title{
Severe Winter Weather in the Continental U.S. and Global Climate Cycles
}

Steven F. Daly, Julie E. Friddell, Kathleen F. Jones,

October 2004 and Carrie M. Vuyovich

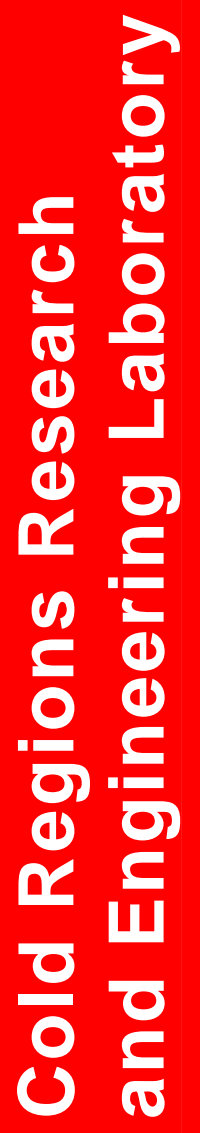





\section{Severe Winter Weather in the Continental U.S. and Global Climate Cycles}

Steven F. Daly, Julie E. Friddell, Kathleen F. Jones, and Carrie M. Vuyovich

Cold Regions Research and Engineering Laboratory

U.S. Army Engineer Research and Development Center

72 Lyme Road

Hanover, New Hampshire 03755

Approved for public release; distribution is unlimited

Prepared for U.S. Army Corps of Engineers 


\section{ABSTRACT}

The relationship between severe winter weather in the United States and global climate indices is investigated using data from 1950 to 2002. Winter severity is characterized by accumulated freezing degree-days (AFDD) and damaging freezing rain storms. The first eigenvector of the AFDD anomaly, based on data from 2282 weather stations, shows a pattern in which the entire country tends to be either warmer or colder than average, while the second eigenvector has opposite deviations in the East and West. The relationship between the first three principal component time series and five climate indices, PDO, SOI, PNA, NAO, and Northern Hemisphere temperatures, is investigated using step-wise linear regression. This analysis shows that the most important indices for explaining the annual variation in AFDD are the NAO and PNA. An estimate of the AFDD anomaly for the winter of 2003 using analog years to hindcast the climate indices significantly underestimates the warmth in the West and the cold in the Northeast. The annual variation in the area and path of ice storms is only weakly correlated with the NAO. However, the averages of the SOI and NAO in winter months with ice storms are closer to zero than their averages in winter months without ice storms. This investigation will be extended to other regions of the world to characterize the regional AFDD as well as summer temperature patterns and determine their relationships to global climate cycles

DISCLAIMER: The contents of this report are not to be used for advertising, publication, or promotional purposes. Citation of trade names does not constitute an official endorsement or approval of the use of such commercial products. All product names and trademarks cited are the property of their respective owners. The findings of this report are not to be construed as an official Department of the Army position unless so designated by other authorized documents. 


\section{CONTENTS}

Conversion factors, non-SI to SI units of measurement ……….......................

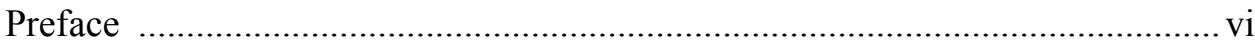

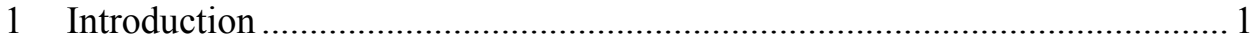

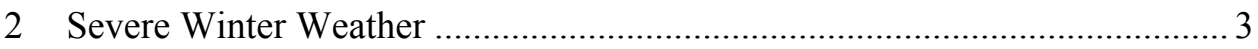

Annual Maximum Accumulated Freezing Degree-Days (AFDD) .................. 3

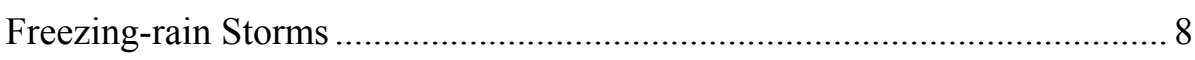

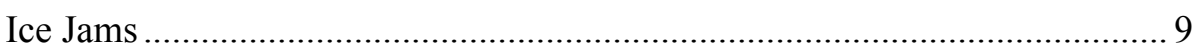

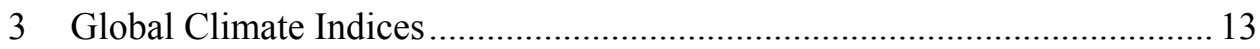

Some Common Climate Indices and Their Methods of Calculation ............. 13

Climate Indices that Impact the U.S......................................................... 16

Correlation of Climate Indices ................................................................. 18

4 Parameterization of severe winter weather................................................. 21

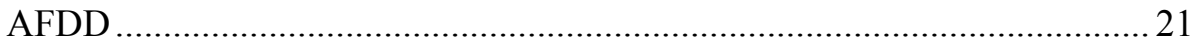

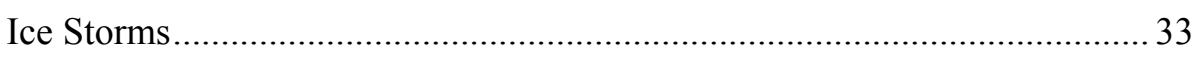

5 Correlation of winter weather with climate indices...................................... 38

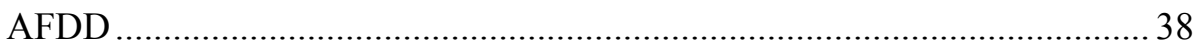

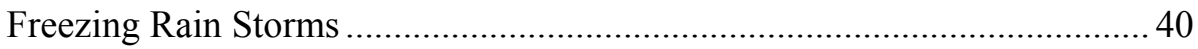

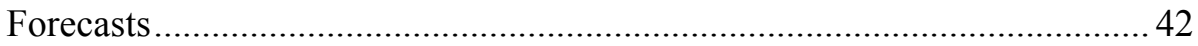

6 Summary, Discussion, and Future Work ...................................................... 46

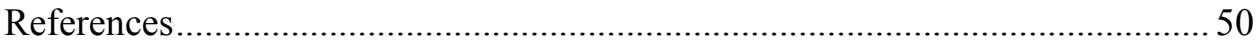

Appendix A : Annual Maps of Severe Winter Weather 1949-2001 ................... 54

\section{ILLUSTRATIONS}

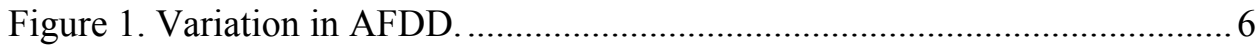

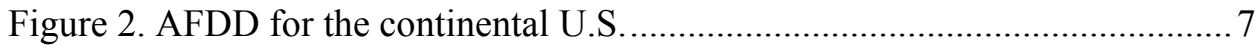

Figure 3. Damaging freezing-rain storms, 1947 to 2003 ..................................... 9

Figure 4. Ice jams................................................................................... 11

Figure 5. Locations for calculation of SOI and NAO difference indices............. 14

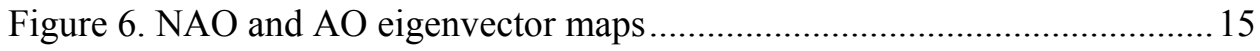

Figure 7. Pacific Decadal Oscillation warm phase and cold phase maps ............ 17 


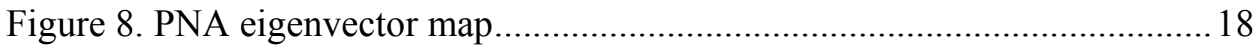

Figure 9. Time series for winter temperature anomalies and climate indices ......20

Figure 10. Teleconnectivity of maximum AFDD...............................................2 22

Figure 11. One-point correlation maps for New York......................................... 23

Figure 12. One-point correlation maps for California. .......................................24

Figure 13. Thiessen polygons for the AFDD stations.......................................25

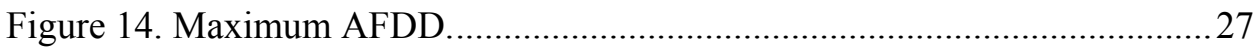

Figure 15. Covariance principal components for eigenvectors of $U_{\max }$..............2 28

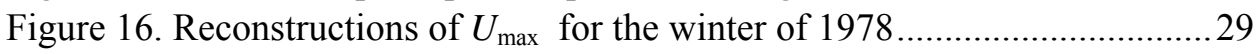

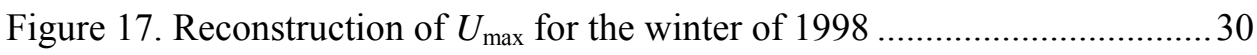

Figure 18. One-point correlation map corresponding to EOF1......................... 31

Figure 19. One-point correlation maps corresponding to EOF2 ......................... 32

Figure 20. Locations of weather stations with hourly data............................... 33

Figure 21. Damage footprint of freezing-rain storm of December 2002 ............ 34

Figure 22. Variation of ice storm area by year. .................................................. 34

Figure 23. Average damaging ice storm area and path........................................35

Figure 24. Annual variation of ice storm area and deviation of average path. .... 37

Figure 25. Comparison of principal components of AFDD ................................ 41

Figure 26. Climate index means in months with and without ice storms. ........... 42

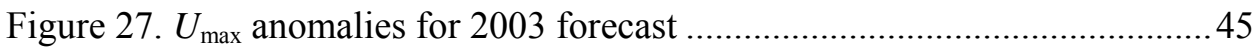

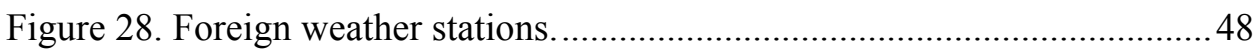

\section{TABLES}

Table 1. Correlation matrix for the eight climate and temperature indices.......... 19 Table 2. Linear correlation of the principal components of $U_{\max }$ and climate

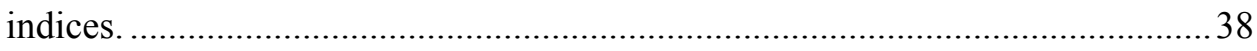

Table 3. Spearman rank-order correlation of ice storm severity with climate indices for each winter. 


\section{CONVERSION FACTORS, NON-SI TO SI UNITS OF MEASUREMENT}

Non-SI units of measurement used in this report can be converted to SI units as follows:

\begin{tabular}{|l|l|l|}
\hline Multiply & By & To obtain \\
\hline $\begin{array}{l}\text { degrees Fahrenheit } \\
\text { inches }\end{array}$ & $5 / 9$ & $\begin{array}{l}\text { degrees Celsius or } \\
\text { kelvins }\end{array}$ \\
meters
\end{tabular}

${ }^{1}$ To obtain Celsius $\left({ }^{\circ} \mathrm{C}\right)$ temperature readings from Fahrenheit $\left({ }^{\circ} \mathrm{F}\right)$ readings, use the following formula: ${ }^{\circ} \mathrm{C}=(5 / 9)\left({ }^{\circ} \mathrm{F}-32\right)$. To obtain kelvin $(\mathrm{K})$ readings, use: $\mathrm{K}=(5 / 9)\left({ }^{\circ} \mathrm{F}-\right.$ 32) +273.15 


\section{PREFACE}

This report was prepared by Dr. Steven F. Daly, Research Hydraulic Engineer, RS/GIS and Water Resources Branch, Dr. Julie E. Friddell, Research Geophysicist, Snow and Ice Branch, Kathleen F. Jones, Research Physical Scientist, Snow and Ice Branch, and Carrie M. Vuyovich, Research Hydraulic Engineer, RS/GIS and Water Resources Branch, U.S. Army Engineer Research and Development Center, Cold Regions Research and Engineering Laboratory. The authors are listed alphabetically as all contributed equally to the work.

Funding for this project was provided by PE 61102 Project T59, Prediction of Land-Atmosphere Interactions, Work Unit Atmospheric Interactions with Terrain. The authors thank Dr. Kathleen White for helpful discussions regarding the ice jam database and Nathan Mulherin for his help in researching climate indices. This report was technically reviewed by Dr. John Weatherly and Dr. George Koenig, and their insightful comments and suggestions are greatly appreciated. The report was edited by Mark Hardenberg.

This report was prepared under the general supervision of Jacqueline A. Richter-Menge, Chief, Snow and Ice Branch; Timothy Pangburn, Chief, RS/GIS and Water Resources Branch; and James Wuebben, Acting Director, CRREL

The Commander and Executive Director of the Engineer Research and Development Center is COL James R. Rowan, EN. The Director is Dr. James R. Houston. 


\title{
Severe Winter Weather in the Continental U.S. and Global Climate Cycles
}

\author{
STEVEN F. DALY, JULIE E. FRIDDELL, KATHLEEN F. JONES, AND \\ CARRIE M. VUYOVICH
}

\section{INTRODUCTION}

Winters in much of the United States are characterized by low temperatures; snow, freezing rain, and ice pellet storms; and ice-covered rivers and lakes. The severity of any winter with respect to each of these aspects of winter weather varies considerably both from year to year and spatially over the country. This variability in severity is reflected in variability in heating costs to homeowners, snow-clearing costs to municipalities, transportation costs to businesses, and emergency response and management costs to utilities and local, state, and Federal governments. With the prospect of continued gradual or even abrupt global climate change, either natural or anthropogenic, winters may change. In addition to changes in mean conditions, global warming is likely to change extreme events, with more frequent heat waves, less frequent cold spells, greater intensity of mean and peak precipitation, an increased intensity of mid-latitude storms, and more intense El Niño-Southern Oscillation events (Folland et al. 2001b). In terms of winter weather, other research suggests that, even with global warming, cold spells could become more frequent in some regions as climate becomes more extreme overall (Friddell et al. 2003, Shabbar and Bonsal 2003). On the other hand, ocean circulation changes could cause abrupt and lasting regional cooling (Pittenger and Gagosian 2003). Because winter weather and climate can have significant effects on our society, we have sought to understand extreme winter weather and its potential for prediction.

This report has two goals. The first is to present the variation of winter weather in the United States over the last half of the twentieth century, using data already compiled at CRREL for other research projects. We have data on snow water equivalent, cold weather, ice covers, and freezing rain storms. In Section 2 and Appendix A, we describe the data and provide maps showing the annual

\footnotetext{
* These authors contributed equally to the work.
} 
variation. Our second goal is to determine the relationships between winter weather and global climate patterns. Large-scale climate patterns have somewhat predictable and reproducible effects on the weather. Many researchers (recently, for example, Huang et al. 1998, McCabe and Dettinger 2001, Rodionov et al. 2001, Rodionov and Assel 2001) have examined the relationship between these climate patterns and aspects of winter weather over a portion of the U.S. McCabe and Dettinger (2001) related snow pack in the western U.S. with Pacific Ocean climate. Rodionov et al. (2001) related the fraction of ice cover on the Great Lakes to modes of large scale atmospheric circulation. Rodionov and Assel (2001) examined flow patterns over North America and winter severity in the Great Lakes basin. Huang et al. (1998) found that the El Niño-Southern Oscillation and the North Atlantic Oscillation (NAO) act together to alter storm track locations over North America and the North Atlantic. El Niño and NAO, as well as several other indices or modes of variability that affect North American climate, are described in Section 3 with the corresponding index showing the variation from winter to winter. In Section 4 we quantify our measures of winter severity, temporally and spatially. In Section 5 we relate the temporal variation of winter severity to the climate indices and provide forecasts based on both predicted and possible changes in the climate patterns. Finally, Section 6 is a discussion of our results and the work we have planned for the future. 


\section{SEVERE WINTER WEATHER}

Researchers at the U.S. Army Engineer Research and Development Center, Cold Regions Research and Engineering Laboratory (CRREL), study aspects of cold weather in many different regions of the world, including the polar regions, potential conflict zones, and the United States. The focus of the research in the U.S. has typically been in the fields of civil works, including navigable waterways, the design of buildings and other structures for wintertime loads, and military base operations. For these projects, various research groups have gathered data for long periods of record in the continental U.S. and Alaska on 1) snow depths or snow water equivalent, or both, 2) accumulated freezing degree-days, 3) freezing rain storms, and 4) ice jams. The snow data base consists of the maximum annual snow depths, or snow water equivalent, depending on the station, for 10,050 stations covering the country in a dense array. However, for most of the stations for most of the period of record, the year in which each maximum occurred was not recorded, so we could not use those data for this study. The data for the other three measures of winter severity are described in the following sections.

\section{Annual Maximum Accumulated Freezing Degree-Days (AFDD)}

The value of annual maximum accumulated freezing degree-days recorded at a site is a good indicator of the severity of the winter with respect to surface ice growth, frost penetration, and other impacts that arise through heat transfer to the atmosphere. The AFDD is a monotonically increasing function calculated as the sum of the positive difference between freezing and the average daily temperature for each day of the winter season. (If the average daily temperature is greater than freezing, the difference is ignored.) The AFDD on any day of the winter season, $U_{\mathrm{n}}$, represents the accumulated difference between freezing and the average daily temperature for the previous $n$ days. The accumulation process starts each fall before the average daily temperature has dropped below freezing.

$$
U_{\mathrm{n}}=\sum_{i=0}^{n}\left(T_{\mathrm{m}}-T_{\mathrm{i}}\right) \quad \text { for }\left(T_{\mathrm{m}}-T_{\mathrm{i}}\right)>0
$$

where $n=$ the number of days since the start of the winter season and $T_{\mathrm{m}}=$ the ice/water equilibrium temperature $\left(32^{\circ} \mathrm{F}\right.$ or $\left.0^{\circ} \mathrm{C}\right)$. The average daily temperature $T_{\mathrm{i}}$ was estimated as the mean of the maximum temperature, $T_{\mathrm{imax}}$, recorded on 
that day and minimum temperature, $T_{\mathrm{imin}}$. The annual maximum AFDD, $U_{\max }$, is the maximum value that $U_{\mathrm{n}}$ attains over the course of the winter.

To demonstrate the utility of $U_{\max }$ to estimate maximum ice thickness, we start with the equation for surface ice growth on water bodies:

$$
\frac{\partial \eta}{\partial t}=\frac{\phi}{\rho \lambda}=\frac{k_{i}}{\rho \lambda \eta}\left(T_{\mathrm{m}}-T_{\mathrm{s}}\right)
$$

where

$$
\begin{aligned}
\eta & =\text { ice thickness } \\
t & =\text { time } \\
\phi & =\text { heat transfer rate per unit area from the ice to the atmosphere } \\
\rho & =\text { ice density } \\
\lambda & =\text { latent heat } \\
k_{\mathrm{i}} & =\text { thermal conductivity of the ice } \\
T_{\mathrm{s}} & =\text { the temperature of the surface of the ice. }
\end{aligned}
$$

Note that we are explicitly assuming that the ice growth occurs at the bottom surface; that the rate-controlling step is heat conduction through the ice cover; and that the temperature profile through the ice is linear. These assumptions are discussed elsewhere (U.S. Army 2002); in general, they lead to useful and accurate estimates of ice thickness. If the surface temperature of the ice is assumed to be at the air temperature (a reasonable assumption if the heat transfer is effectively controlled by conduction through the ice cover), eq 2 can be solved as

$$
\eta_{\mathrm{n}}=\sqrt{\frac{2 k_{\mathrm{i}}}{\rho \lambda} \int_{0}^{t=n \text { days }}\left(T_{\mathrm{m}}-T_{\mathrm{i}}\right) d t}=\alpha \sqrt{U_{\mathrm{n}}}
$$

where $\alpha$ varies depending on the physical location of the site of interest. For example, $\alpha$ varies from 0.2 for a small sheltered river to 0.8 for a windy lake with no snow cover, if AFDD is calculated using degrees Fahrenheit and the ice thickness is in inches (U.S. Army 2002). The maximum ice thickness expected over the course of a winter can be found by using $U_{\max }$ in eq 3 .

The annual maximum accumulated freezing degree-days were determined for the continental United States, where there is a dense array of weather stations 
with electronically archived data for a long period of record, using the daily maximum and minimum temperatures recorded at first-order National Weather Service stations (NOAA 1950-present) and cooperative stations (NOAA 2001). The following steps were taken in estimating $U_{\max }$ :

- The stations that reported data in 2001 and had a record of at least 30 years were selected from the original pool of 7827 cooperative stations and 1496 first-order stations. This provided 257 first-order NWS stations and 2025 cooperative stations that were used in the analysis.

- The average temperature for each day was estimated for the period of record for each station based on the maximum and minimum air temperatures recorded at that station. If either a maximum or minimum was missing, then the average temperature was considered missing for that day.

- The accumulated freezing degree-days were estimated for the period of record for each station based on the estimated average daily temperature. The AFDD for each station was set to zero on 1 August of each year and allowed to accumulate from that point onward.

- The annual maximum AFDD, $U_{\max }$, for each station, for each winter was then found as the maximum of the AFDD accumulated over the course of the winter season. We generally found that the annual maximum AFDD was reached in March or April for most of the continental United States. If daily average temperature was missing for more than 7 days over the course of the winter, $U_{\max }$ was set to missing for the entire winter season.

- After running the program for all 2282 stations, approximately $18 \%$ of the annual maximum AFDDs were not calculated between 1949 and 2001. Each missing value was then interpolated based on the inverse distance squared weighted values at the 15 closest stations.

This analysis provided us with a time series of annual maximum accumulated freezing degree-days at 2282 stations. This record is analyzed using empirical orthogonal functions (EOF) as discussed in the Empirical Orthogonal Function (EOF) Analysis subsection of Section 4. A limited overview is presented here to provide familiarity with the results and to set the stage for the climate discussion and EOF analysis to follow.

\section{Accumulation period}

Freezing degree-days accumulate predominantly over the months of December, January, and February (Fig. 1), with approximately $86 \%$ of the AFDDs recorded during these months. This period can be defined quantitatively as the 
winter period for the continental U.S. and the specific period of time over which the climate indices are averaged for each winter season.

\section{Geographic distribution}

The average of $U_{\max }$ over the period of record was estimated for each station and mapped for the U.S. As might be expected, the geographic distribution of $U_{\max }$ is primarily from north to south (Fig. 2), with the largest values occurring in the northern part of Upper Midwest in the states of Minnesota and North Dakota.

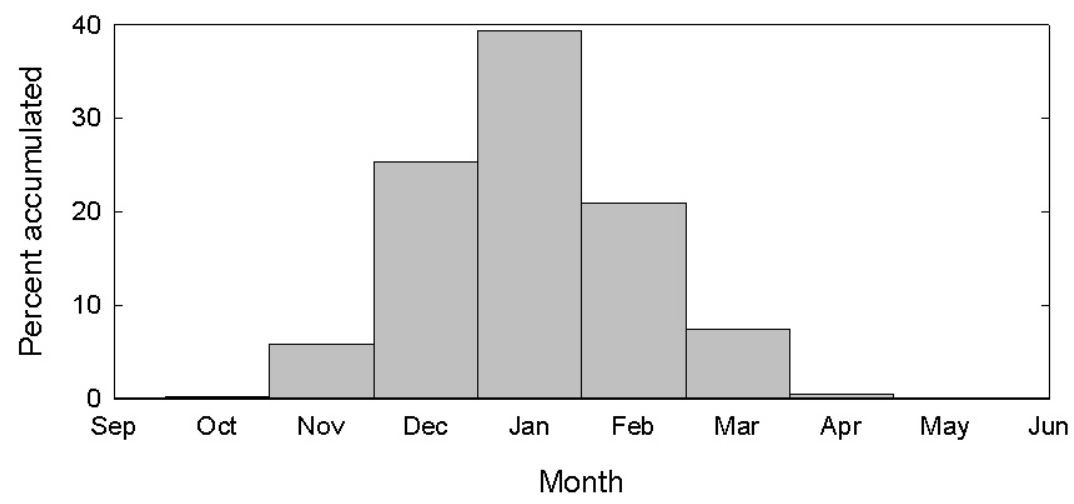

a. Accumulation of AFDD by month.

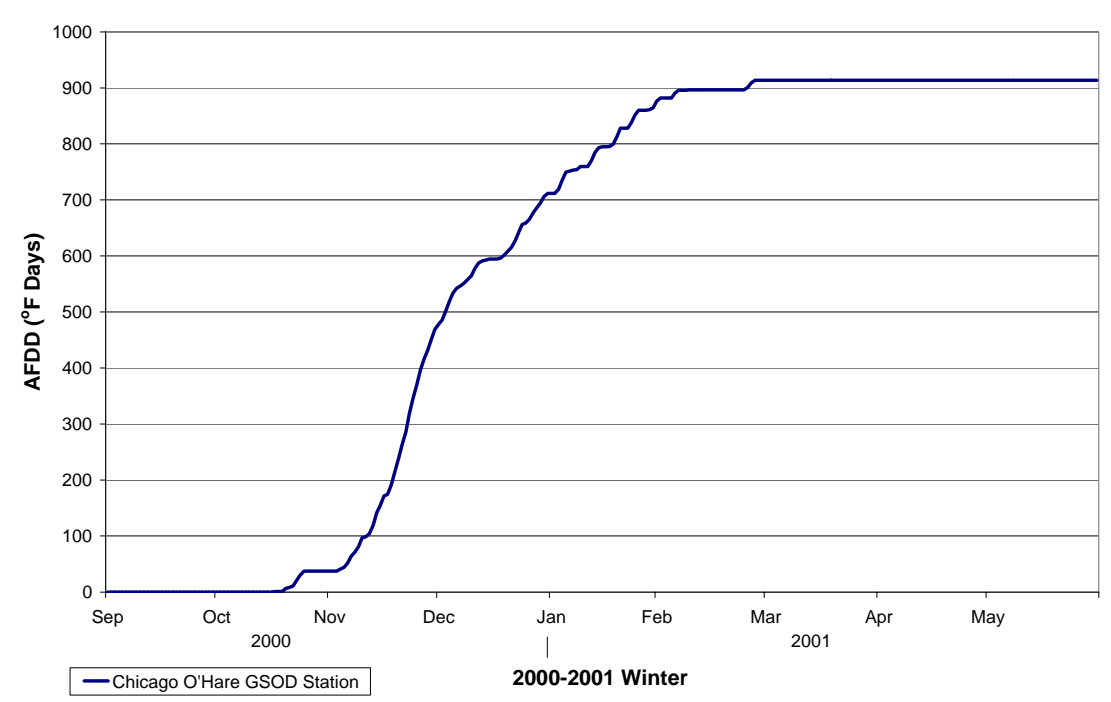

b. AFDD at Chicago O'Hare airport for the winter of 2000-2001.

Figure 1. Variation in AFDD. 


\section{Time series}

The area-weighted average of $U_{\max }$ for all stations for each year was then calculated. The area associated with each station was found by developing Thiessen polygons around each station within the borders of the continental U.S. This area weighting was done to offset the unequal geographic distribution of meteorological stations across the country. In general, there are more stations located in the eastern half of the U.S. than the western half. These annual area-weighted averages form a time series (Fig. 3) that can be used to identify particularly severe winters and relatively mild winters over the period of record.

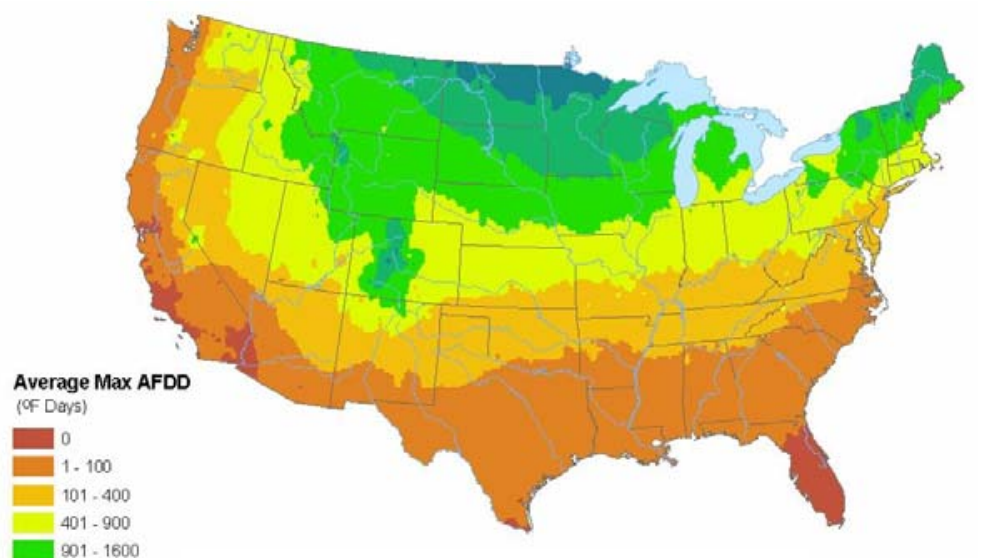

a. Mean (1950 to 2002) maximum.

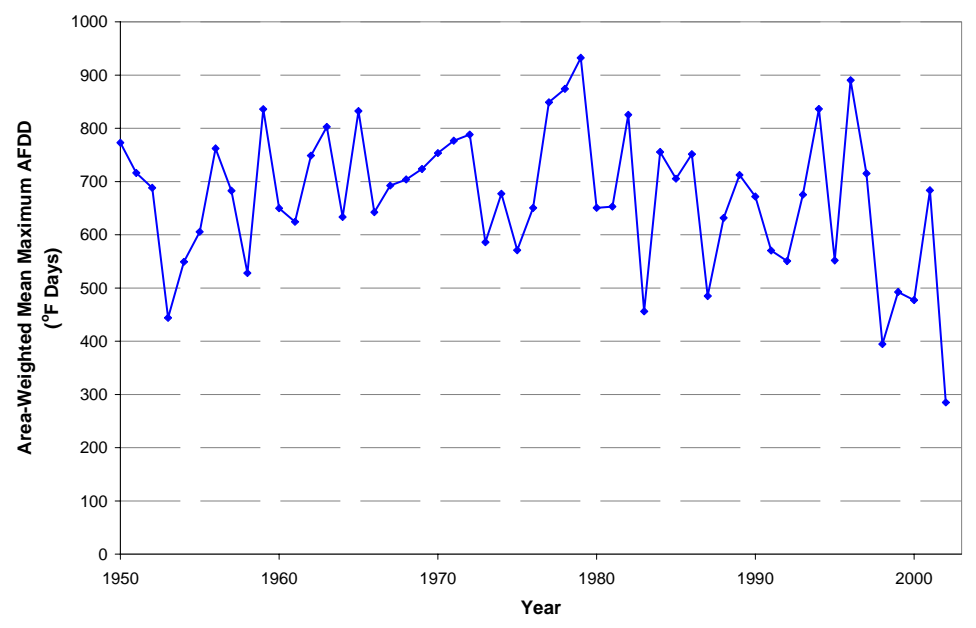

b. Variation of annual mean maximum AFDD from 1950 to 2002.

Figure 2. AFDD for the continental U.S. 
For example, the winter of 1978 was particularly cold and the winter of 1998 warm (see Appendix A). References to particular winters are by the year in which the winter ends. For example, 1978 refers to the winter beginning in 1977 and ending in 1978.

\section{Freezing-rain Storms}

Potentially damaging freezing-rain storms were investigated in newspapers, Storm Data (NOAA 1959-present) and its predecessor, Climatological Data, National Summary (NOAA 1950-1958), Federal Emergency Management Agency (FEMA) mitigation reports, and journal articles. Storms were chosen for investigation if the modeled equivalent radial ice thickness (Jones 1996, Jones et al. 2002) on a wire perpendicular to the wind direction was about 0.5 in. or more at one or more of 490 stations with full-time hourly weather data and daily or, for some stations, 6-hourly precipitation data. Damage information was obtained from any location with an equivalent radial ice thickness of about $0.25 \mathrm{in}$. or more. For each event the region where the ice storm was severe enough to damage overhead lines (telegraph, phone, electricity, cable television), trees, and communication towers was delineated.

A compilation of ice storm footprints for 1947 to 2003 is shown in Figure 3a. Alaska was included in that investigation; however, because damaging ice storms appear to occur very rarely there, it is not included in this study. Note that in the West damaging ice storms occur primarily in the Pacific Northwest in the Willamette Valley, Columbia River Gorge, and the mouth of the Fraser Valley. In the Southwest freezing rain occurs very rarely, if at all, and the amount of ice that forms in the occasional storm is only enough to cause slippery roads. The map shows relatively few ice storms along the spine of the Appalachian mountains from Tennessee north to New York. While this may be correct, it is also likely that freezing rain storms do occur at higher elevations in the mountains but are not recorded in weather data or noted in newspaper reports because weather stations tend to be at airports in the mountain valleys and because of the low population density at higher elevations.

The annual average area of damaging ice storms in each month is shown in Figure $3 \mathrm{~b}$. The months of December through February account for $77 \%$ of the storms and $90 \%$ occur between December and March. Maps of damaging ice storms for each winter from 1950 to 2001 are shown in Appendix A. 


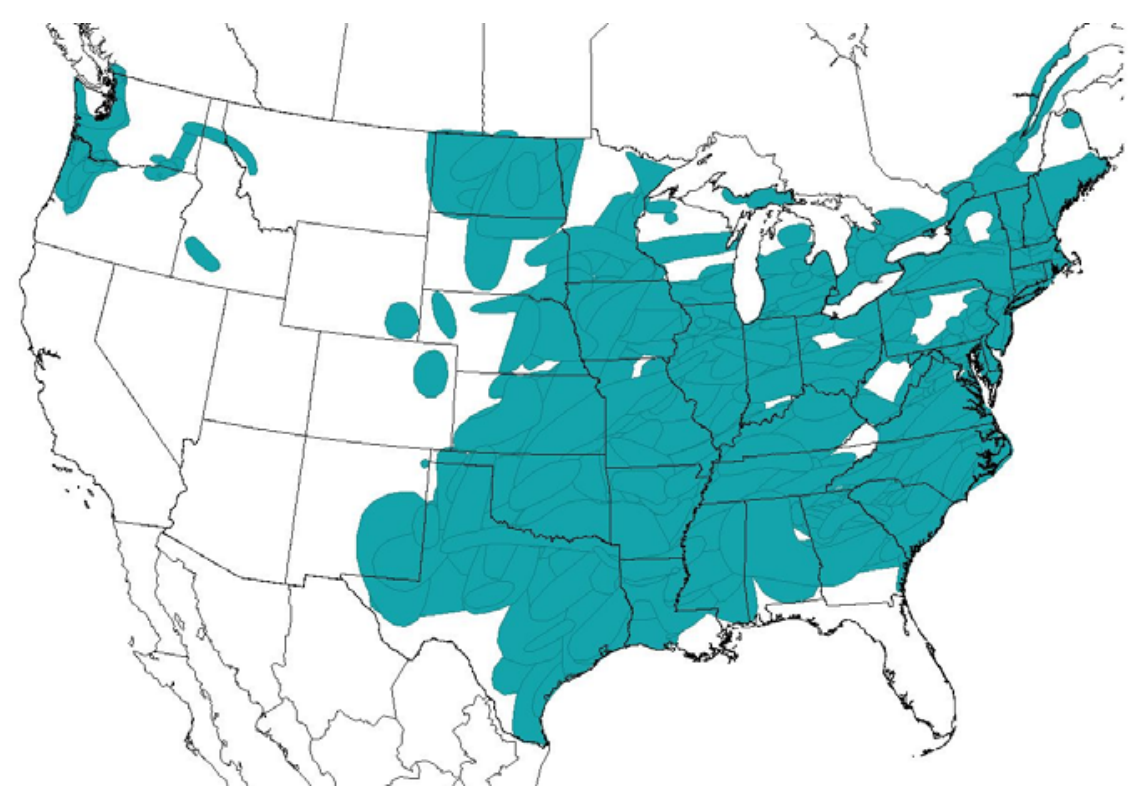

a. Location.

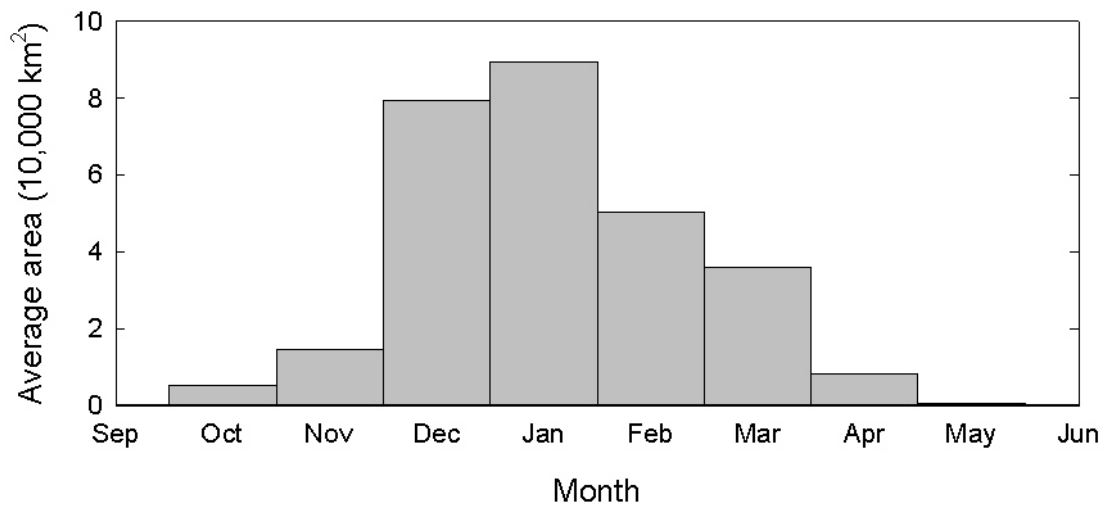

b. Occurrence of ice storms by month.

Figure 3. Damaging freezing-rain storms, 1947 to 2003.

\section{Ice Jams}

Ice on northern rivers can lead to formation of ice jams, defined as "accumulations of fragmented or frazil ice that restrict flow" (IAHR Working Group on River Ice Hydraulics 1986). Ice jams can lead to sudden and devastating 
flooding when they form and they can also cause flooding when they release. Ice jams have been the focus of much research (see, for example, Ashton 1986, Beltaos 1995) but forecasting ice jam flooding still remains elusive. Ice jams cause flood damage and, in extreme cases, loss of life; interference with waterborne navigation; reduced hydropower production; channel erosion and damage to channel training structures; and impacts on the riparian environment.

Several types of ice jams are recognized. Freezeup jams are composed primarily of frazil ice, with some fragmented ice included. They occur during early winter to midwinter. The floating frazil may slow or stop because of a change in water slope from steep to mild, because it reaches an obstruction to movement such as a sheet ice cover, or because some other hydraulic occurrence slows the movement of the frazil. Low air and water temperatures, fairly steady water and ice discharges, and a consolidated top layer of ice characterize freezeup jams.

Breakup jams happen during periods of thaw, generally in late winter and early spring, and are composed primarily of fragmented ice formed by the breakup of an ice cover or freezeup jam. The ice cover breakup is usually associated with a rapid increase in runoff and corresponding river discharge attributable to a significant rainfall event or snowmelt. The broken, fragmented ice pieces move downstream until they encounter a strong, intact downstream ice cover, other surface obstruction to flow, or other adverse hydraulic conditions, such as a significant reduction in water-surface slope. Once they reach such a jam initiation point, the fragmented ice pieces stop moving, begin to accumulate, and form a jam. The ultimate size of the jam (i.e., its length and thickness) and the severity of the resulting flooding depend on the flow conditions, the available ice supply from the upstream reaches of the river, and the strength and size of the ice pieces. Mid-winter jams are breakup jams that occur during the winter and refreeze into place, often providing locations were breakup jams can form later in the winter season.

An on-going ice jam database developed by White and Eames (1999) includes the date, location (latitude and longitude), river, municipality, type, and other information on over 14,000 ice jams and other river ice cover events that have occurred in the continental U.S. and Alaska. The locations of the ice jams in the continental U.S. are shown in Figure 4a. Historical information on river ice jams is limited. The major sources of data were the United States Geological Survey (USGS) report series that provides gaging station data collected for a study of the magnitude and frequency of floods (e.g., Green 1964); the annual USGS Water-Data Reports (e.g., Toppin et al. 1993); and in recent years, National Weather Service flood alerts. Additional sources include newspaper and historical records, such as town histories and government agency reports, and anecdotal reports by local residents obtained from personal interviews. In addi- 
tion, collection efforts were focused on specific regions. These regions include New Hampshire (Herrin et al. 2000), Vermont (White 1995), Montana (Eames et al. 1998), the Susquehanna River Basin (White 1999a), and within the boundaries of the St. Louis District of the Corps of Engineers (White 1999b).

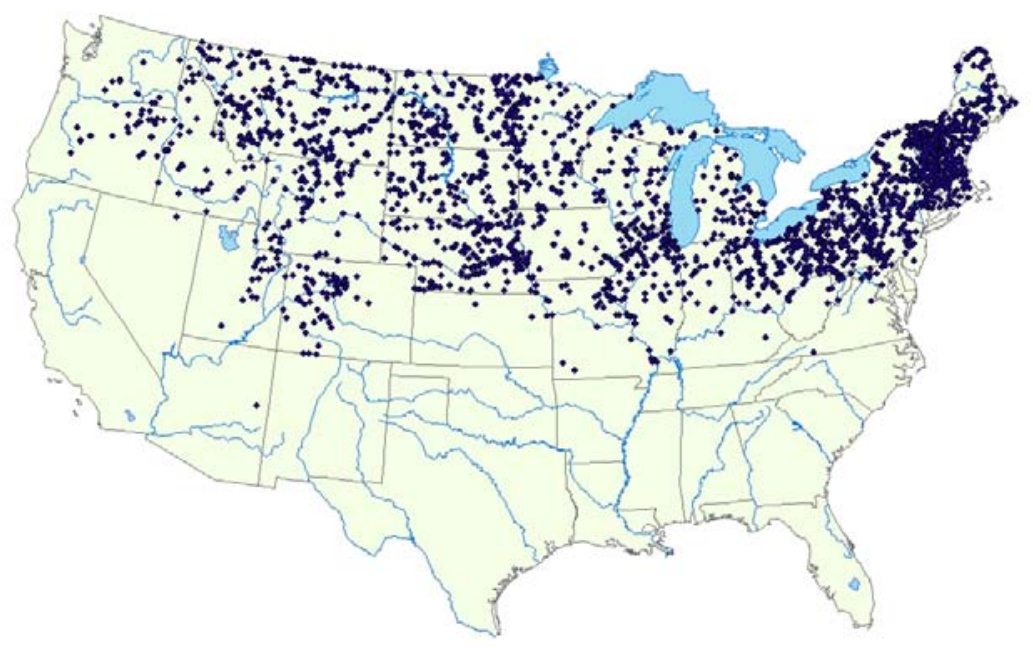

a. Ice jam and ice cover locations, 1950-2001.

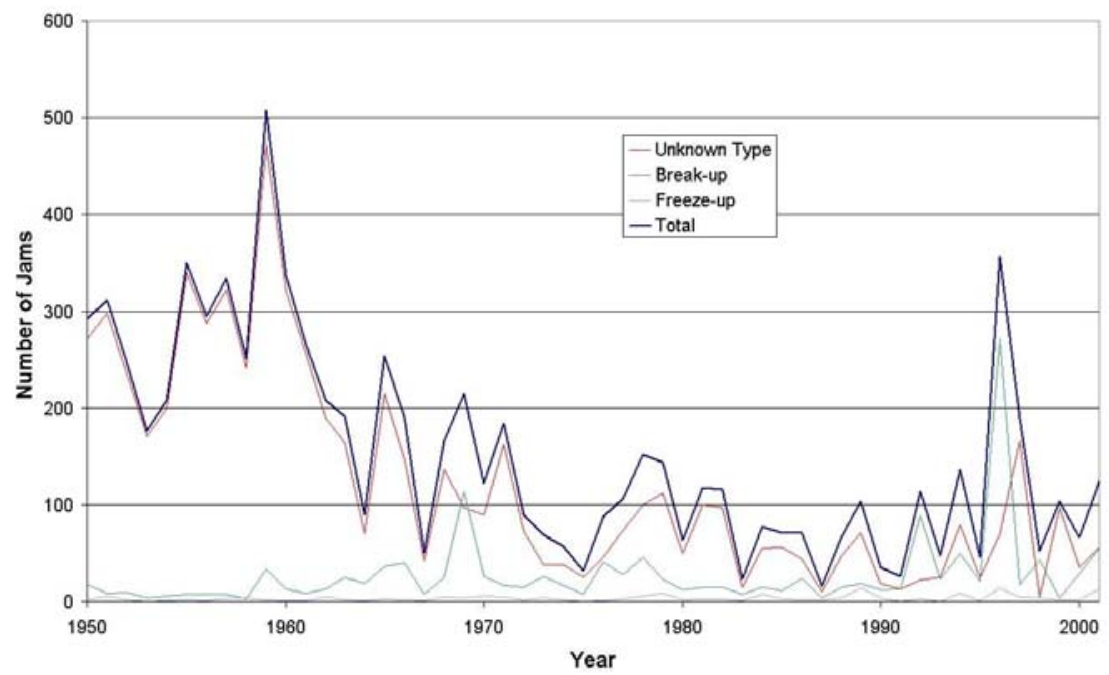

b. Annual variation in the number of ice jams and ice covers.

Figure 4. Ice jams. 
The lack of a consistent historical source on ice jams combined with focused studies of specific areas has resulted in a record that is not homogenous in time or space. The number of ice jams recorded in the ice jam database each year is shown in Figure 4b. Although the ice jam type is one of the descriptors included in the ice jam database, the majority of entries in the database have been entered with "Unknown" type. This usually means that not enough information was available on the ice jam event to allow the type of jam to be determined. The data prior to 1963 are primarily from the USGS record. The study of the magnitude and frequency of floods was ended in about 1965; the large drop in recorded ice events after that time is apparent. The regions that were the focus of specific studies have, in general, more ice jam events listed in the database than other regions. Unfortunately, this means that the spatial distribution of ice jams does not reflect their actual occurrence but rather the vagaries of the data collection effort. Thus, the information in the database does not represent the spatial and temporal variation of ice jams across the country and cannot be used as a measure of the variation in winter severity in the U.S. 


\section{GLOBAL CLIMATE INDICES}

Long-term, interannual- or decadal-scale changes in regional weather patterns are often described in terms of climate indices. A climate index is a measurement through time of one or more meteorological parameters that is understood to be representative of environmental conditions in a particular location. These parameters can be air or ocean temperature, atmospheric pressure, precipitation, humidity, windiness, or other measured variables that express the character of local or regional climate. Many indices are useful to a specific group of people. For example, measures of the soil moisture levels in the Great Plains are useful to farmers and consumers of their products. Other indices have direct bearing on the physics of the climate system and help the scientific community understand the drivers and mechanisms of global climate, as well as how climate is changing over years and decades. Some climate indices are designed to reach a pre-defined threshold numerical value, such as plus or minus one standard deviation, when the climate changes enough that most people will notice a difference between today's weather patterns and those of past decades. An example of this type of index is the Common Sense Climate Index, which is based on a combination of several climate indicators, such as heating degree-days and the frequency of intense precipitation (Hansen et al. 1998). Most climate indices are calculated as standardized deviates $s_{\mathrm{i}}=\left(x_{\mathrm{i}}-m\right) / \sigma$ of a single meteorological variable $x_{\mathrm{i}}$ from the average $m$ and standard deviation $\sigma$ for a base time interval, commonly the years 1961-1990, such that the largest deviates represent periods of extreme climate. In this study, we have chosen a set of indices commonly used in the climate research community to represent climate changes in the U.S. during the second half of the $20^{\text {th }}$ century.

\section{Some Common Climate Indices and Their Methods of Calculation}

There are dozens of indices of climate, but for this study we concentrate only on those that provide information on climate changes occurring in the U.S. The El Niño-Southern Oscillation Index (SOI) is one of the most familiar climate indices to people in the U.S. because of the damaging storms that hit the west coast and the Northeast during the strong El Niño event of 1997-98. Although other definitions of this index exist, the SOI is traditionally defined as the difference in sea-level atmospheric pressure (SLP) between Darwin, Australia, and the mid-Pacific island of Tahiti (Fig. 5). This index has been recorded for over 100 years and was originally designed to be a measure of the oceanic and atmospheric conditions in the equatorial Pacific Ocean. 


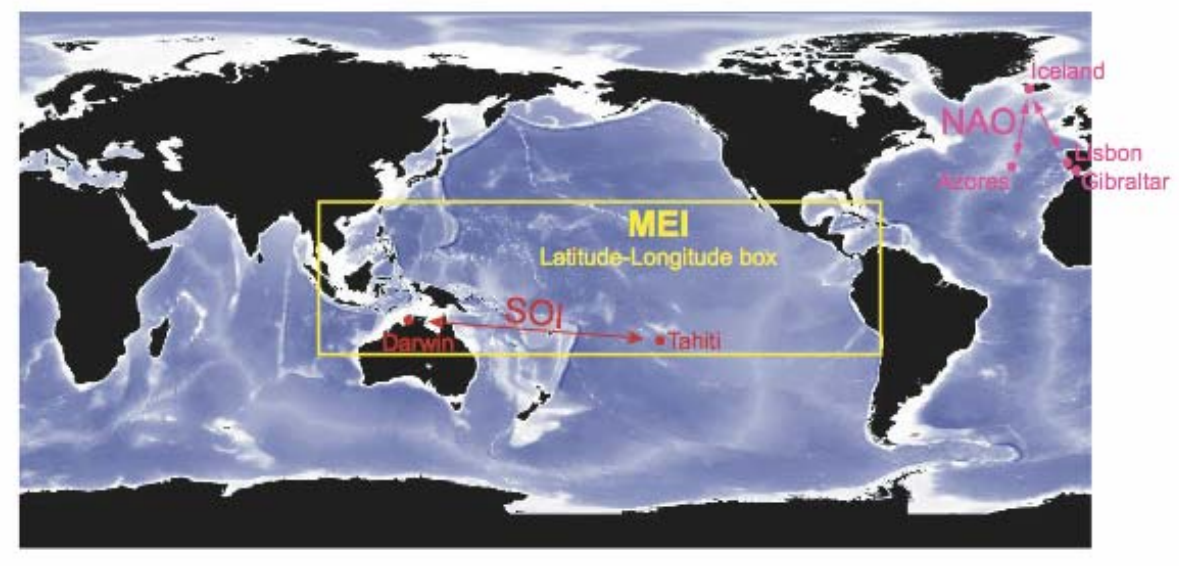

Figure 5. Locations for calculation of SOI and NAO difference indices. Also shown is the latitude-longitude box over which the six variables are averaged for calculation of the MEI (after Wolter and Timlin 1993).

However, the mechanism that causes changes in the index itself, warmer or cooler ocean water near the South American coast resulting from changes in the direction of the equatorial Pacific winds, also influences weather patterns in other parts of the western hemisphere, including the U.S. Most notably, when the SOI is negative and an El Niño event is occurring, the upper U.S. Midwest is anomalously warm and the Southeast is cool, and rainfall in the western U.S. is heavier than normal. ${ }^{*}$ During the last strong El Niño event in 1997-98, flowers bloomed in California's Mojave Desert whose seeds had been dormant for decades, and the Atlantic hurricane season was one of the quietest on record. Positive SOI, on the other hand, is called La Niña, and many of the U.S. weather patterns are opposite those of an El Niño event. SOI usually swings from an El Niño state to La Niña and back again every 3 to 7 years. An absence of either markedly positive or negative SOI during 2003 and 2004 has presented climatologists difficulty in forecasting El Niño or La Niña conditions owing to an apparent lack of seasonal predictability of this climate phenomenon.

Another climate index that is becoming more familiar to the general public owing to its effect on winter weather in the U.S. is the North Atlantic Oscillation (NAO). The NAO, a measure of primarily winter conditions in the North Atlantic Ocean, is traditionally defined as the SLP difference between the northern North Atlantic low pressure center, usually identified as Iceland, and the midlatitude eastern North Atlantic high pressure center, identified as the Azores, Lisbon, or Gibraltar (Fig. 5). Positive NAO, as was prevalent in the 1980s and

${ }^{*}$ http://www.pmel.noaa.gov/tao/elnino/impacts.html 
1990s, is related to zonal flow across North America and the Atlantic and higher than average temperatures across the U.S., especially in the Southeast, because of a very fast jet stream carrying warmth from the Pacific to the Atlantic (Hurrell et al. 2003). Negative NAO is associated with blocking of the jet stream by high pressure over the far northern North Atlantic, usually Greenland. This blocking was present during the last two winters (2003 and 2004) and results in harsh winter weather and low temperatures in the eastern U.S. and Europe.
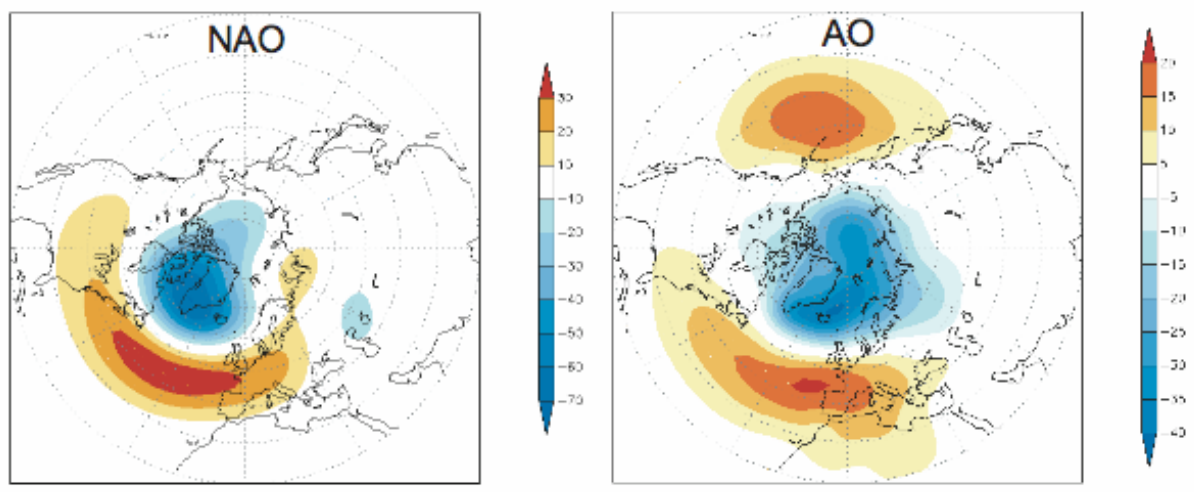

Figure 6. NAO and AO eigenvector maps from EOF analysis of $20^{\text {th }}$ century Northern Hemisphere atmospheric height anomalies. Contours are representative of positive and negative poles in the NAO dipole and the AO tripole such that when atmospheric height is anomalously low over the blue areas, it is anomalously high over the orange areas, and vice versa."

The NAO index definition is comparable to the SOI definition presented above - both are calculated from time series of meteorological data from two locations. However, climate indices are more commonly calculated from a global or hemispheric data set, such as temperature or atmospheric pressure. The NAO that we use in this project is derived from an empirical orthogonal function (EOF) analysis (see Section 4 for a discussion of EOFs) of Northern Hemisphere monthly atmospheric height anomalies (i.e., the altitude of a specified atmospheric pressure at a specified location). The pattern that results (Fig. 6) shows the same Iceland-Azores dipole that is captured by the two-station difference (Fig. 5). However, as the EOF analysis employs data from many additional locations, it provides information on the spatial extent of the dipole across the North Atlantic basin and adjacent continents. The indices used in climate studies, including SOI, NAO, and most of the others we will discuss below, have a variety of definitions and methods of calculation. Even with these differences, the various time

\footnotetext{
* Adapted from http://www.cpc.ncep.noaa.gov/products/precip/CWlink/pna/nao_loading.html and http://www.cpc.ncep.noaa.gov/products/precip/CWlink/daily ao index/loading.html)
} 
series for a particular index tend to be well correlated with each other. For this study, we have chosen climate indices from EOF analyses, when they are available, so that the teleconnection pattern is based on the entire pressure or temperature field, rather than on anomalies at a few selected locations.

\section{Climate Indices that Impact the U.S.}

Because we are investigating the relationship between global climate and winter weather in the continental U.S., we chose indices whose regional influence includes the U.S. We initially compiled monthly values of six global climate indices for the years 1950 to 2001 . The indices are reported as standardized deviates from a base time period (usually 1961-1990) and therefore are dimensionless and usually lie between -3 and +3 .

The eastern tropical Pacific Ocean, represented by the two indices SOI ${ }^{*}$ and the Multivariate ENSO Index (MEI) ${ }^{\dagger}$ (Wolter and Timlin 1993), influences U.S. climate through demonstrated temperature and precipitation teleconnections. One of the dominant teleconnections with the tropical SOI is greater precipitation in the western and southeastern U.S.during an El Niño event (when SOI is negative) (e.g., Ropelewski and Halpert 1987). As outlined above, the SOI is the sealevel pressure difference between Darwin and Tahiti (Fig. 5). The MEI is a more complex index: it is a weighted average of the main El Niño features contained in the six variables of sea-level pressure, the east-west and north-south components of the surface wind, sea surface temperature (SST), surface air temperature, and total amount of cloudiness over the equatorial Pacific (Fig. 5).

The North Atlantic Ocean influences the U.S. primarily through the trough/ridge vs. zonal flow pattern of the jet stream and is represented by both the NAO $^{\ddagger}$ and the Arctic Oscillation (AO). ${ }^{\S}$ The AO, which behaves similarly to the NAO and is considered by some to be its climatological equivalent, is the first eigenvector of the 1000 -mbar height anomaly from $20^{\circ} \mathrm{N}$ poleward and thus represents the dominant pattern of atmospheric pressure variation over most of the Northern Hemisphere (Thompson and Wallace 1998) (Fig. 6). Positive NAO and $\mathrm{AO}$, as have been seen increasingly during the last half of the $20^{\text {th }}$ century (see Fig. 9), are related to net melting of the sea ice in the Arctic Ocean (Rothrock et al. 1999, Tucker et al. 2001), and negative NAO is associated with snowy winters in the eastern U.S.

\footnotetext{
* ftp://ftpprd.ncep.noaa.gov/pub/cpc/wd52dg/data/indices/reqsoi.for

$\dagger$ http://www.cdc.noaa.gov/people/klaus.wolter/MEI/table.html

\pm http://www.cpc.ncep.noaa.gov/products/precip/CWlink/pna/norm.nao.monthly.b5001.current.ascii

${ }^{\S}$ http://www.cpc.ncep.noaa.gov/products/precip/CWlink/daily ao index/monthly.ao.index.b50.current.ascii
} 

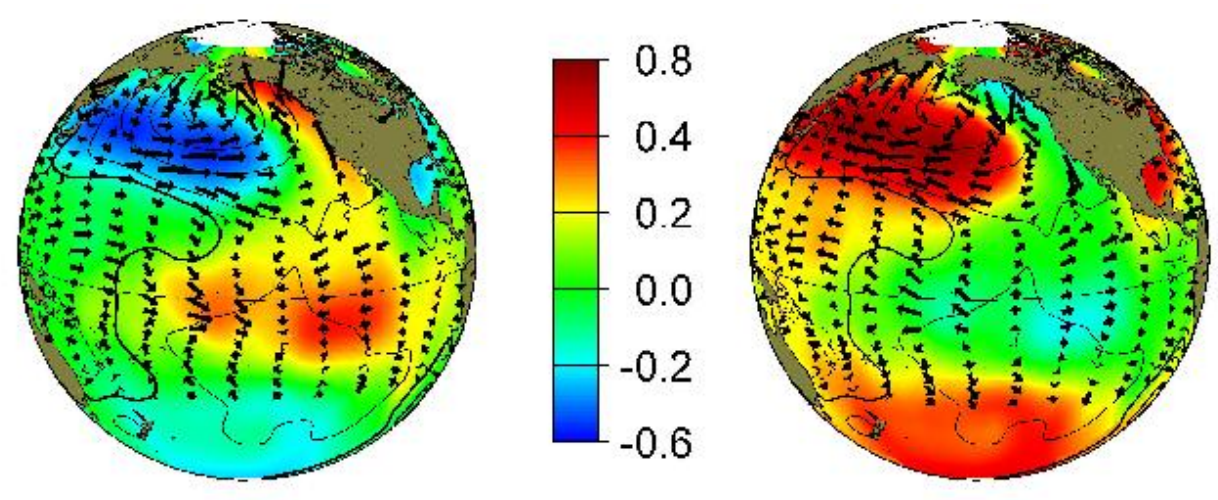

Figure 7. Pacific Decadal Oscillation warm phase (left) and cold phase (right) maps. Winter sea surface temperature is colored and wind directions are represented by arrows (adapted from Mantua et al. 1997; Obtained from the University of Washington's Joint Institute for the Study of the Atmosphere and Oceans with permission from Nathan Mantua).

Climatic variations in the north Pacific Ocean, represented by the Pacific Decadal Oscillation (PDO) ${ }^{*}$ (Mantua et al. 1997), influence the U.S. climate through the mid-latitude westerlies. The PDO is defined as the dominant mode of variability of North Pacific monthly sea surface temperature poleward of $20^{\circ} \mathrm{N}$. In general, when the PDO is in its positive (warm) phase (Fig. 7), as it was during the 1980s and 1990s, the western U.S. has relatively warm and wet winters and the southeast U.S. is cool. The PDO switches from dominantly cold phase to warm phase (and vice versa) every few decades; thus, forecasting of this unusually persistent index is being actively investigated. The equatorial Pacific SOI and MEI appear to be related to PDO: During the last half century, El Niño events were more common during warm PDO phases and less common during cool PDO phases (Mantua and Hare 2002).

The Pacific North American Pattern (PNA) is a quadrupole pattern of atmospheric pressure anomalies that connects the Aleutian Islands of the north Pacific with the southeastern U.S. (Fig. 8). ${ }^{\dagger}$ The PNA is derived from the same EOF analysis that produces the NAO: the NAO is the first EOF of the 500-mbar atmospheric height anomaly, and the PNA is the second EOF of this same global data set (CPC, NOAA). Like the NAO and AO, the PNA is related to the trough/ridge pattern over the U.S. - when the PNA is positive, the eastern U.S. is under a cold trough and the west is dominated by a warm ridge, and the trough and ridge are damped for negative PNA. During the winter of 2002-2003, the

\footnotetext{
${ }^{*}$ http://jisao.washington.edu/pdo/PDO.latest

† http://www.cpc.ncep.noaa.gov/products/precip/CWlink/pna/norm.pna.monthly.b5001.current.ascii
} 
PNA was quite positive, resulting in a very cold winter for the eastern U.S. (especially January in the Northeast) and record warmth for the West. The PNA index has the largest variability during the cold season; thus, the PNA spatial variability map (Fig. 8) primarily captures characteristics of the winter PNA pattern.

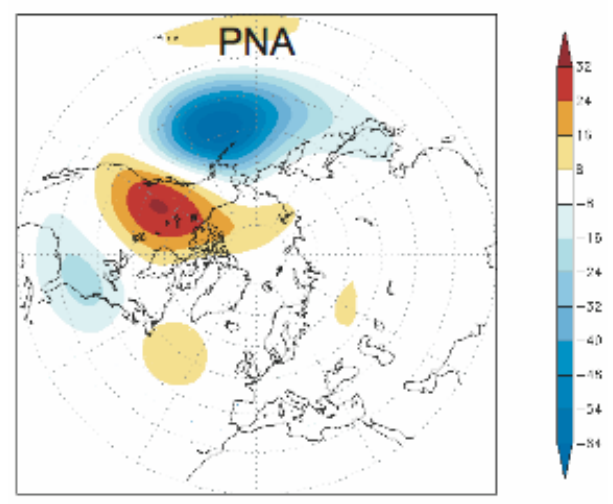

Figure 8. PNA eigenvector map from EOF analysis of 20th century Northern Hemisphere atmospheric height anomalies. Contours are as in Figure 6.*

To this set of six regional indices we added the monthly Northern Hemisphere temperature $(\mathrm{NHT})^{\dagger}$ and global temperature anomalies $(\mathrm{GT})^{\ddagger}$ to directly represent global and hemispheric temperature changes over our 50-year study period (Folland et al. 2001a). These two data sets are areally weighted, gridded monthly averages of surface air temperature from over 3000 land stations and sea surface temperature from merchant and naval vessels sailing the world oceans. These data are anomalies $\left({ }^{\circ} \mathrm{C}\right)$ from the 1961-1990 base period and demonstrate increasing hemispheric and global temperatures over the past two decades.

\section{Correlation of Climate Indices}

We calculated the linear correlation for each pair of these eight climate indices to choose five to optimally span the meteorological space of the U.S. We eliminated the index in each pair (SOI/MEI, NAO/AO, and NHT/GT) that was most highly correlated with the other indices (Table 1). For example, SOI and

\footnotetext{
* Adapted from http://www.cpc.ncep.noaa.gov/products/precip/CWlink/pna/pna_loading.html

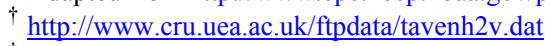

$\$$ http://www.cru.uea.ac.uk/ftpdata/tavegl2v.dat
} 
MEI describe the same climate feature, the E1 Niño system; thus, we chose the index of this pair that was least well correlated with all the other indices. The five indices we ultimately chose to use, PDO, SOI, NAO, PNA, and NHT (in blue in Table 1) provide maximal orthogonality, thus maximal difference, between our independent variables. The highest correlation remaining is between PDO and PNA, where $0.71^{2}=50 \%$ of the variation in PNA is explained by the variation in PDO. As this may represent some overlap between the mechanistic drivers of the PNA and the PDO, simultaneous use of these two moderately correlated indices does not provide independent information, which we must keep in mind when we attempt to develop a relationship between the measures of winter severity and the climate indices.

Table 1. Correlation matrix for the eight climate and temperature indices. The five indices chosen for this project are highlighted in blue.

\begin{tabular}{l|cccccccc}
\multicolumn{2}{c}{ PDO } & SOI & MEI & NAO & AO & PNA & NHT & GT \\
\hline PDO & 1 & -0.38 & 0.51 & -0.13 & -0.27 & $\mathbf{0 . 7 1}$ & $\mathbf{0 . 4 0}$ & 0.52 \\
SOI & -0.38 & 1 & -0.90 & $\mathbf{0 . 0 8}$ & 0.13 & -0.31 & -0.16 & - \\
MEI & 0.51 & -0.90 & 1 & -0.02 & -0.07 & 0.42 & 0.43 & 0.56 \\
NAO & -0.13 & $\mathbf{0 . 0 8}$ & -0.02 & 1 & 0.90 & -0.09 & $\mathbf{0 . 2 5}$ & 0.23 \\
AO & -0.27 & 0.13 & -0.07 & 0.90 & 1 & -0.28 & 0.27 & 0.25 \\
PNA & $\mathbf{0 . 7 1}$ & -0.31 & 0.42 & -0.09 & -0.28 & 1 & 0.45 & 0.47 \\
NHT & $\mathbf{0 . 4 0}$ & -0.16 & 0.43 & $\mathbf{0 . 2 5}$ & 0.27 & $\mathbf{0 . 4 5}$ & 1 & 0.95 \\
GT & 0.52 & -0.26 & 0.56 & 0.23 & 0.25 & 0.47 & 0.95 & 1
\end{tabular}

The time series for these five climate indices are shown in Figure 9. To compare them with our measures of winter severity, which have one value for each winter season, we have averaged each climate index for each winter, defined as December, January, and February, in which $86 \%$ of $U_{\max }$ accumulates and $77 \%$ of damaging ice storms occur. Some of the indices begin in 1950, so for that winter only the January and February values were averaged for all five indices. The Northern Hemisphere temperature index shows a pronounced warming beginning in the 1980s, a feature preceded by the strong positive shift that occurred in PDO in the late 1970s. The strong El Niño events of 1982-83 and 1997-98 are quite evident as negative excursions in the SOI, as are the extended La Niña conditions from 1999 to 2002. The NAO follows a generally positive trend over the entire period of record. The PNA does not demonstrate a distinct trend over the 50 -year record, but this index does contain many of the same year-to-year fea- 
tures of the PDO along with increased variability during the 1970s and 1980s not present in the PDO. As mentioned previously, El Niño events appear to be associated with warm phases of the PDO. This relationship is reflected in the moderate but significant correlations between PDO and SOI (-0.38) and PDO and MEI (0.51) in Table 1.
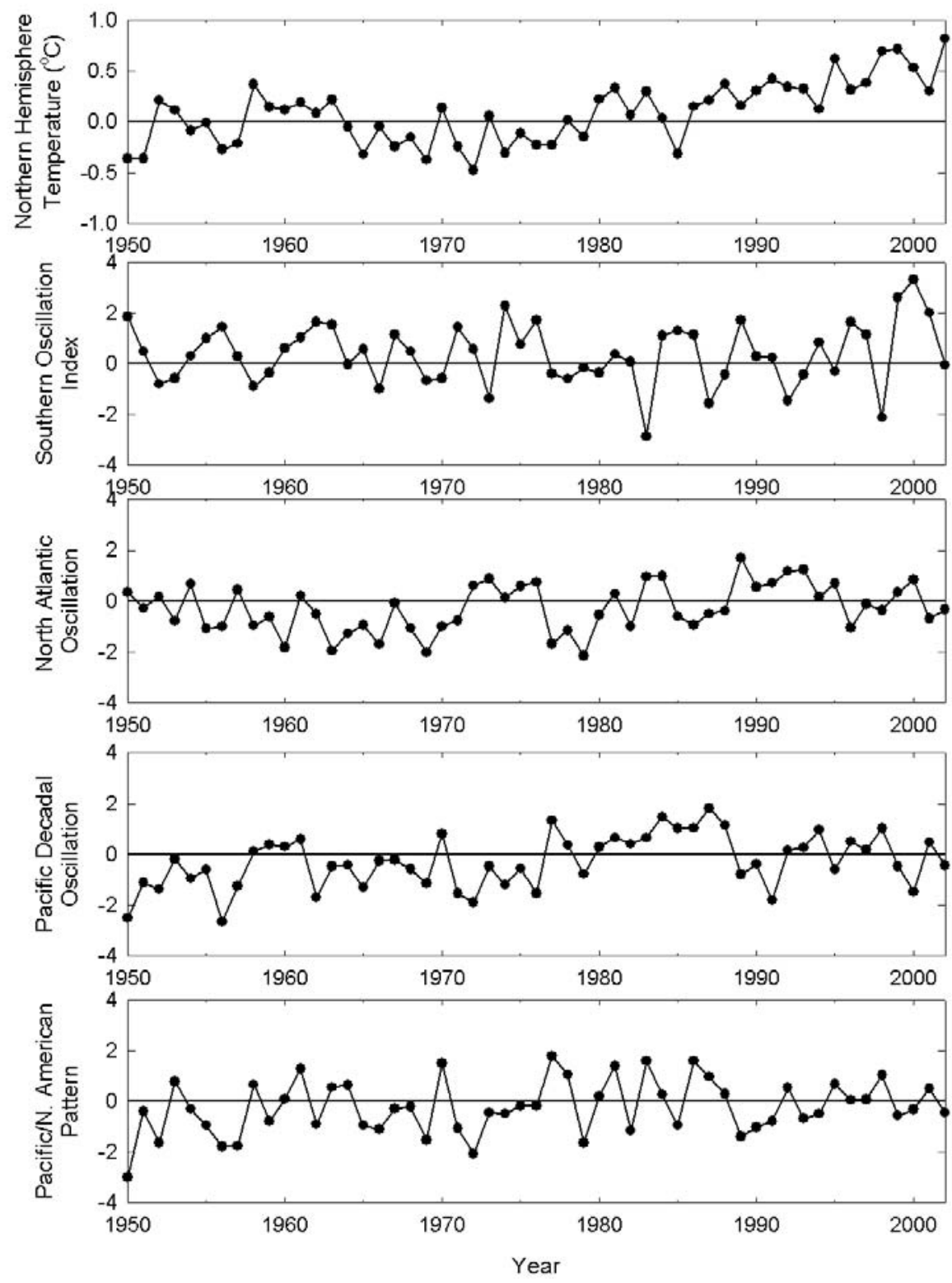

Figure 9. Time series for winter (December to February) temperature anomalies and climate indices, 1950-2002. 


\section{PARAMETERIZATION OF SEVERE WINTER WEATHER}

AFDD

The variation of the areally averaged maximum AFDD for the U.S. was presented in Figure 2b; however, this method of quantifying $U_{\max }$ does not supply any information on its spatial variation. An empirical orthogonal function (EOF) analysis of the data would provide temporal variation of the underlying spatial patterns. In the next two sections, we examine the teleconnectivity of $U_{\max }$ in the U.S., and then quantify it using EOFs.

\section{Teleconnectivity}

We investigated the spatial behavior of $U_{\max }$ using teleconnectivity and onepoint correlation maps (Wilks 1995). The linear correlation $r_{\mathrm{i}, \mathrm{j}}$, and significance of that correlation, for every station $i$ with every other station $j$ was calculated. In determining the most negative correlation for each station for the teleconnectivity map, we required the correlations to be significant at the $90 \%$ level. Stations with moderately high $(0.5$ to 0.75$)$ teleconnectivity values $T_{\mathrm{i}}$

$$
T_{\mathrm{i}}=\left|\min _{j} r_{\mathrm{i}, \mathrm{j}}\right|
$$

extend along the west coast, from central California to western Oregon, and in the east from New Hampshire to New York and south into the Carolinas (Fig. 10). Wallace and Gutzler (1980) have found that $T_{\mathrm{i}}>0.75$ tends to indicate significant teleconnections. Figure 10 shows only spotty occurrences of $T_{\mathrm{i}}>0.75$, and, in the central U.S., where the teleconnectivity is particularly low, the minimum correlations tend to be positive. To further examine areas with moderate teleconnectivity, we mapped one-point correlations for stations in the regions with highest teleconnectivity: two in New York (Ithaca and Tupper Lake) and two in central California (Independence and Sonora). We used all calculated correlations in these maps, without checking their significance. Figure 11 for the New York stations shows the expected region of high positive correlations surrounding the station, with no consistent pattern of high negative correlations in any other region. The region of positive correlations $>0.25$ for Tupper Lake (at an elevation of $512 \mathrm{~m}$ ) extends across the northern tier of states to Montana, with negative correlations in California, Oregon, and the central Rocky Mountains 
(Fig. 11a). However, the region of positive correlations $>0.25$ for Ithaca $(293 \mathrm{~m})$, which tends to have warmer winters, is confined more to the east, with negative correlations north to south across the western states (Fig. 11b). Figure 12 illustrates the correlation of the two California stations with the rest of the country. Positive correlations $>0.25$ extend farther east for Sonora $(510 \mathrm{~m})$ than for Independence $(1204 \mathrm{~m})$, which experiences more frequent winters with subfreezing temperatures. There is a small area of relatively high negative correlations for Sonora centered in the Carolinas, while the corresponding area for Independence covers a much larger region, extending from Alabama into New England.

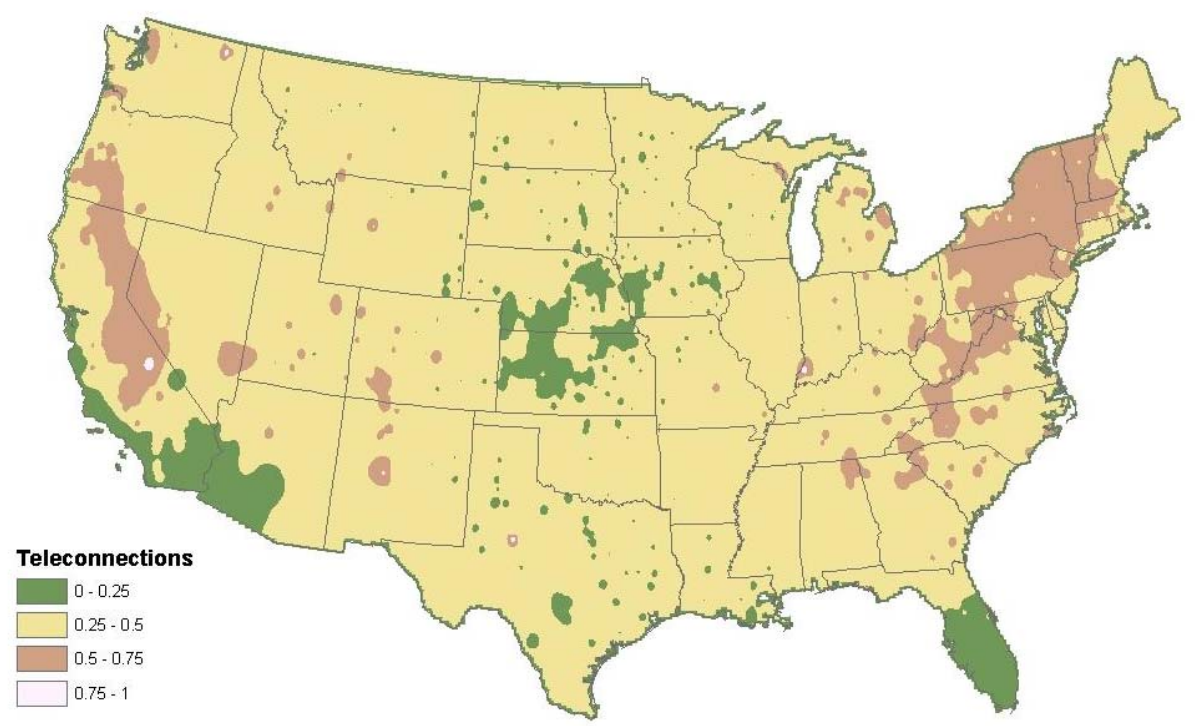

Figure 10. Teleconnectivity of maximum AFDD.

This analysis shows that the tendency for cold or warm winters tends to be correlated across the country, with a gradual decrease in correlation as the distance from the station increases. However, as we have seen in Figures 11 and 12, even stations that are relatively close together in space can exhibit differences in their correlation patterns. These differences probably result from differences in station elevation, exposure, nearby topography, etc. Overall, this one-point correlation comparison indicates that there are not naturally defined regions of the U.S. that should be independently analyzed. Therefore, in the following we analyze the country as a whole. 


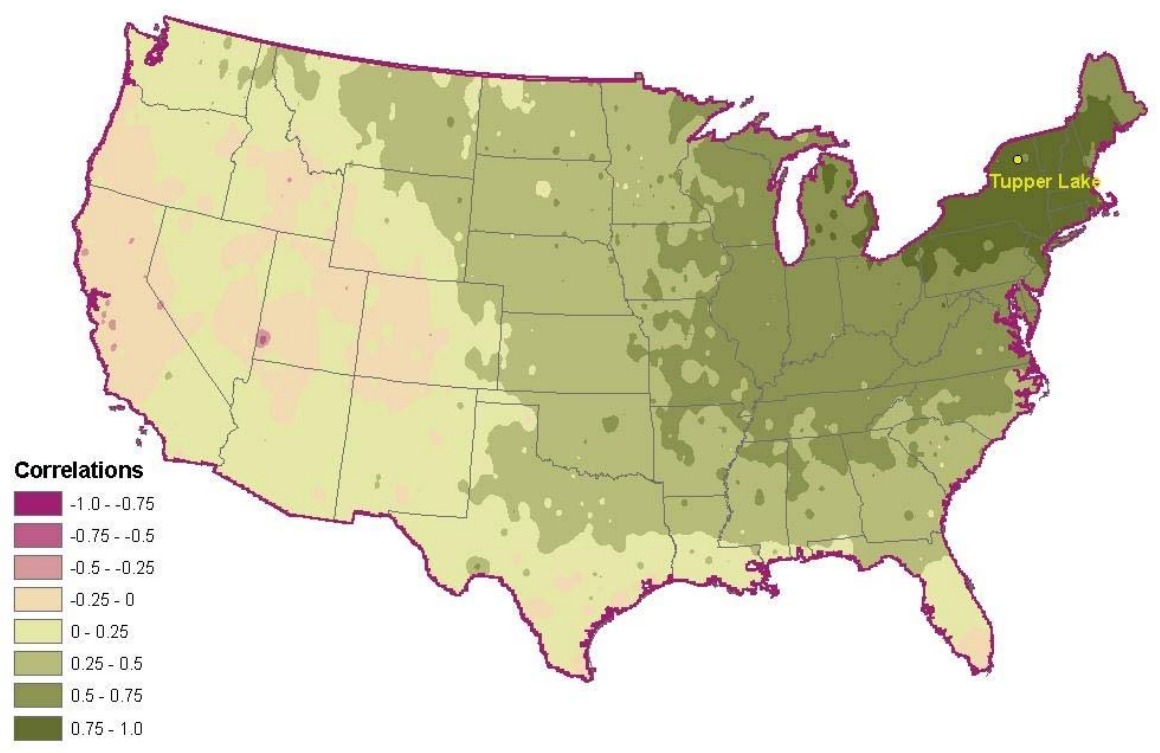

a. Tupper Lake.

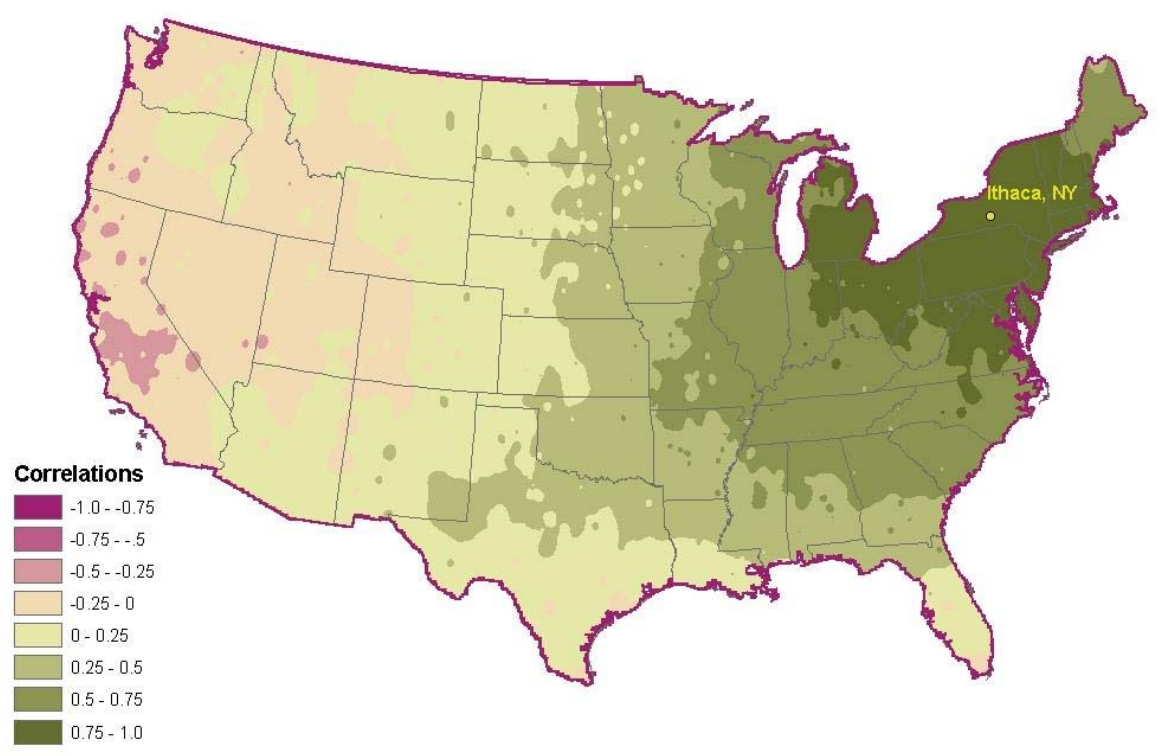

b. Ithaca.

Figure 11. One-point correlation maps for New York. 


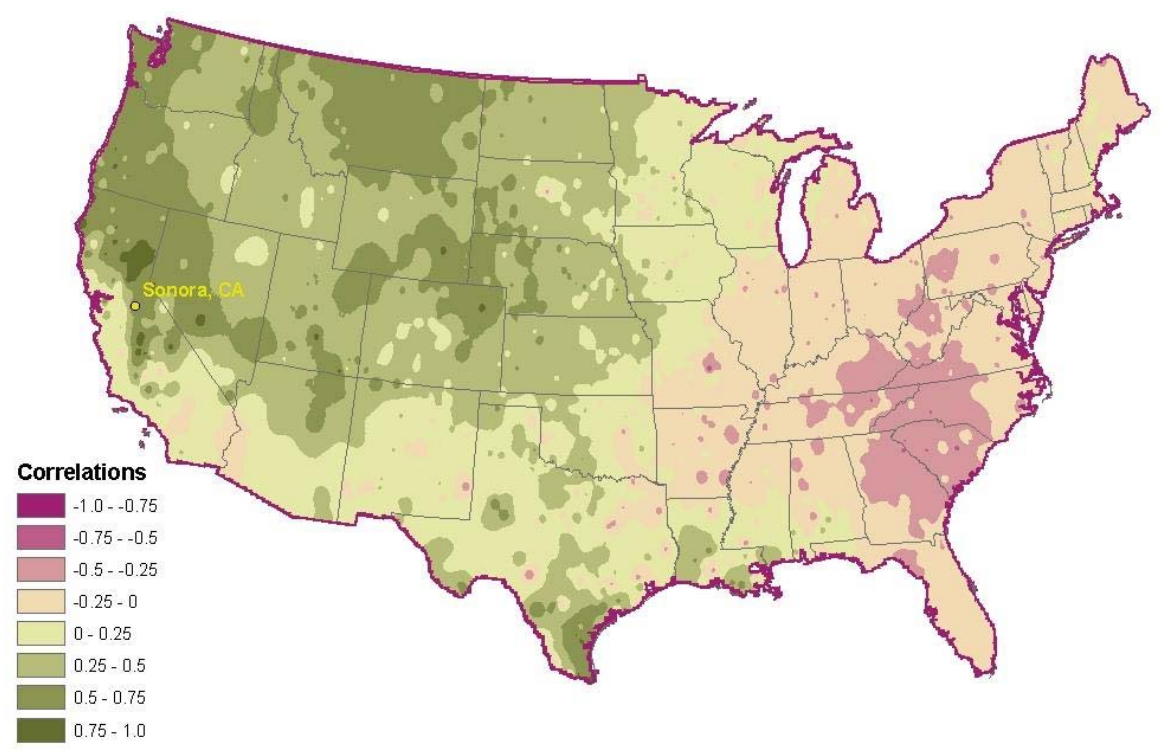

a. Sonora.

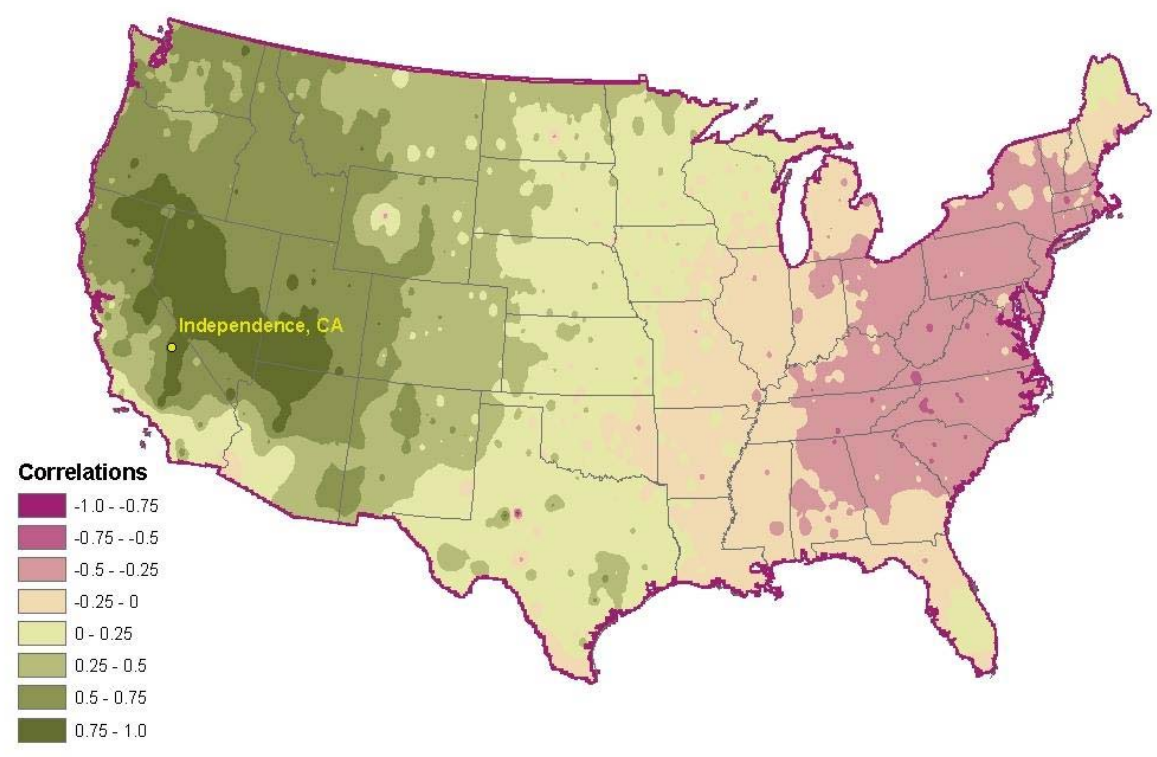

b. Independence.

Figure 12. One-point correlation maps for California. 


\section{Empirical orthogonal function (EOF) analysis}

Empirical orthogonal function (EOF) analysis (see Section 9.3 in Wilks [1995] for a good introduction) can be used to find the underlying spatial and associated temporal pattern of time-varying data from a set of weather stations. The EOF results represent the data by spatially varying, mutually orthogonal eigenvectors, each represented by a contour map that is associated with a temporally varying principal component. Although the original data at $N$ stations are reproduced exactly by the complete set of $N$ eigenvectors and principal components, in many cases the significant variation in the station values can be represented using only the first few eigenvectors because of correlation among the stations. Thus, the large scale spatial variability in the original data set is often shown by the first few eigenvectors, with the less significant, higher order eigenvectors representing local variations.

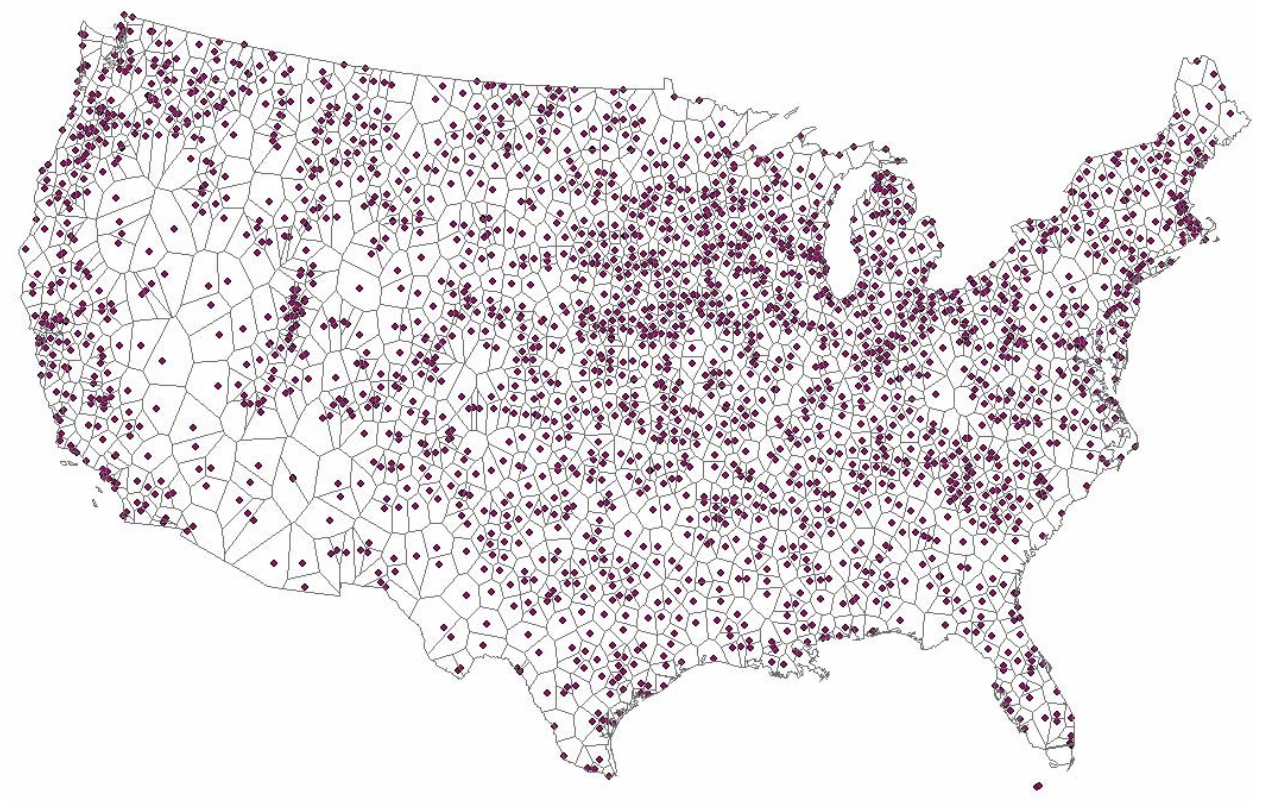

Figure 13. Thiessen polygons for the AFDD stations.

For this project, we used a Fortran program modified from David Pierce's EOF software to analyze the $U_{\max }$ data. From the annual $U_{\max }$ at each station, we calculated the station averages (contoured in Figure 2) for our 53 year period of record. The input to the EOF program is the set of maximum AFDD anomalies, the annual maxima minus the mean maximum, at each station for each year. The

${ }^{*}$ Available at http://meteora.ucsd.edu/ pierce/eof/eofs.html 
program uses either the covariance or the correlation of the anomalies, specified by the user. For this analysis, we used the covariance of the anomalies, which results in eigenvectors that tend to align with the stations with the largest variances. Results from analyzing $U_{\max }$ based on correlation are similar. To account for the non-uniform spatial distribution of the U.S. weather stations, the country was divided into 2282 Thiessen polygons, one for each weather station (Fig. 13). The polygon area is used to weight the contribution of that station in the EOF analysis. This weighting results in decreasing the influence of stations that are highly correlated only because they are close together.

\section{Eigenvectors and principal components}

The first, second, and third eigenvectors for AFDD are shown in Figure 14 with the corresponding principal components in Figure 15. The units on the maps are arbitrary; the EOF software normalizes each eigenvector so that its length is one. This normalization then affects the scaling of the principal components because the sum of the product of the principal components and the eigenvectors are the station anomalies. The first eigenvector EOF1 (Fig. 14a), explaining 55\% of the variance in $U_{\max }$, shows an anomaly pattern that decreases from north to south and looks similar to the pattern of the average maximum AFDD in Figure 2. Thus, the primary mode of variation in AFDD is for winters to be colder or warmer than the average over the whole country, with the difference being greater in the north-central states than towards the South and the Pacific coast and, to a lesser extent, the Atlantic coast. The second eigenvector EOF2 (Fig. $14 \mathrm{~b}$ ) is a northeast-west dipole and explains $13 \%$ of the variance in $U_{\max }$. It appears to represent the trough and ridge pattern that often separates the U.S. into eastern and western halves during the winter and is consistent with many of the east-west U.S. impact differences noted above for the individual climate indices. When the East is under a trough in the winter, it is usually colder than average, and the West is correspondingly influenced by warmer than average air under the ridge. These patterns, of course, do not last an entire winter, but any particular winter may be dominated by an eastern trough-western ridge pattern (or vice versa) so that the average AFDDs for that winter show a significant east-west variation. The third eigenvector EOF3 (Fig. 14c), explaining 8\% of the variance, has both north-south and east-west variations, with shorter wavelengths than the first and second eigenvectors. There is a high across the middle latitudes with maximum amplitude in the Rockies and in the Midwest and Northeast, a slight high in the South, a slight low along the west coast, and a pronounced low in the north-central states. 


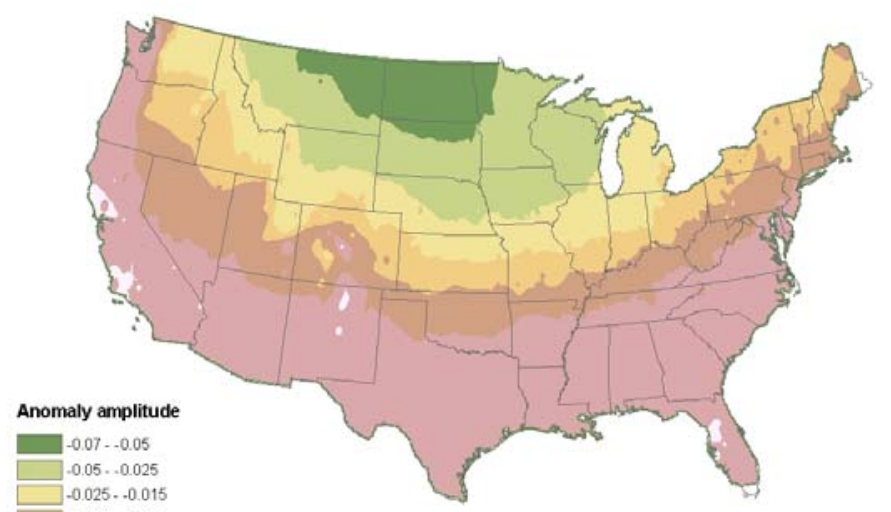

a. First eigenvector.

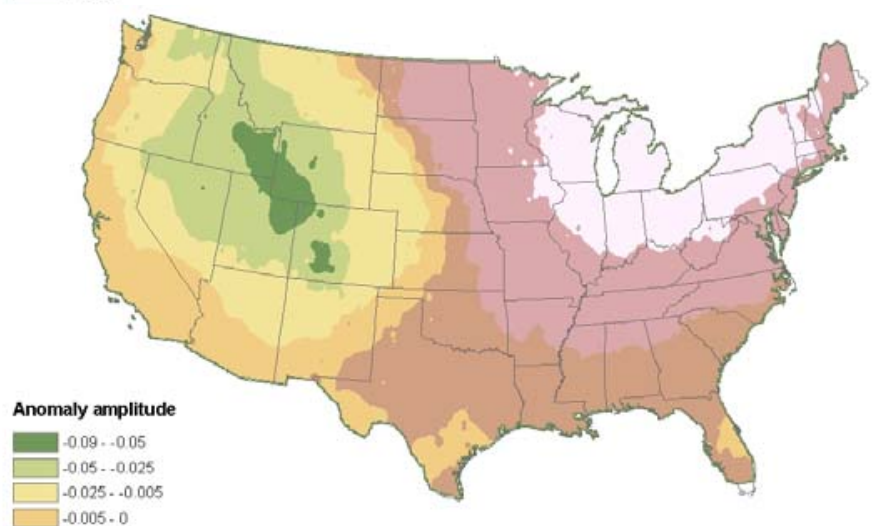

$$
\begin{aligned}
& 0.005 \cdot 0 \\
& 0.0 .005 \\
& 0.005 \cdot 0.025 \\
& 0.025 \cdot 0.055
\end{aligned}
$$

b. Second eigenvector.

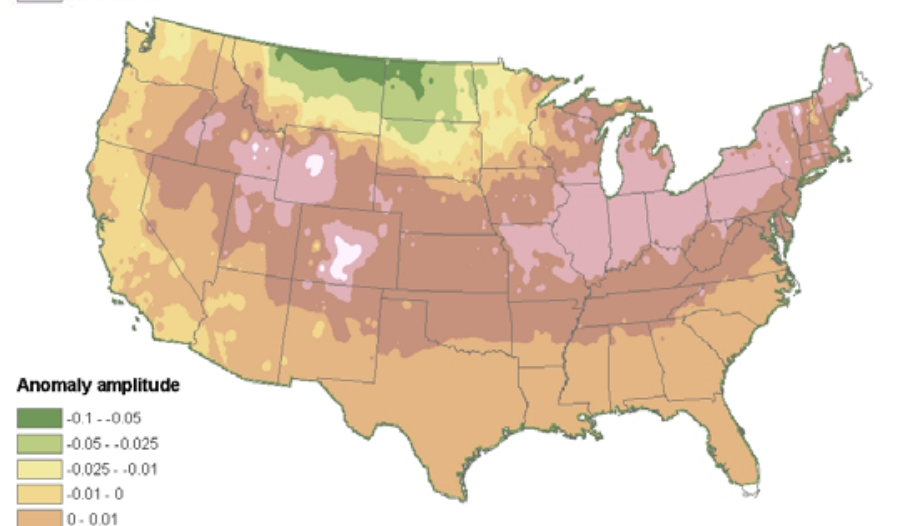

c. Third eigenvector.

Figure 14. Maximum AFDD. 


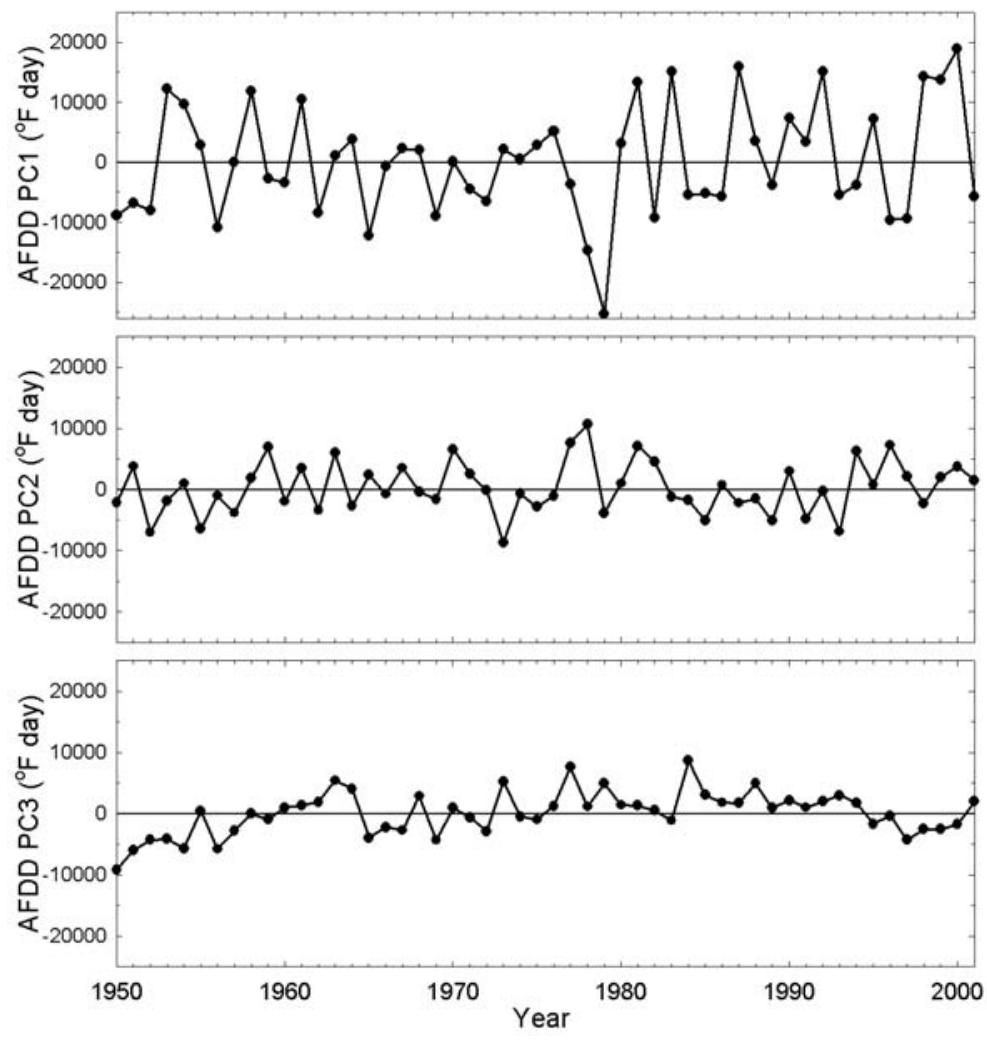

Figure 15. Covariance principal components for the first three eigenvectors of $U_{\max }$.

The ability of the first three eigenvectors to represent the annual variation in $U_{\max }$ is shown for two notable years, the cold winter of 1978 (Fig. 16) and the warm winter of 1998 (Fig. 17). In 1978, in addition to being relatively cold over the entire country, it was relatively colder in the East than in the West, especially in the Ohio River Valley (U.S. Army 1978). In January 1978, ice jams in the Ohio River essentially closed the river to navigation and led to 19 barges and a towboat being swept downstream against Markland Lock and Dam, located near Cincinnati, Ohio. Figure 16a shows that EOF1 replicates the generally cold conditions quite well. Incorporating EOF2 makes the map better match the warmer conditions in the West and the colder conditions in the East, while the small amplitude of EOF3 causes little additional change. Similarly, EOF1 in Figure 17 represents the warm winter in 1998 well. The addition of the second eigenvector, with a smaller magnitude and opposite sign from that in 1978, makes the map better match the somewhat cooler conditions in the West and warmer conditions in the East. The addition of EOF3 with its small negative amplitude in 1998 further warms the Northeast. 
a. First eigenvector.
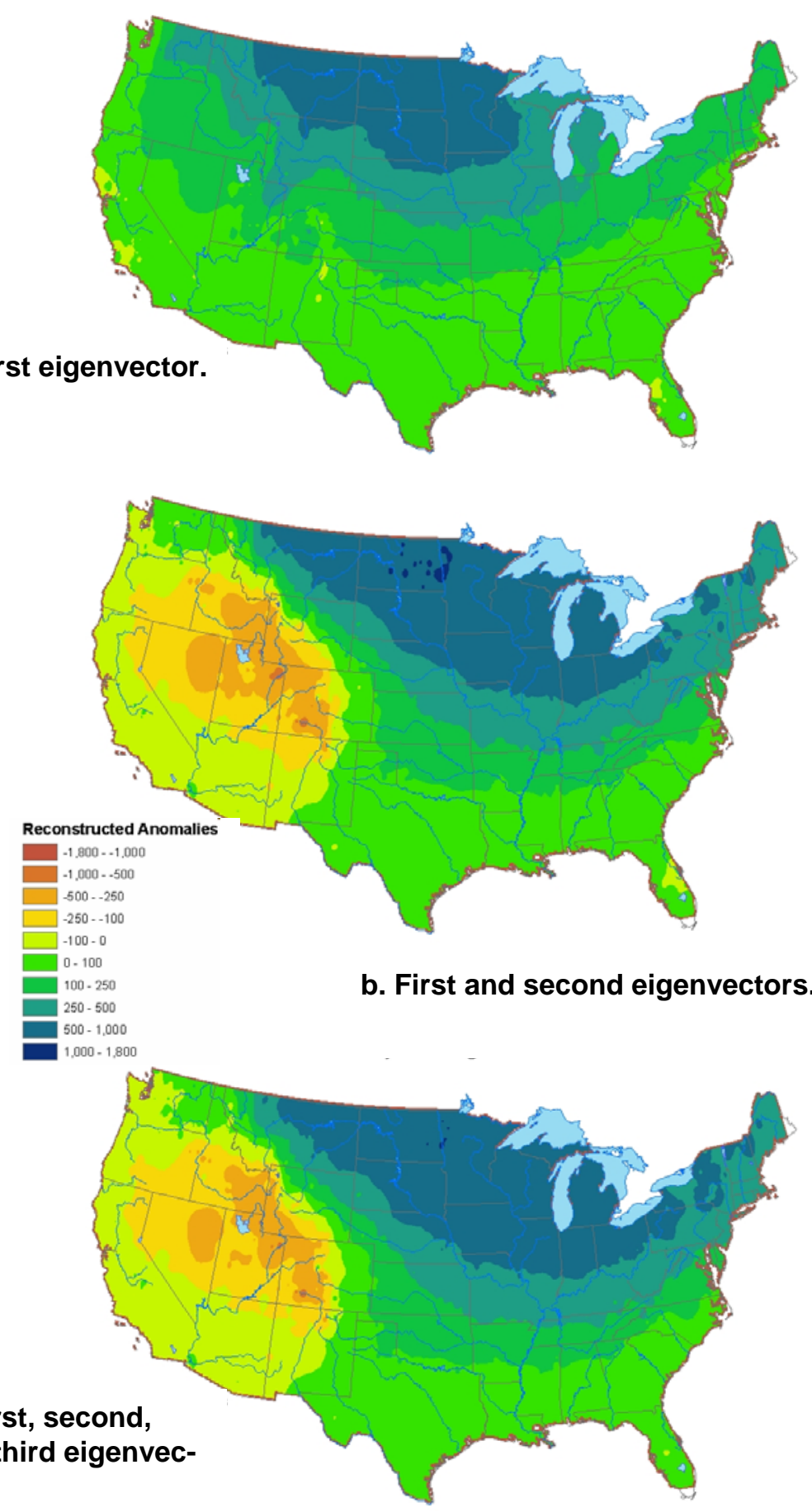

Figure 16. Reconstructions of $U_{\max }\left({ }^{\circ} \mathrm{F}\right.$-day) for the winter of 1978 . The actual $U_{\max }$ for 1977-1978 is in Appendix A. 
a. First eigenvector.
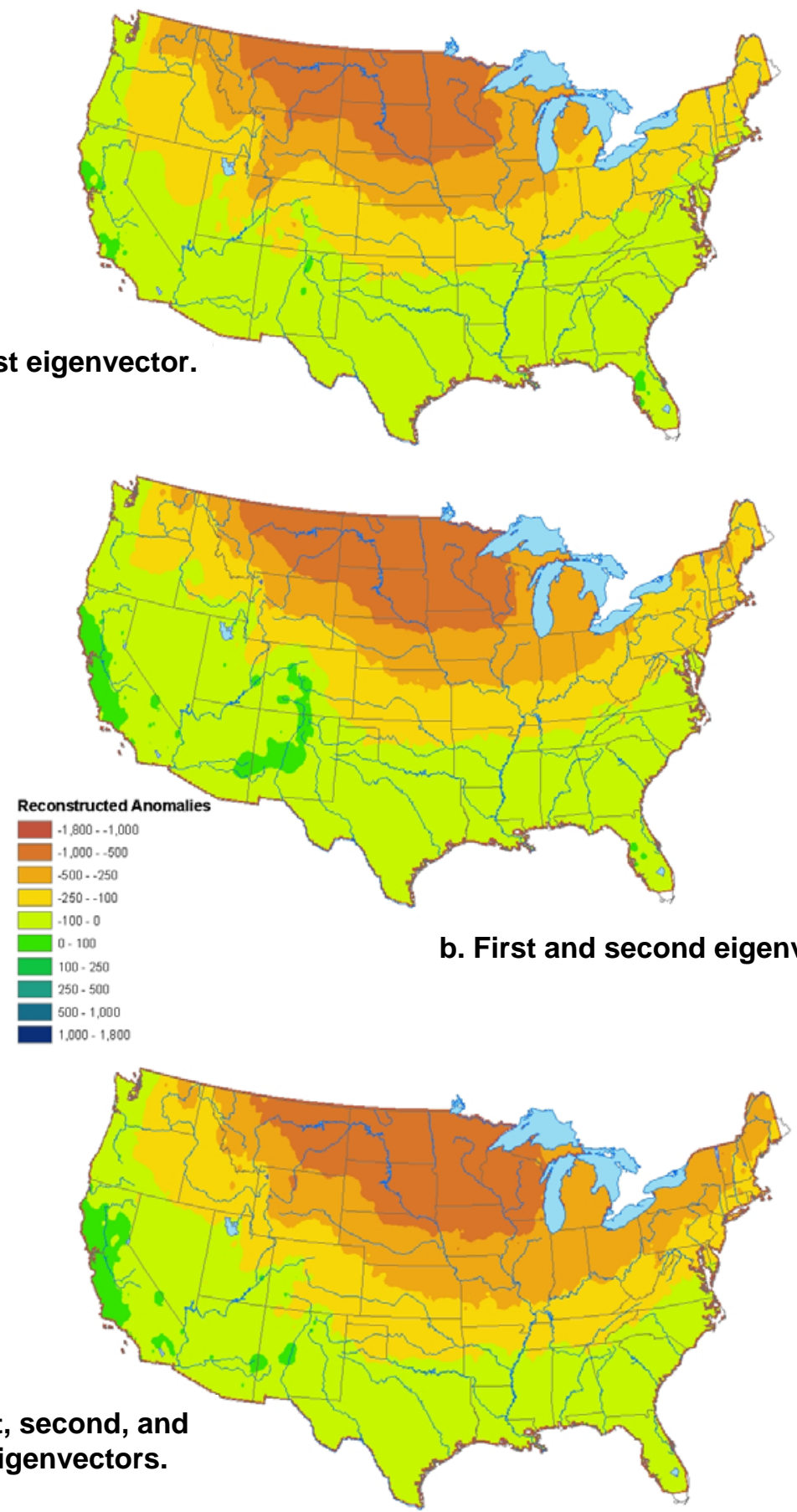

c. First, second, and third eigenvectors.

Figure 17. Reconstruction of $U_{\max }\left({ }^{\circ} \mathrm{F}\right.$-day) for the winter of 1998 . The actual $U_{\max }$ for 1997-1998 is in Appendix A. 
To better understand the first two eigenvector patterns, we mapped one-point correlations using stations near the eigenvector maximum amplitudes. EOF 1 is represented by McClusky, North Dakota, and EOF2 by Salina, Pennsylvania, and Alta, Wyoming. The North Dakota one-point correlation map (Fig. 18) shows positive correlations across almost the entire U.S., with the expected decrease with distance, consistent with the pattern of EOF1 (Fig. 14a). The Pennsylvania map shows moderate negative correlations with stations in the region from western Colorado to the west coast (Fig. 19a). The Wyoming map shows slightly negative correlations in the east-central U.S. (Fig. 19b). Both these patterns are consistent with the EOF2 pattern in Figure 14b. EOF3 explains relatively little of the variation in $U_{\max }$ compared to the first two eigenvectors, so we do not expect that more complex pattern to be apparent in one-point correlation maps.

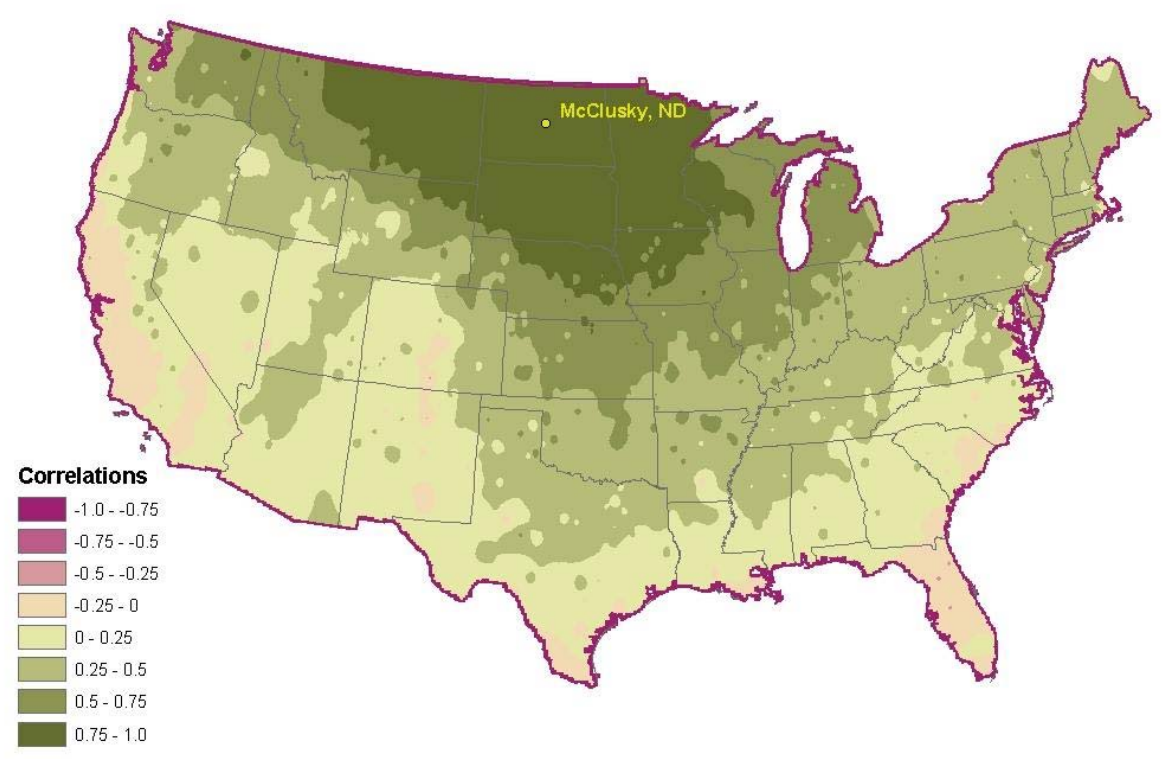

Figure 18. One-point correlation map for McClusky, North Dakota, corresponding to EOF1. 


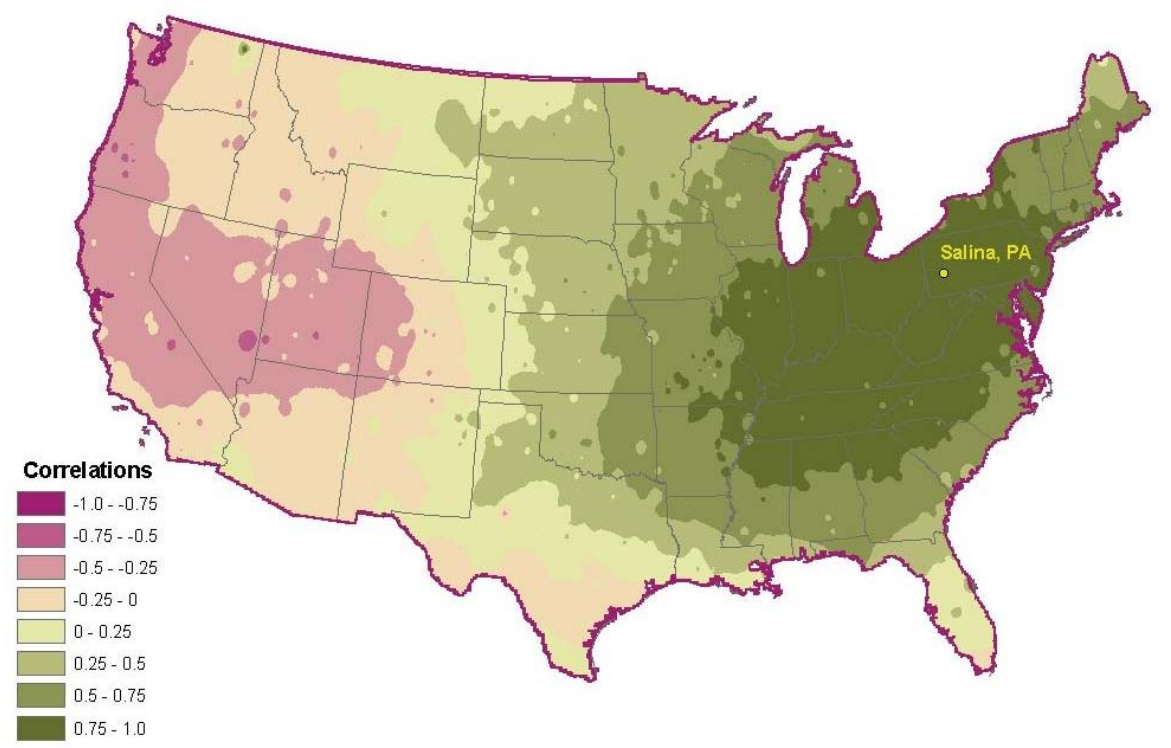

a. Salina, Pennsylvania.

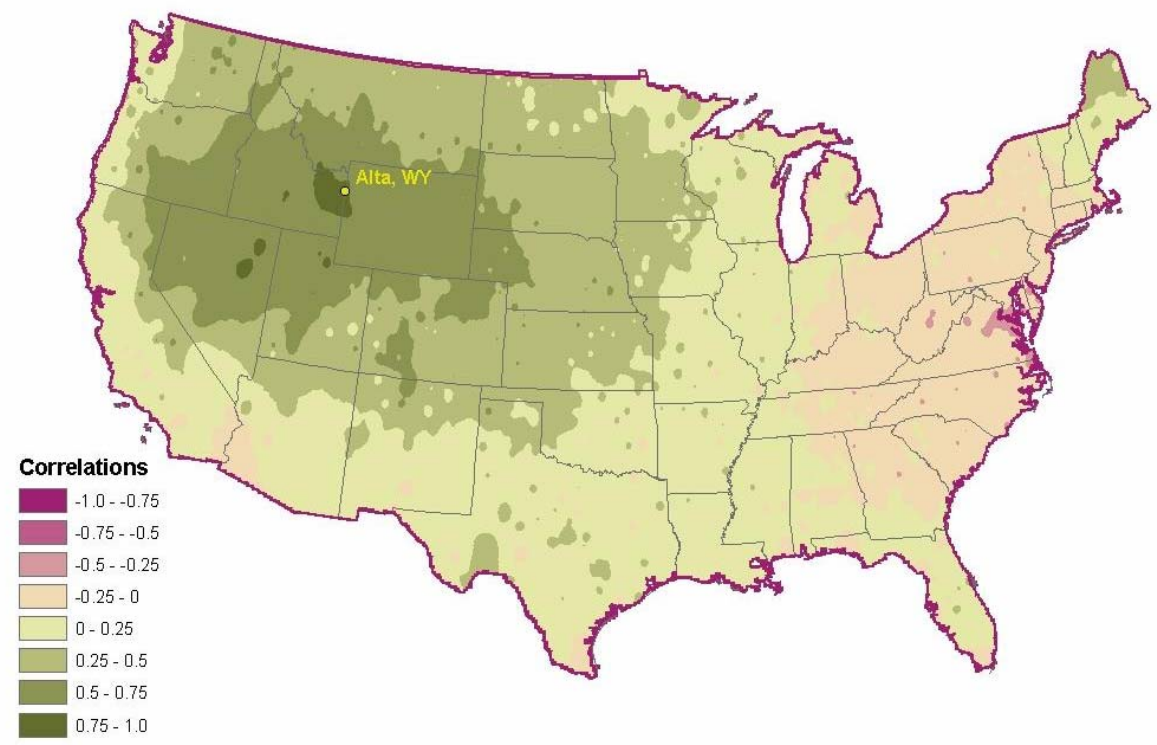

b. Alta, Wyoming.

Figure 19. One-point correlation maps corresponding to EOF2. 


\section{Ice Storms}

The footprints of damaging ice storms were delineated using weather data from the 460 stations with hourly data shown in Figure 20 to model the accretion of ice from freezing rain on overhead wires in the contiguous 48 states and neighboring Canadian provinces. Because the conditions (particularly precipitation type, precipitation intensity, and wind speed) in storms that include freezing rain tend to vary significantly over short distances, and because the weather stations are relatively widely spaced, we rely primarily on damage reports rather than on model results to characterize the storms. Figure 21 shows, for example, the model results and the damage footprint for the severe freezing rain storm in early December 2002. For this recent storm, we have model results at many additional Automatic Surface Observing System (ASOS) weather stations that began to be commissioned typically in the late 1990s.

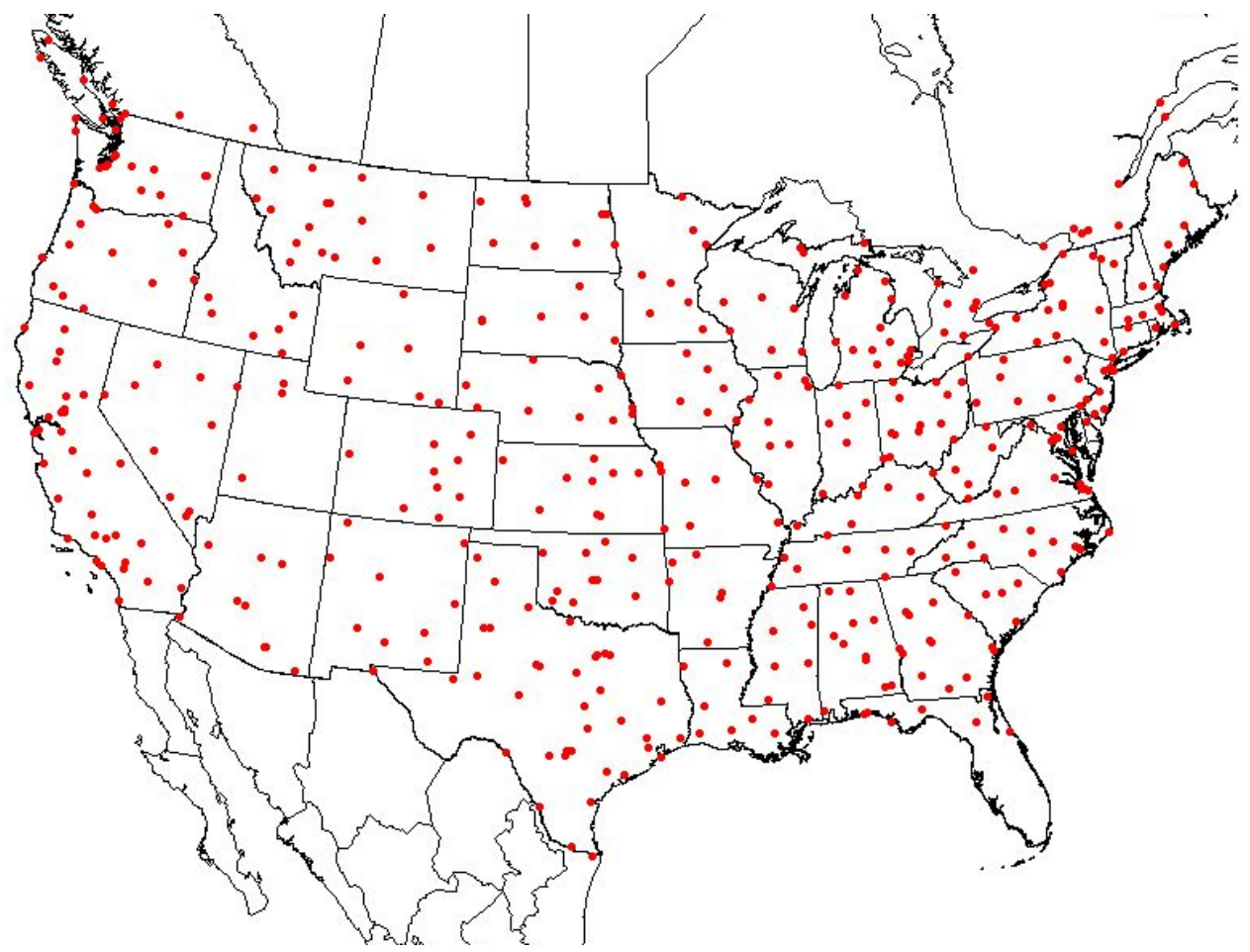

Figure 20. Locations of weather stations with hourly data. 


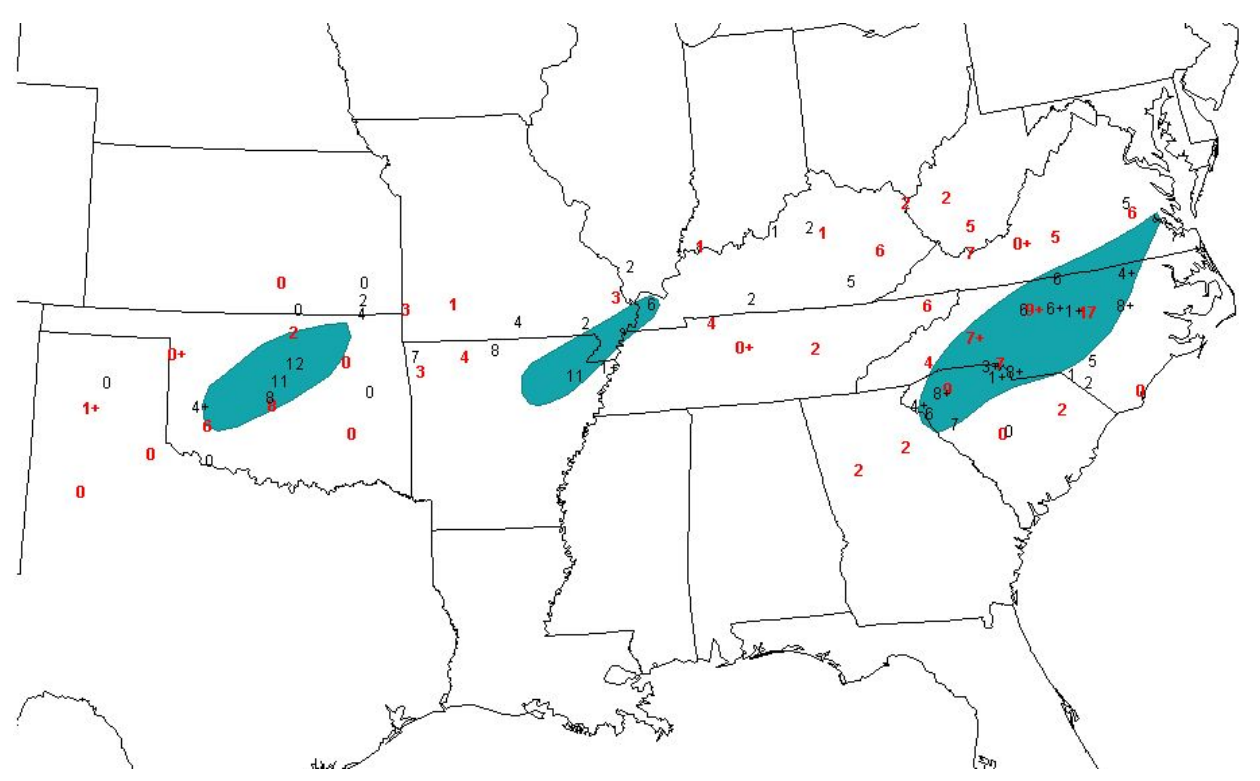

Figure 21. Damage footprint of freezing-rain storm of December 2002. For stations with freezing rain, equivalent radial ice thicknesses $(\mathrm{mm})$ are shown in red at stations in Figure 20 , and in black at recently commissioned ASOS stations. A "+" indicates incomplete or erroneous weather data that would tend to cause the modeled ice thickness to be underestimated.

The total damaging ice storm area for each year is shown in Figure 22. The ice storm area varies significantly from year to year, with only a few local storms in some years and very large damaging storms in other years.

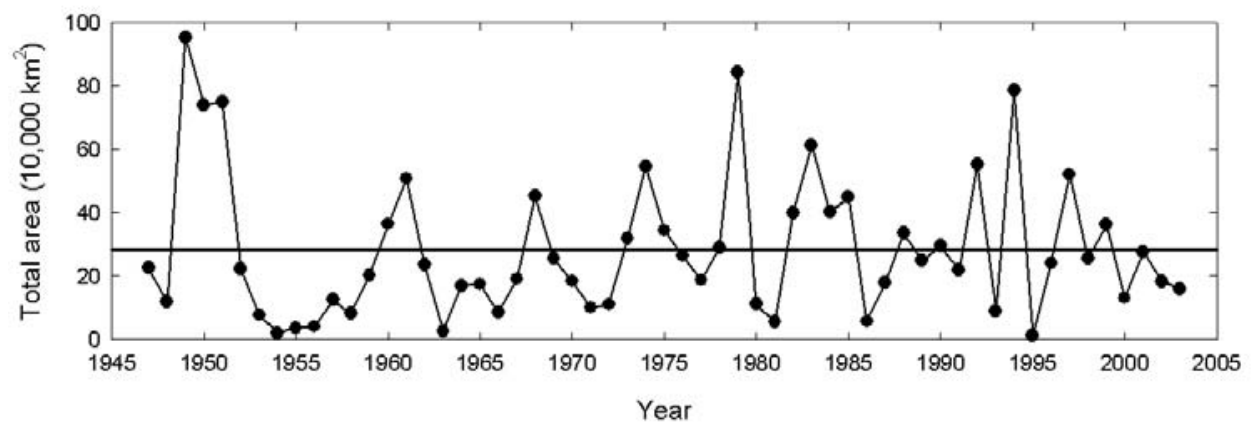

Figure 22. Variation of ice storm area by year.

Ice storms are different from accumulated freezing degree-days in a number of ways: 
- Ice storms occur in discrete events, while AFDD increases, or remains constant, throughout the winter.

- Ice storms cover discrete regions when they occur, typically with snow, rain, or ice pellets falling in surrounding areas, while AFDD varies relatively continuously in space.

- Ice storms, particularly storms with enough freezing rain to damage trees and structures, occur rarely at any location, while the low temperatures that contribute to $U_{\max }$ occur relatively frequently over most of the country in the winter.

Because of these characteristics of ice storms, empirical orthogonal functions are not useful in quantifying the variability of their occurrence. Instead, we have chosen to describe each winter by the total area of ice storms and their trajectory, compared to the average. The average ice storm trajectory, along with the average absolute deviation north and south, is shown in Figure 23, superposed on contours of the average area affected by ice storms annually. The trajectory and deviations from it were calculated from the centroids and areas of the storm footprints in each of $1^{\circ}$ longitude strips. In the $i^{\text {th }}$ strip

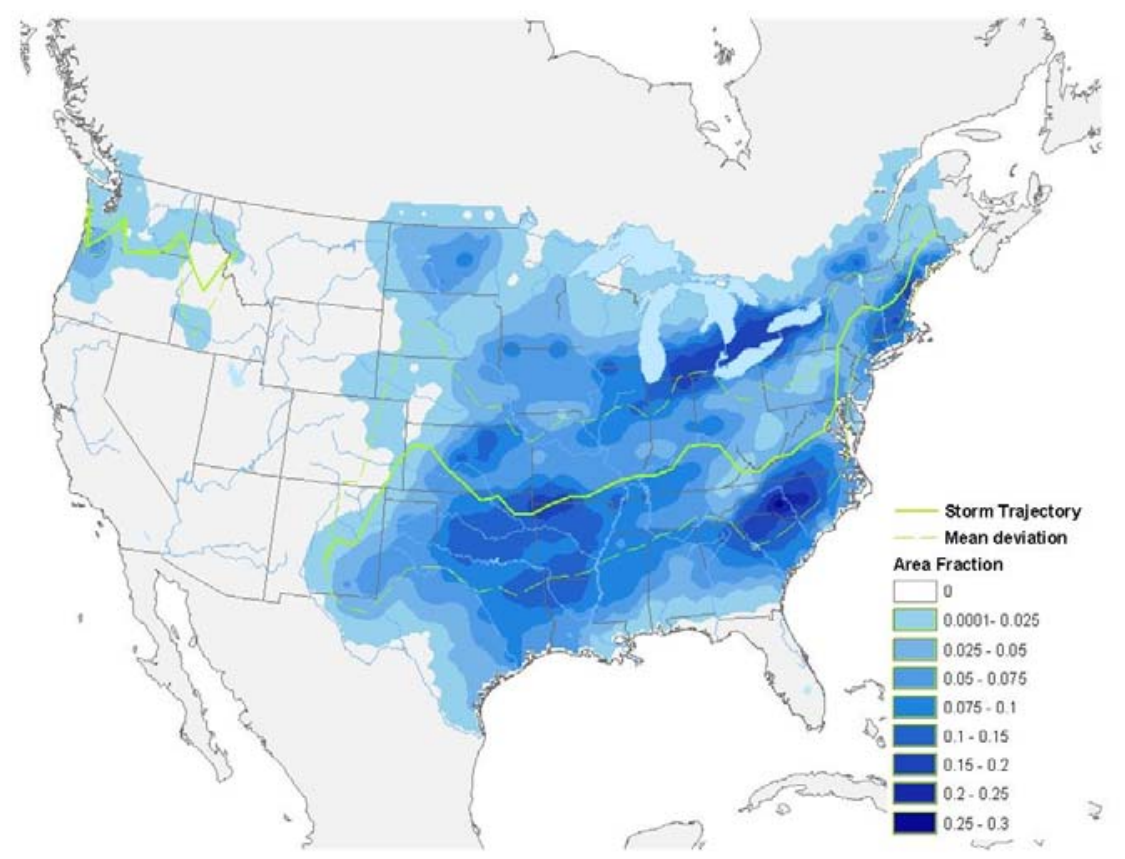

Figure 23. Annual average area fraction affected by damaging ice storms and average ice storm path. 


$$
\begin{aligned}
\bar{y}(i) & =\frac{\sum_{j} y(i, j) A(i, j)}{\sum_{j} A(i, j)} \\
\Delta y(i) & =\frac{\sum_{j}|y(i, j)-\bar{y}(i)| A(i, j)}{\sum_{j} A(i, j)}
\end{aligned}
$$

where $A(i, j)$ and $y(i, j)$ are the area and latitude of the centroid of the portion of the $j^{\text {th }}$ ice storm in the $i^{\text {th }} 1^{\circ}$ strip, and $\bar{y}(i)$ and $\Delta y(i)$ are the area weighted latitude and the average absolute deviation of the trajectory.

The annual ice storm area and standardized deviate of the ice storm trajectory are used to characterize each winter's ice storms, separately in the East and the West. For year $n$, the total ice storm area $A_{\mathrm{n}}$ and the average standardized deviate of the path $d_{\mathrm{n}}$ are:

$$
\begin{aligned}
& A_{\mathrm{n}}=\sum_{j \text { in year } n} \sum_{i} A(i, j) \\
& d_{\mathrm{n}}=\frac{1}{A_{\mathrm{n}}} \sum_{j \text { in year } n} \sum_{i} \frac{A(i, j)[y(i, j)-\bar{y}(i)]}{\Delta y(i)}
\end{aligned}
$$

Damaging ice storms occur relatively frequently in the East and tend to affect large areas. In any year the standardized deviate is about 1 or smaller (Fig. 24, top). In contrast, ice storms in the West occur less frequently and typically are topographically limited, with intense storms damaging relatively small areas in the Columbia River gorge, the Willamette Valley, and the mouth of the Fraser Valley. However, the average ice storm trajectory in the West is determined primarily by the infrequent storms that have affected larger areas, with the typical local storms deviating significantly from this average (Fig. 24, bottom). We will use the ice storm measures in Figure 24 to determine the correlation of damaging ice storms with the climate indices. 

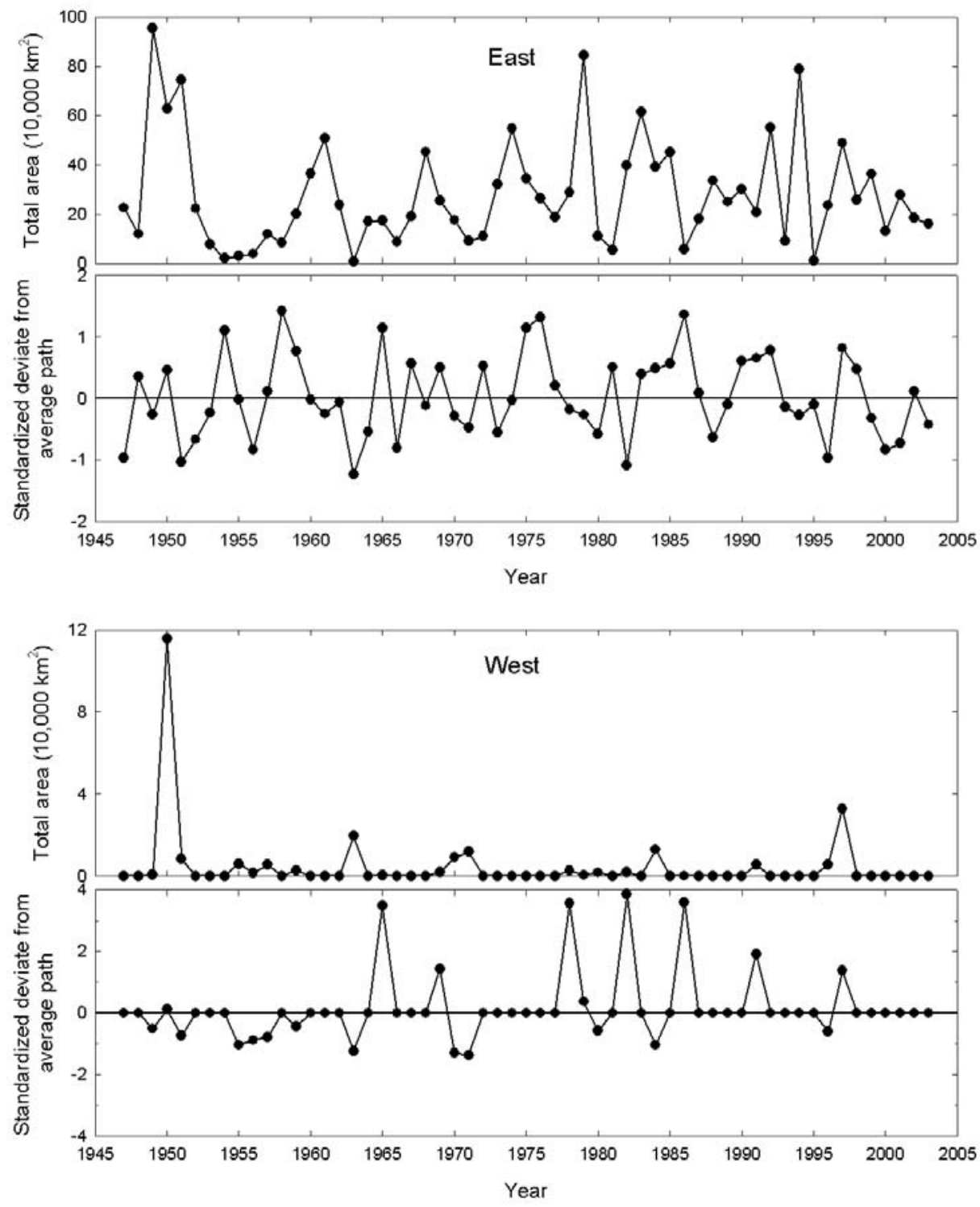

Figure 24. Annual variation of ice storm area and deviation of average path. 


\section{CORRELATION OF WINTER WEATHER WITH CLIMATE INDICES}

AFDD

\section{Correlation}

The correlations between the first three principal components of $U_{\max }$ (Fig. 15) and the climate indices (Fig. 9) are shown in Table 2. There is no significant correlation between $U_{\max }$ and the Southern Oscillation Index; however, one or more of the climate indices is moderately associated with each of the first three principal components of $U_{\max }$.

Table 2. Linear correlation of the principal
components of $U_{\max }$ and climate indices.
\begin{tabular}{l|ccc} 
& AFDD PC1 & AFDD PC2 & AFDD PC3 \\
\hline NAO & 0.40 & -0.27 & -0.10 \\
NHT & 0.52 & 0.08 & 0.17 \\
PDO & 0.22 & 0.28 & 0.55 \\
PNA & 0.47 & 0.40 & 0.42 \\
SOI & -0.20 & 0.14 & -0.09
\end{tabular}

The correlations between AFDD PC1 and NHT, PNA, and NAO are significant at the $99 \%$ level. These positive correlations indicate that warmer winters in the U.S. (i.e., smaller $U_{\max }$ ) tend to occur with

- Warmer weather across the Northern Hemisphere.

- A positive phase of the PNA, which is associated with cool weather in the Southeast and warmth in the Northwest.

- Positive NAO, which is associated with zonal jet stream flow usually resulting in warmth across the U.S. and anomalously mild and wet winters in the East (Hurrell et al. 2003).

Cooler U.S. winters would likewise be associated with the opposite index values: negative NHT, PNA, and NAO.

The first principal component of $U_{\max }$ is the dominant signal, explaining $55 \%$ of the variation in maximum AFDD, with the second and third components providing relatively small corrections, 13 and $8 \%$, respectively. The correlations 
between AFDD PC2 and PNA, PDO, and NAO are significant at the 95\% level. These correlations indicate that relatively cooler winters in the Great Lakes and Northeast and warmer winters in the West occur with

- Positive PNA, as discussed above.

- Positive PDO, which is associated with wet and warm conditions in the West (Mantua and Hare 2002).

- Negative NAO, where a blocking high in Greenland causes buckling of the jet stream and allows cold air and storms to spill into the eastern U.S. (Hurrell et al. 2003).

Northeast and Great Lakes warmth and a cool West are accompanied by positive NAO and negative PNA and PDO.

AFDD PC3 is also positively correlated with PDO and PNA at the 99\% level. The map of EOF3 is more complex than the first two eigenvector maps, with warm winters in the north central states occurring with cool winters in the central Rockies and in the Midwest and Northeast (Fig. 14). When PDO is positive, as it was during the 1980s and 1990s, warmth along the U.S. west coast is consistent with EOF3. The quadrupole pattern of the PNA, however, produces a mode of variability that pairs cooler weather in the Southeast with warmth in the inter-mountain West. The contribution of AFDD PC3 to the overall maximum AFDD is small, so the relationships between the climate indices and this principal component provide relatively small corrections to the dominant EOF1 and EOF2 pattern.

\section{Linear regression}

The significant linear correlations between the first three AFDD principal components and the climate indices indicate that we may be able to determine the AFDD from the climate indices. We investigated this dependence by doing a step-wise regression analysis, and found the following relationships:

$$
\begin{aligned}
A F D D P C 1 & =1378+7776 N H T+3646 N A O+3395 P N A \\
\text { or } A F D D P C 1 & =2398+4420 P N A+4356 N A O \\
A F D D P C 2 & =-21+1906 P N A+1090 S O I-1120 N A O \\
A F D D P C 3 & =576+1871 P D O
\end{aligned}
$$

The units of the principal components and coefficients are ${ }^{\circ} \mathrm{F}$-day, with the exception of the coefficient of NHT, which has units ${ }^{\circ} \mathrm{F}$-day ${ }^{\circ} \mathrm{C}^{-1}$. In each regression equation in eq 6 , the climate indices are in order of their importance in 
explaining the dependent variable. Together, NHT, NAO, and PNA explain 46\% of the variation in AFDD PC1, with the coefficients of the climate indices having the same sign as the correlations in Table 2 . In the alternative regression equation for AFDD PC1 that excludes NHT, PNA and NAO explain $42 \%$ of the variation. Thus, the moderate correlations of NHT with PNA and NAO (Table 1) are from essentially the same information that causes the moderate correlation of AFDD PC1 with PNA and NAO. As PNA and NAO are almost uncorrelated, the second regression equation for AFDD PC1 is preferable to the first, even though it explains slightly less of the variation in AFDD PC1. PNA, SOI, and NAO explain $30 \%$ of the variation in AFDD PC2. Note that this regression equation includes SOI, even though AFDD PC2 and SOI are not significantly correlated (Table 2). This implies that SOI is correlated with the residual of AFDD PC2 after the effect of PNA is accounted for. Finally, PDO explains $30 \%$ of the variation in AFDD PC3, consistent with the correlation $\left(0.30=0.55^{2}\right)$ in Table 2 . These results suggest that, with the regression equations in eq 6 and the three EOF eigenvector maps (Fig. 14), we should be able to reconstruct or predict a significant component of a winter's AFDD if we know or can forecast the climate indices for that winter. The first three principal components of the maximum AFDD are compared to those calculated from eq 6 in Figure 25.

\section{Freezing Rain Storms}

\section{Correlations}

The correlation between the annual variation of ice storm severity, measured by the total area of damaging ice storms and the deviation of the average ice storm path from the overall average path, is shown in Table 3 for both the East and the West. The values are the Spearman rank-order correlation coefficient $r_{\mathrm{s}}$ (Press et al. 1986), which we use rather than the linear correlation coefficient because of the non-Gaussian distribution of ice storm area. None of the correlations is high, but a couple are significant. In the East the correlation between the ice storm path and the North Atlantic Oscillation is 0.28, significant at the 95\% level. This correlation is consistent with the association between a positive NAO and winter storms crossing the Atlantic on a more northerly track. In the West there is a correlation of -0.29 between ice storm area and the NAO, also significant at the 95\% level. This negative correlation indicates an association between the infrequent ice storms with large areas in the Pacific Northwest and weaker surface westerly winds over the north Atlantic. Note that there is no significant correlation between ice storms and Northern Hemisphere temperatures, indicating that the warming observed in the past 20 years is not reflected in the occurrence or path of damaging ice storms in the U.S. 

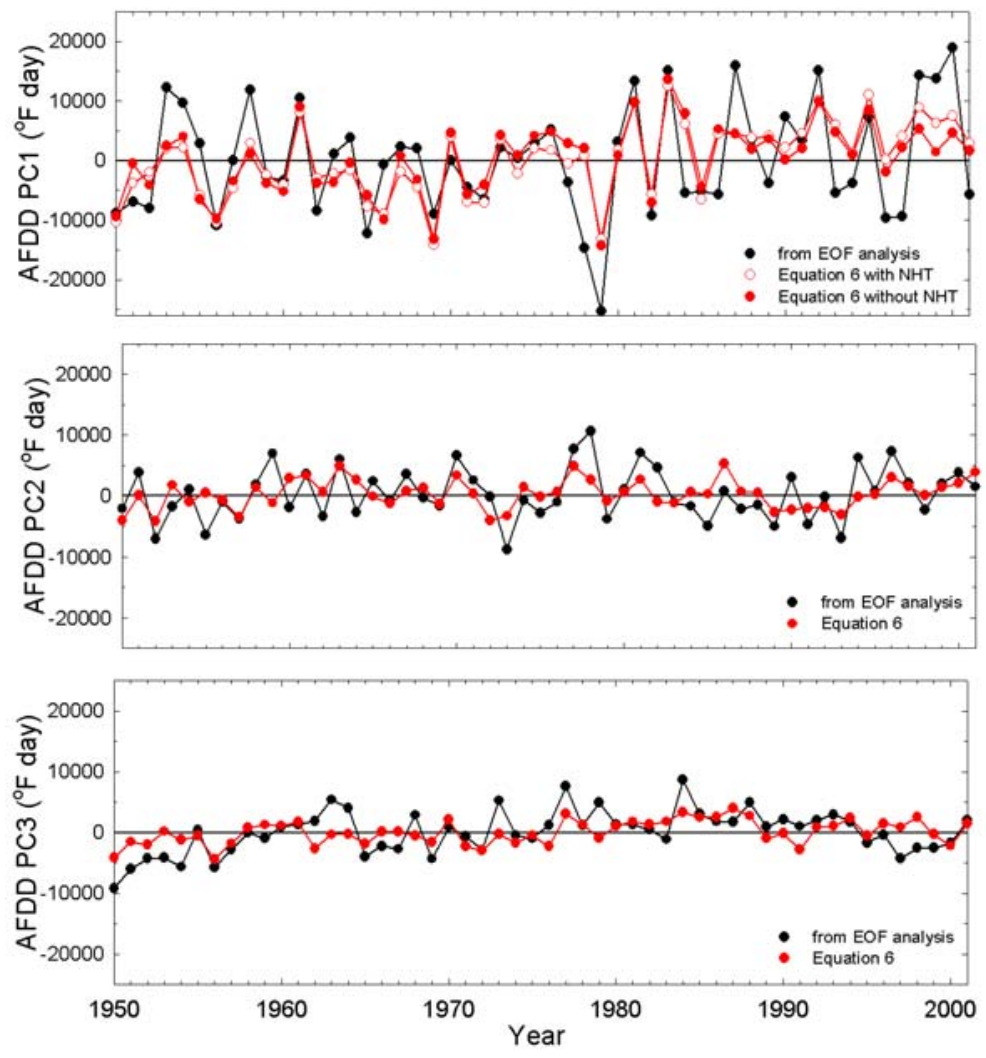

Figure 25. Comparison of principal components of AFDD and those calculated from the climate indices.

Table 3. Spearman rank-order correlation of ice storm severity with climate indices for each winter.

\begin{tabular}{l|llll} 
& $\begin{array}{l}\text { East ice } \\
\text { storm area }\end{array}$ & $\begin{array}{l}\text { East path } \\
\text { std dev }\end{array}$ & $\begin{array}{l}\text { West ice } \\
\text { storm area }\end{array}$ & $\begin{array}{l}\text { West path } \\
\text { std dev }\end{array}$ \\
\hline NAO & 0.16 & 0.28 & -0.29 & -0.01 \\
NHT & -0.09 & -0.09 & -0.19 & 0.02 \\
PDO & 0.16 & 0.02 & -0.14 & -0.02 \\
PNA & -0.08 & 0.09 & -0.20 & -0.03 \\
SOI & 0.08 & -0.06 & 0.16 & -0.12
\end{tabular}

T-tests

The correlations between damaging ice storms and winter climate indices are weak. This may be because ice storms are episodic, occurring only with particularly favorable atmospheric conditions. To try to better capture these episodes, 
we compared months with ice storms to months without ice storms, using only the relatively numerous eastern ice storms. For this comparison, we considered the months from December to March, when $90 \%$ of ice storms occur, and used data from 1950 to 2002. In this period there were 144 months with ice storms and 68 months without. We found no difference in mean PDO, PNA, and NHT; however, both NAO and SOI were significantly different at the $95 \%$ level. NAO tends to be more negative and SOI tends to be more positive in months without ice storms than in months with ice storms (Fig. 26).

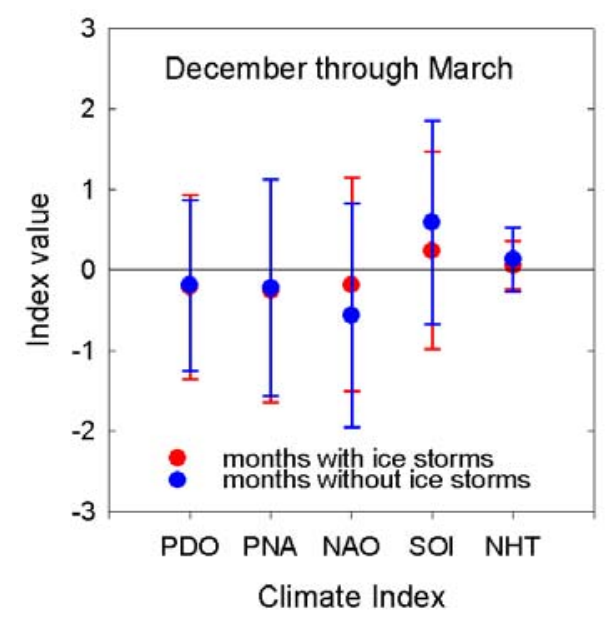

Figure 26. Comparison of climate index means in months with and without ice storms.

\section{Forecasts}

One of the goals of this project is to use the relationships we have found between climate indices and severe winter weather to provide operational forecasts for the upcoming winter. The Army and the Corps of Engineers currently use static climatology to predict weeks to months in advance the weather in which their personnel will be required to operate. Static climatology is used instead of real-time weather information largely because of limited weather data in many parts of the world and can result in weather predictions that are very different from the actual conditions that occur. We have found that large-scale climate systems, whose characteristics are captured by climate indices, can have predictable and reproducible effects on winter severity in the U.S. To improve forecasting for the benefit of Army and Corps personnel, we aim to go beyond the use of static climatology and incorporate the results of this study into a forecasting 
method that will allow forecasts of $U_{\max }$ from eq 6 based on forecasts of climate indices.

We have found, however, that operational forecasts of the indices are yet not readily available in the climate community. Several groups, including NOAA* and the Scripps Institution of Oceanography ${ }^{\dagger}$ forecast El Niño and SOI; NOAA* and the British Met Office ${ }^{\S}$ are two of the groups pursuing forecasts of NAO. In addition, studies are being made of the predictability of the PDO. ${ }^{* *}$ There exists, however, no consensus on a preferred forecasting method for these or the other indices; thus, we choose to employ another predictive method that uses the historical AFDD and climate index data themselves.

This method is based on the concept of analog years, and we use it to provide a test forecast for the winter of 2003. Analog years are the years that are most similar to the current year with respect to the independent variables (the climate indices). To find the best analog year, we look at evolution of the relevant climate indices over the summer and fall prior to the winter in question. This requires using the original monthly climate indices. Once the best analogs to the year under scrutiny have been identified, the relationships between the climate indices and $U_{\max }$ are used to make a forecast.

For the winter of 2003, the best analog years for the evolution of the climate indices from May through September are 1992, 1966, 1953, and 1987. These winters all had moderately to strongly negative SOI. Results for the other four indices were mixed across the years. PNA was positive and NAO negative for three of the four winters, NHT and PDO were near zero for three of these analog years, but NHT reached its tenth highest value in 1992 and PDO its highest in 1987. Based on the regression results in eq 6, the average climate index values for these winters result in slightly positive AFDD PC1 and PC3 (1947 and 1271, respectively) and neutral PC2 (-211). Neutral PC2 and positive PC1 and PC3 translate into overall warmth across the northern half of the country, especially across the north-central states (from EOF1), with the southern half of the country (excluding California and Nevada) and mid-Atlantic being slightly colder than average (Fig. 27a). The national maximum AFDD patterns in Appendix A for these four years show slightly above average warmth across the entire country (with the exception of 1966, which is near average), with the Great Plains being the warmest region overall. When we look at actual observations from the winter of 2003, we find that our analog years prediction of positive PNA (actual value

\footnotetext{
${ }^{*}$ http://www.cpc.ncep.noaa.gov/products/predictions/90day/SSTs/

$\dagger$ http://meteora.ucsd.edu/ pierce/elnino/pictures.html

$\$$ http://www.cpc.ncep.noaa.gov/products/precip/CWlink/pna/new.nao index_ensm.html

$\S$ http://www.metoffice.gov.uk/research/seasonal/regional/nao/index.html

*** Personal communication with M. Newman, CIRES, NOAA, 2004.
} 
was +0.71 ) and negative NAO (actual value was -0.70 ) and SOI (actual value was -0.47 ) indeed occurred. However, warmth in the West and Plains, under a persistent ridge, was accompanied by cold under an eastern trough (Fig. 27c). New England was particularly cold, and the West was warm, resulting in a winter that was more extreme than the forecast.

There could be several reasons for the divergence of the observations from the forecast. Primarily, because each index is different in the four analog years, averaging the index values from the analog winters will skew our forecasts toward the overall average values of the climate indices. This is seen clearly in Figure $27 \mathrm{a}$, where the vast majority of the country lies within $100^{\circ} \mathrm{F}$-days of zero. The reconstruction using the actual index values for winter 2003 (Fig. 27b) produces the same general pattern of anomalies as the analog years average forecast, but it also yields more extreme values that are closer to the observations (Fig. $27 \mathrm{c})$. Another possible cause for the difference between the forecast and the observations is the PDO - it was the most positive of the entire 50-year index record in $2003(+1.98)$ and could have contributed to the observed heat in the Northwest and cold in the Northeast. We did predict positive PDO for 2003, although of much smaller magnitude $(+0.37)$ than actually occurred. Inclusion of this high PDO value in the forecast map (with the other four indices the same as in Fig. 27a) results in increased warmth in the north-central states and additional cooling in the northeast, but it also cools much of the rest of the southern U.S. and the intermountain west, diverging further from the 2003 winter observations. The extremely high PDO during the 2003 winter is, therefore, not the reason for the differences between the forecast and the observations. Instead, the errors in the predicted values of the more influential indices, such as PNA and NAO, are the more likely cause.

Although our 2003 forecast of relatively warm north-central states and near average conditions across the rest of the country does not correspond exactly to the analog year warmth across the entire U.S. or to the observed significant warmth in the West and cold in the East, these results suggest that our forecasting method is moderately effective at predicting $U_{\max }$ at the regional scale. Additionally, even though the magnitudes were not the same, the analog years method produced index forecasts that were all of the correct sign. More reliable forecasts of all five index values (NAO and PNA in particular, as they are the most influential indices for AFDD PC1 and PC2), whether they are derived from other parties' index forecasts or from an improved analog years method, are required for construction of a forecast that better represents the actual winter cold. To this end, we will work in the next phase of our research on obtaining more reliable climate index forecasts, either from the available data or from other sources of index forecasts. 

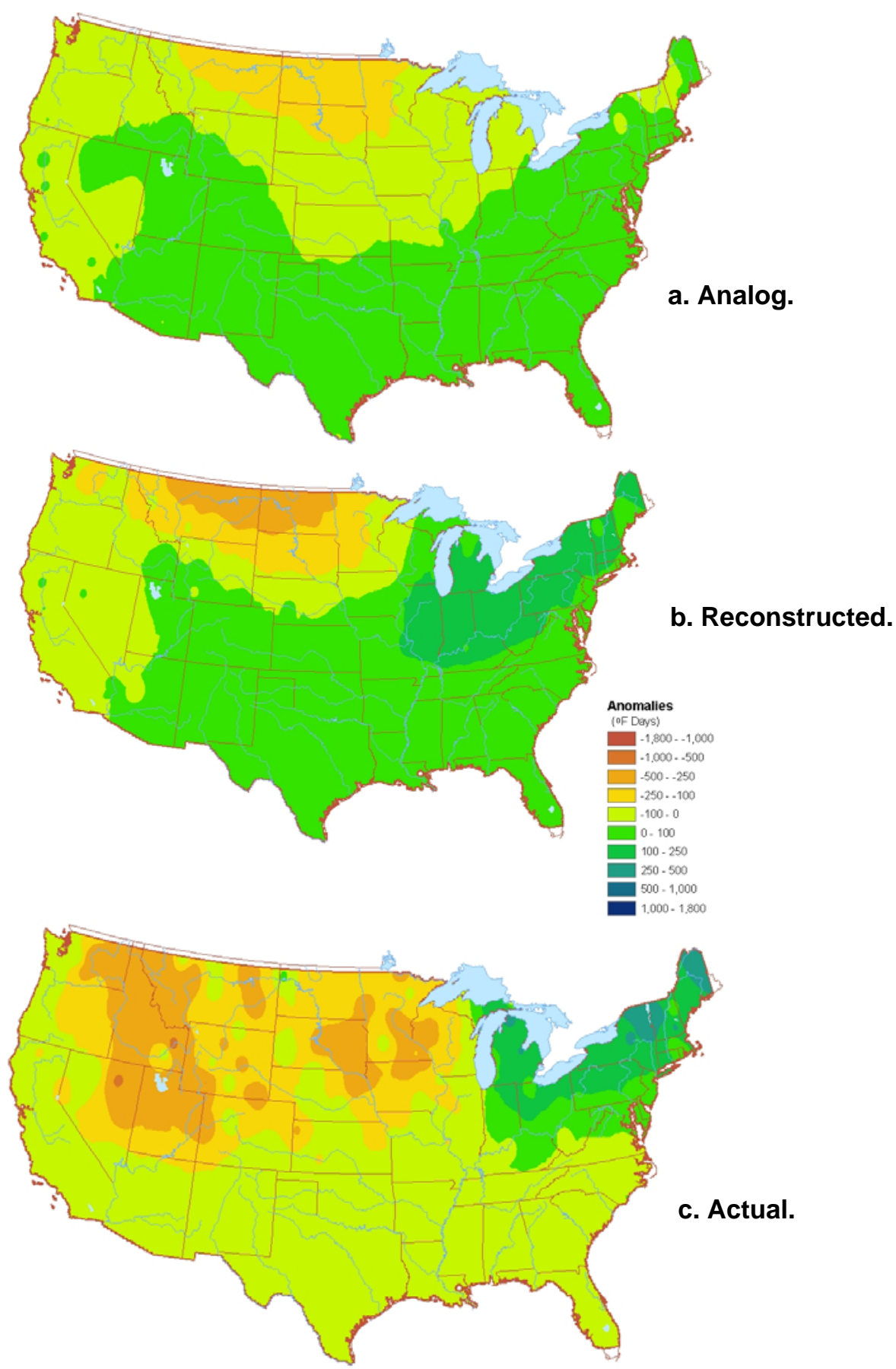

Figure 27. $U_{\max }$ anomalies for 2003 forecast based on average climate indices for analog years (a), reconstructed from climate indices for winter 2003 (without NHT) (b), and actual (c) based on data from 257 first-order stations. 


\section{SUMMARY, DISCUSSION, AND FUTURE WORK}

For this report we analyzed data available at CRREL on various measures of severe winter weather. The available snow depth and ice jam data were insufficient for characterizing their temporal and spatial variation, so this report focuses on maximum accumulated freezing degree-days, which determines the thickness of ice covers on rivers and lakes, and freezing rain storms that were severe enough to damage trees, overhead wires, and communication towers. We analyzed the spatially and temporally continuous maximum AFDD using empirical orthogonal functions and characterized the episodic ice storms by the area of the storm footprints and the deviation of those footprints from the mean storm trajectory.

The dominant $U_{\max }$ anomaly is for the entire country to be warmer or colder than the mean winter, with the maximum amplitude in the north-central states. That this anomaly pattern provides a physical representation of the AFDD, and is not just an artifact of the EOF analysis, is demonstrated by the one-point correlation analysis. Our regression results in eq 6 show that this anomaly is related to the PNA and NAO, with meridional flows from a positive PNA and zonal flows from a positive NAO associated with warmer than average winters. Positive values of these indices are also associated, through the second eigenvector, with somewhat cooler than average winters in the East and warmer in the West. However, this secondary anomaly is modified by the SOI. Positive SOI values, which are associated with relatively cool waters in the central and eastern tropical Pacific and strong trade winds, enhance the warm conditions in the West and the cool East. The PDO, with positive (negative) values occurring with cool (warm) waters in the western North Pacific and warm (cool) waters in the eastern North Pacific, is associated with warmer (cooler) than average winters in the northcentral states and cooler (warmer) winters from the intermountain region through the Great Lakes. However, this tertiary anomaly explains only $8 \%$ of the variation in $U_{\max }$, compared to 55 and $13 \%$ for the first and second eigenvectors. For negative PNA and NAO values of comparable magnitude, with zonal flow from a negative PNA and meridional flow from a negative NAO, the winter is colder than average across the country, with the cold enhanced in the West and diminished in the East through the second eigenvector. These conditions may be further enhanced by a negative SOI, associated with warmer than average water in the central and eastern tropical Pacific and weak trade winds. When the PNA and PDO values are equal in magnitude but opposite in sign, the overall flow is zonal $(\mathrm{PNA}<0$, NAO $>0$ ), with the West anomalously cold and the East warm, or meridional (PNA $>0, \mathrm{NAO}<0$ ), with a warm West and cold East. As described 
above, these conditions are modified by the SOI, with a negative SOI enhancing a cold-warm east-west pattern and a positive SOI enhancing a warm-cold eastwest pattern. While these regression equations explain much of the large-scale annual variation of maximum AFDD, they leave a significant portion of the temporal behavior of the principal components of $U_{\max }$ unexplained, particularly for the second and third EOFs. This may be because of the constraints inherent in a linear regression analysis. Other methods, such as classification and regression trees (CART) used by Rodionov et al. (2001), that allow for nonlinear relationships may provide better relationships between $U_{\max }$ and the climate indices.

From a practical standpoint, the association we found between $U_{\max }$ and the climate indices is difficult to use in forecasting AFDD because of the lack of climate index forecasts. In the long term, as climatologists discover and confirm relationships between the ocean-atmosphere system and changes in climate, the relationships we have determined between winter weather in the U.S. and climate indices should be useful for understanding the driving mechanisms of the climate system and their effects on U.S. winter weather. Although they are not available now, climate index forecasts, whether from other people's work or from our continued study, should allow us to use the relationships we have determined between these indices and winter weather in the U.S. to relate shifts in the amplitude and phase of the climate indices to the severity of the winter.

Damaging ice storms are only slightly related to the climate indices, with the NAO providing the most information. While the NAO is typically associated with conditions in and around the North Atlantic, in its incarnation as the Arctic Oscillation, it also has a center of action in the north Pacific. A positive NAO (zonal flow) is associated with a more northerly track of damaging ice storms in the East, and with the relatively frequent, intense ice storms with small areas in the Pacific Northwest. On average, months without ice storms in the east tend to have NAO indices that are more negative and SOI indices that are more positive than months with ice storms. There is no significant correlation between ice storms and NHT, indicating that the warming observed in the past 20 years is not reflected in the occurrence or path of damaging ice storms in the U.S.

The small correlation we found between ice storms and climate indices is consistent with recent results for tornadoes. Marzban and Schaefer (2000) found that there is a small negative correlation between tornadoes in the northeastern U.S. and equatorial Pacific sea surface temperatures, indicating a slight tendency for tornadoes to occur in La Niña months. They found no significant correlation with equatorial Pacific sea surface temperatures for tornadoes in Tornado Alley or the southeastern states. The occurrence and severity of both ice storms and tornadoes are likely to be strongly affected by local to mesoscale conditions, with 
the general circulation patterns having a smaller influence. The low correlations of ice storms and tornadoes with climate indices may hold also for other storm types, such as blizzards, tropical storms, hailstorms, and thunderstorms.

We are extending our analysis of $U_{\max }$ to include Alaska and an additional 3000 foreign stations. Alaskan data are from the same mix of first-order and cooperative stations that we used for the contiguous 48 states. Data at the foreign stations are from NCDC's Integrated Surface Hourly database. For most foreign stations, those data begin in the early 1970 s, so we do not have the 50 -year period of record that is available for the U.S. Furthermore, there are few or no data available in many areas (Fig. 28) for a variety of reasons, including low population densities and interruptions in data collection because of wars and local conflicts. We are attempting to deal with temporal gaps in the data by allowing for missing values in calculation of correlations and covariances in the EOF software. The spatial gaps are not so readily overcome, and are likely to result in a more homogeneous winter temperature pattern than actually exists.

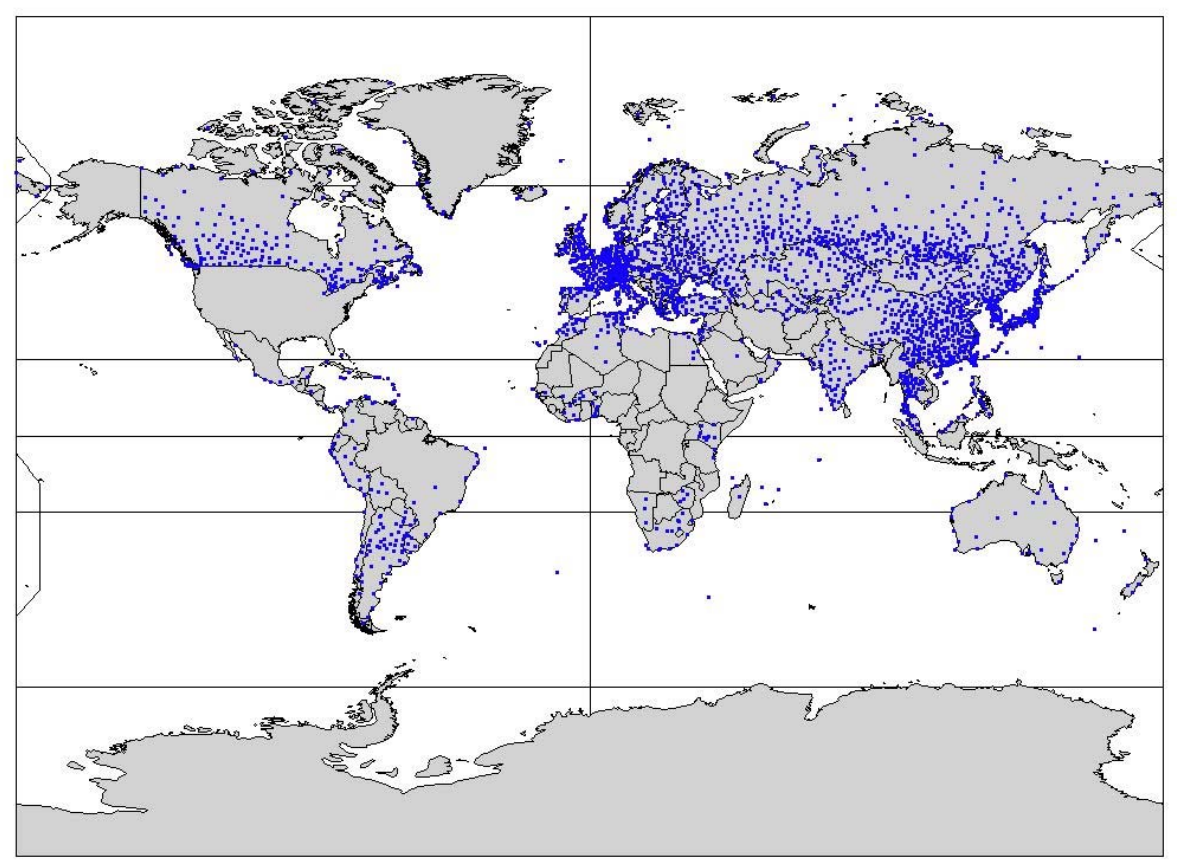

Figure 28. Foreign weather stations.

Ultimately, we can use this same data set for investigating the spatial and temporal structure of other parameters, such as summertime temperatures and seasonal rainfall amounts. Determining the relationship between these parameters 
and climate indices on a continental and global scale will provide us with a better indication than we now have of the interrelationships between weather and climate. 


\section{REFERENCES}

Ashton, G.D. (Ed.) (1986) River and Lake Ice Engineering. Littleton, Colorado: Water Resources Publications.

Beltaos, S. (Ed.) (1995) River Ice Jams. Littleton, Colorado: Water Resources Publications.

Eames, H.J., L. Herrin, and K. White (1998) Ice Jams in Montana. Ice Engineering Information Exchange Bulletin Number 19. U.S. Army Cold Regions Research and Engineering Laboratory, Hanover, New Hampshire. http://www.crrel.usace.army.mil/ierd/tectran/IERD26.pdf

Folland, C.K., N.A. Rayner, S.J. Brown, T.M. Smith, S.S.P. Shen, D.E.Parker, I. Macadam, P.D. Jones, R.N. Jones, N. Nicholls, and D.M.H. Sexton (2001a) Global temperature change and its uncertainties since 1861. Geophysical Research Letters 28: 2621-2624.

Folland, C.K., T.R. Karl, J.R. Christy, R.A. Clarke, G.V. Gruza, J. Jouzel, M.E. Mann, J. Oerlemans, M.J. Salinger, and S.-W. Wang (2001b) Observed climate variability and change. In: Climate Change 2001: The Scientific Basis. Contribution of Working Group I to the Third Assessment Report of the Intergovernmental Panel on Climate Change (J.T. Houghton, Y. Ding, D.J. Griggs, M. Noguer, P.J. van der Linden, X. Dai, K. Maskell, and C.A. Johnson, Eds.). Cambridge, United Kingdom: Cambridge University Press, pp. 99-181.

Friddell, J., R. Thunell, T. Guilderson, and M. Kashgarian (2003) Increased northeast Pacific climatic variability during the warm middle Holocene. Geophysical Research Letters, 30(11): doi:10.1029/2002GL016834.

Green, A.R. (1964) Magnitude and frequency of floods in United States, part 1A. North Atlantic slope basins, Maine to Connecticut. U.S. Geological Survey, Water-Supply Paper 1671.

Hansen, J., M. Sato, J. Glascoe, and R. Ruedy (1998) A common-sense climate index: Is climate changing noticeably? Proceedings, National Academy of Science, 95, 4113-4120.

Herrin, L, H.J. Eames, and K. White (2000) Ice Jams in New Hampshire. Ice Engineering Information Exchange Bulletin Number 26. U.S. Army Cold Regions Research and Engineering Laboratory, Hanover, New Hampshire. http://www.crrel.usace.army.mil/ierd/tectran/IERD26.pdf

Huang, J., K. Higuchi, and A. Shabbar (1998) The relationship between the North Atlantic Oscillation and El Niño-Southern Oscillation. Geophysical Research Letters, 25: 2707-2710. 
Hurrell, J.W., Y. Kushnir, G. Ottersen, and M. Visbeck (Eds) (2003) The North Atlantic Oscillation, Climate Significance and Environmental Impacts. Geophysical Monograph Series, 134.

IAHR Working Group on River Ice Hydraulics (1986) River ice jams: A state-of-the-art report. In Proceedings, IAHR Symposium on Ice, 18-22 August, Iowa City, vol. 3, pp. 561-594.

Jones, K.F. (1996) Ice accretion in freezing rain. U.S. Army Cold Regions Research and Engineering Laboratory, Hanover, New Hampshire, CRREL Report 96-2.

http://www.crrel.usace.army.mil/techpub/CRREL_Reports/reports/CR96 02.pdf

Jones, K.F., R. Thorkildson and J.N. Lott (2002) The development of the map of extreme ice loads for ASCE Manual 74, Electrical Transmission in a New Age. Reston Virginia: American Society of Civil Engineers, pp. 9-31. ftp://ftp.ncdc.noaa.gov/pub/data/techrpts/tr200201/tr2002-01.pdf.

Keigwin L.D. (1996) The Little Ice Age and Medieval Warm Period in the Sargasso Sea. Science, 274(5292) 1504-1508.

Mantua, N.J. and S.R. Hare, Y. Zhang, J.M. Wallace, and R.C. Francis (1997) A Pacific interdecadal climate oscillation with impacts on salmon production. Bulletin of the American Meteorological Society, 78: 1069-1079.

Mantua, N.J., and S.R. Hare (2002) The Pacific Decadal Oscillation. Journal of Oceanography 58(1): 35-44.

Marzban, C., and J.T. Schaefer (2000) The correlation between U.S. tornadoes and Pacific sea surface temperature, Monthly Weather Review, 129: 884-895.

McCabe, G.J., and M.D. Dettinger (2001) Primary modes and predictability of year-to-year snowpack variations in the western United States from teleconnections with Pacific Ocean Climate. Journal of Hydrometeorology, 3: 13-25.

Minobe, S. (1999) Resonance in bidecadal and pentadecadal climate oscillations over the North Pacific: Role in climatic regime shifts. Geophysical Research Letters, 26: 855-858.

NOAA (1950-1958) Climatological Data, National Summary. Asheville, North Carolina: National Climatic Data Center.

NOAA (1950-present) Global Summary of the Day Data. Asheville, North Carolina: National Climatic Data Center.

http://www.ncdc.noaa.gov/oa/climate/climatedata.html

NOAA (1959-present) Storm Data. Asheville, North Carolina: National Climatic Data Center. 
NOAA (2001) Cooperative Summary of the Day Data (1950-2001). Asheville, North Carolina: National Climatic Data Center. http://www.ncdc.noaa.gov/oa/climate/climatedata.html

Pittenger, R.F., and R.B. Gagosian (2003) Global warming could have a chilling effect on the military. Defense Horizons, 33:1-8.

Press, W.H., B.P. Flannery, S.A. Teukolsky, and W.T. Vetterling (1986) Numerical Recipes. New York: Cambridge University Press.

Rodionov, S., and R. Assel (2001) A new look at the Pacific/North American index. Geophysical Research Letters, 28(8): 1519-1522.

Rodionov, S., R. Assel, and L. Herche (2001) Tree-structured modeling of the relationship between Great Lakes ice cover and atmospheric circulation patterns, Journal of Great Lakes Research, 27(4): 486-502.

Ropelewski, C.F., and M.S. Halpert (1987) Global and regional scale precipitation patterns associated with the El Niño/Southern Oscillation. Monthly Weather Review, 115: 1606-1626.

Rothrock, D.A., Y. Yu, and G.A. Maykut (1999) Thinning of the arctic sea-ice cover, Geophysical Research Letters, 26(23): 3469-3472.

Shabbar, A. and B. Bonsal (2003) An assessment of changes in winter cold and warm spells over Canada. Natural Hazards 29(2): 173-188.

Thompson, D.W.J., and J.M. Wallace (1998) The Arctic Oscillation signature in the wintertime geopotential height and temperature fields. Geophysical Research Letters, 25(9): 1297-1300.

Toppin, K.W., K.E. McKenna, J.E. Cotton, and J.C. Denner (1993) Water resources data New Hampshire and Vermont, water year 1993. U.S. Geological Survey Water-Data Report NH-VT-93-3.

Tucker, III, W.B., D.L. Bentley, J.W. Weatherly, D.T. Eppler, and L.D. Farmer (2001) Evidence for rapid thinning of sea ice in the Western Arctic Ocean at the end of the 1980s. Geophysical Research Letters, 28(14): 28512854.

U.S. Army (2002) Engineer Manual, Ice Engineering, EM 1110-2-1612 http://www.usace.army.mil/inet/usace-docs/eng-manuals/em1110-2-1612/toc.htm U.S. Army Corps of Engineers (1978) Report Ohio River Division Ice Committee, 14 June. 
Wallace, J.M., and D.S. Gutzler (1981) Teleconnections in the geopotential height field during the northern hemisphere winter. Monthly Weather Review, 109: 784-812.

White, K.D. (1995) Characterizing ice jams in New Hampshire and Vermont using the CRREL ice jam data base. USA Cold Regions Research and Engineering Laboratory, Ice Engineering Information Exchange Bulletin No. 9.

White, K.D., and H.J. Eames (1999) CRREL ice jam database. USA Cold Regions Research and Engineering Laboratory, CRREL Report CR 99-02.

White, K.D. (1999a) Ice events in the Susquehanna River Basin. Ice Engineering Information Exchange Bulletin Number 21 April 1999 USA Cold Regions Research and Engineering Laboratory.

http://www.crrel.usace.army.mil/ierd/tectran/IERD21.pdf

White, K.D. (1999b) Ice events in the St. Louis District. USA Cold Regions Research and Engineering Laboratory, Ice Engineering Information Exchange Bulletin No. 20.

Wilks, D. (1995) Statistical Methods in the Atmospheric Sciences. Academic Press.

Wolter, K., and M.S. Timlin (1993) Monitoring ENSO in COADS with a seasonally adjusted principal component index. Proc. of the 17th Climate Diagnostics Workshop, Norman, Oklahoma. NOAA/N MC/CAC, NSSL, Oklahoma Clim. Survey, CIMMS and the School of Meteor., Univ. of Oklahoma, pp. 5257. 
APPENDIX A : ANNUAL MAPS OF SEVERE WINTER WEATHER 1949-2001
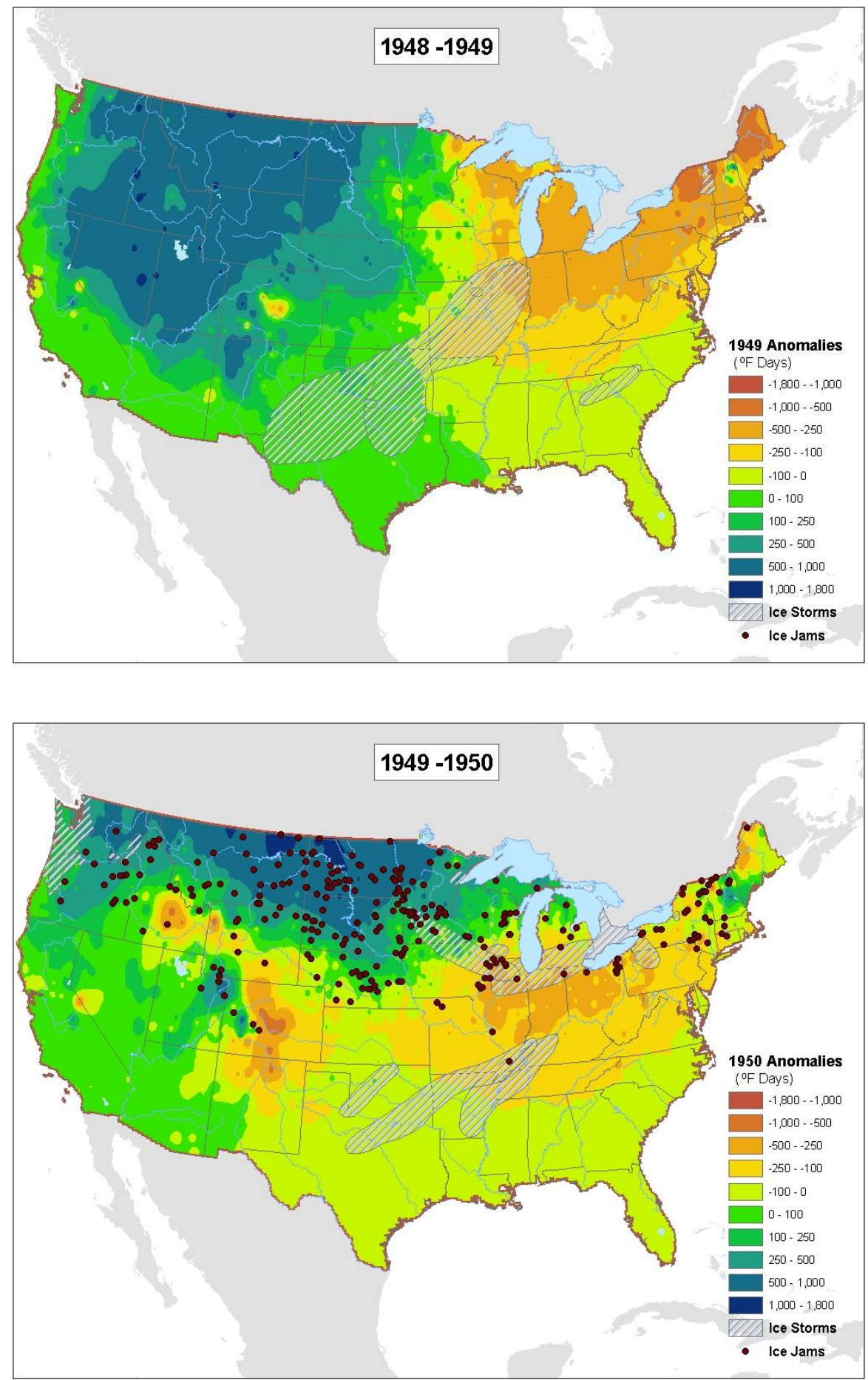

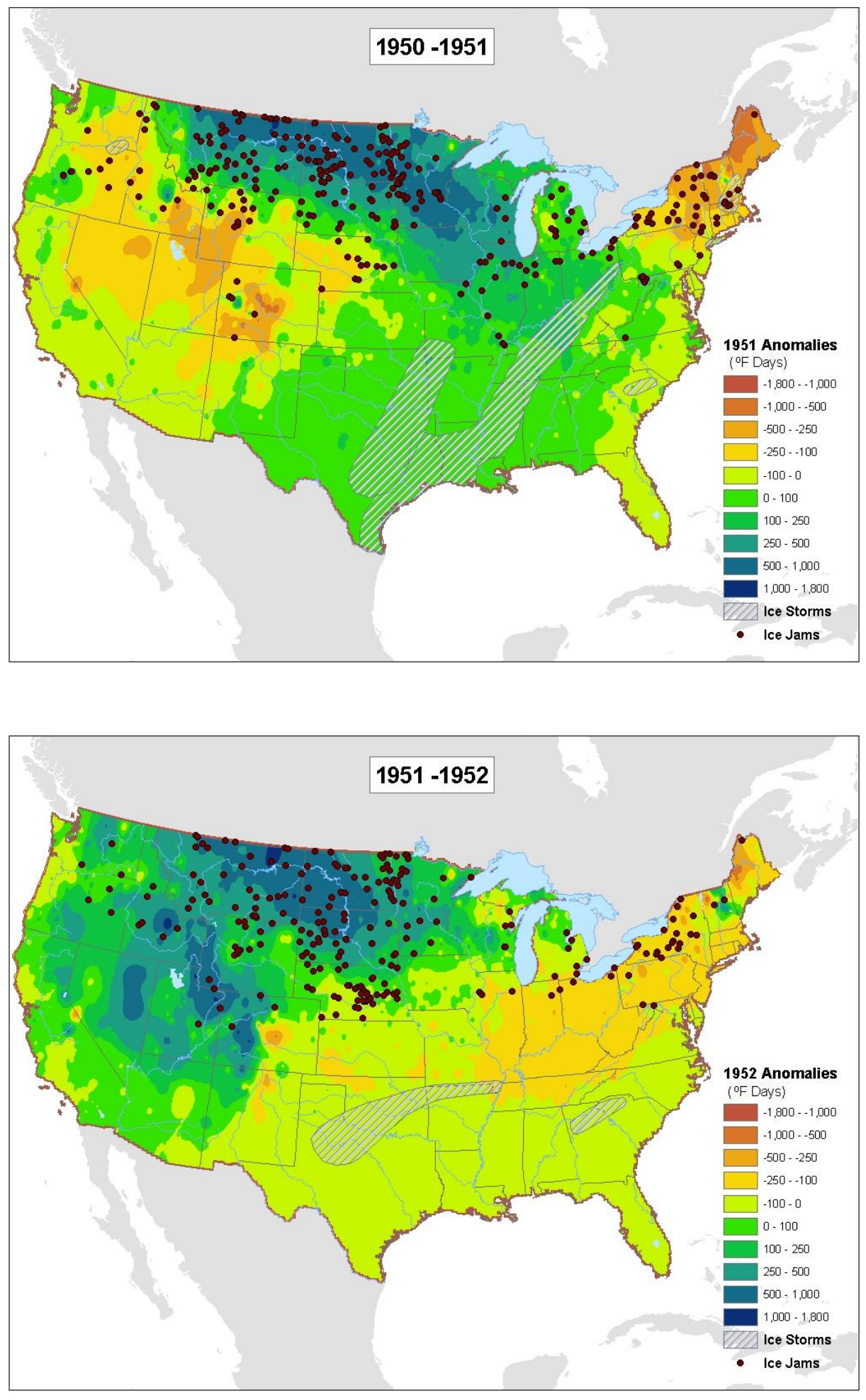

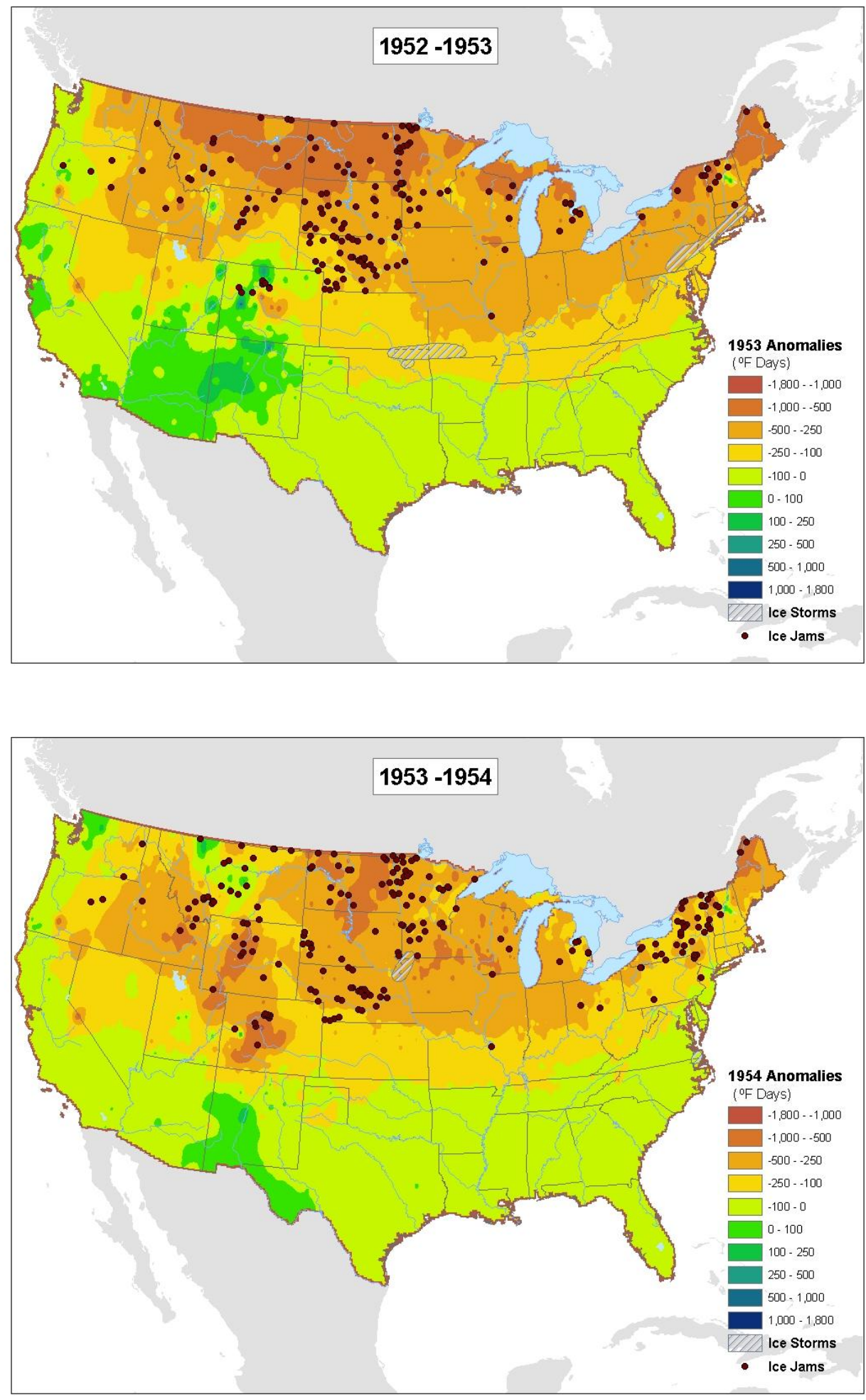

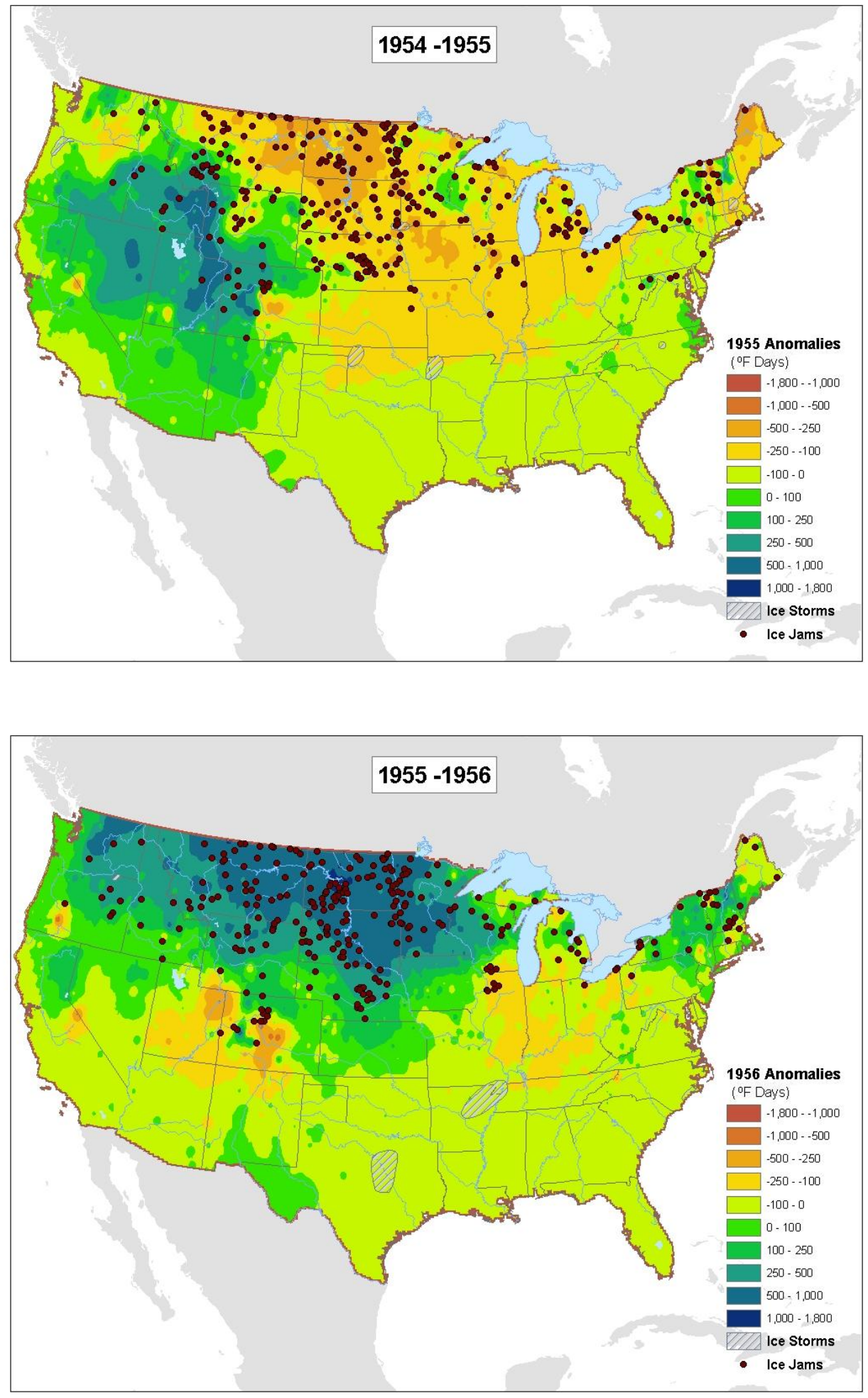

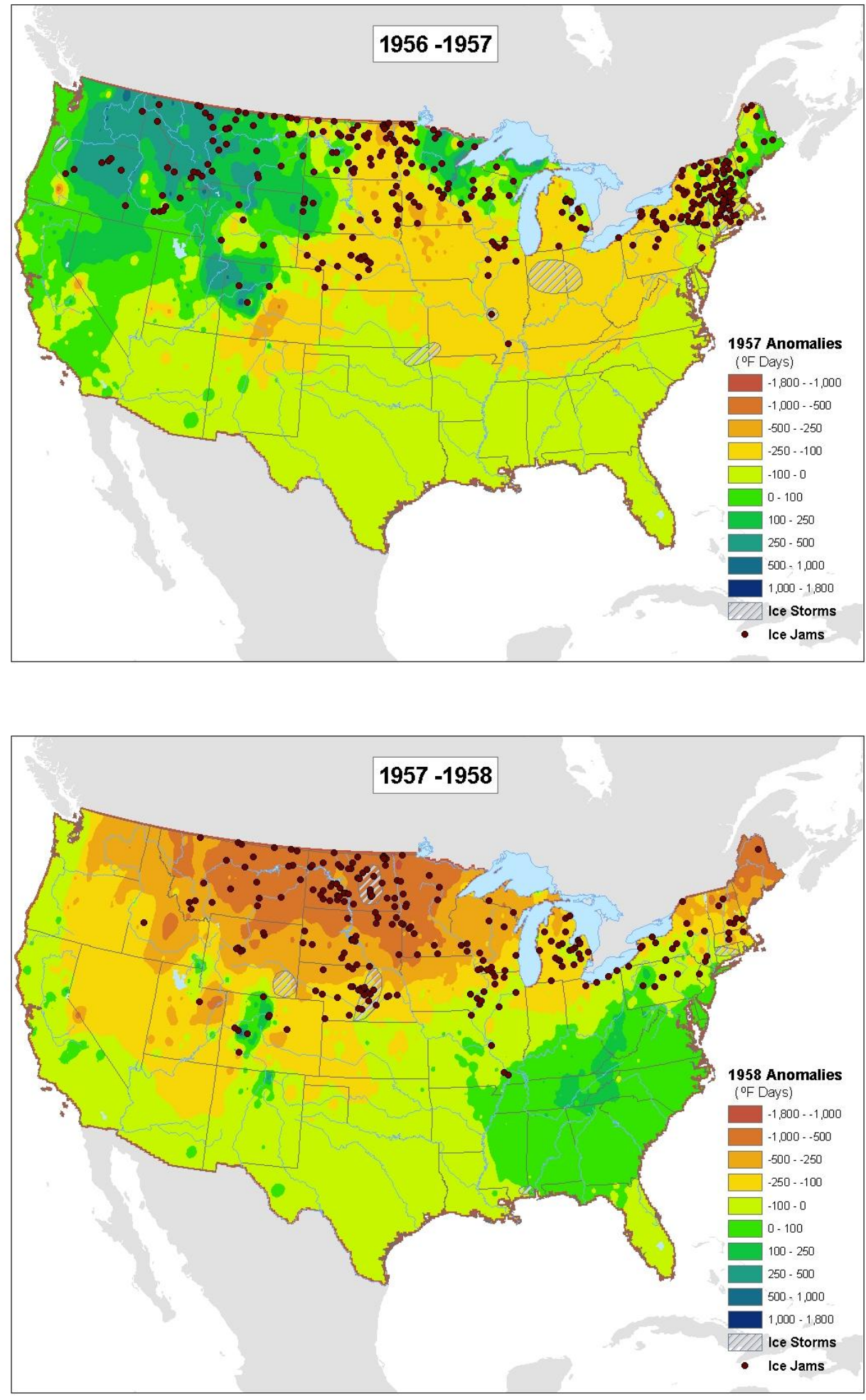

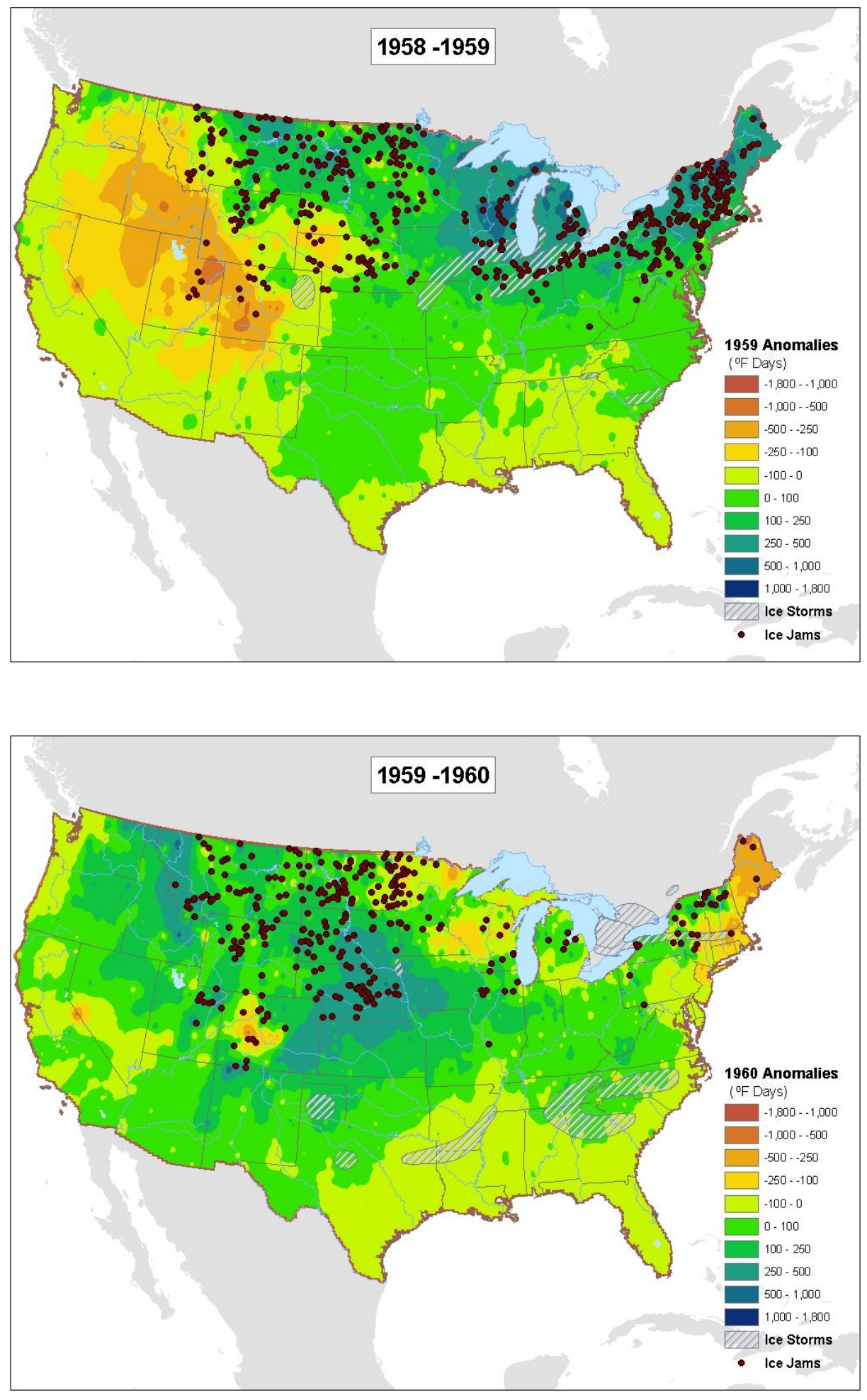

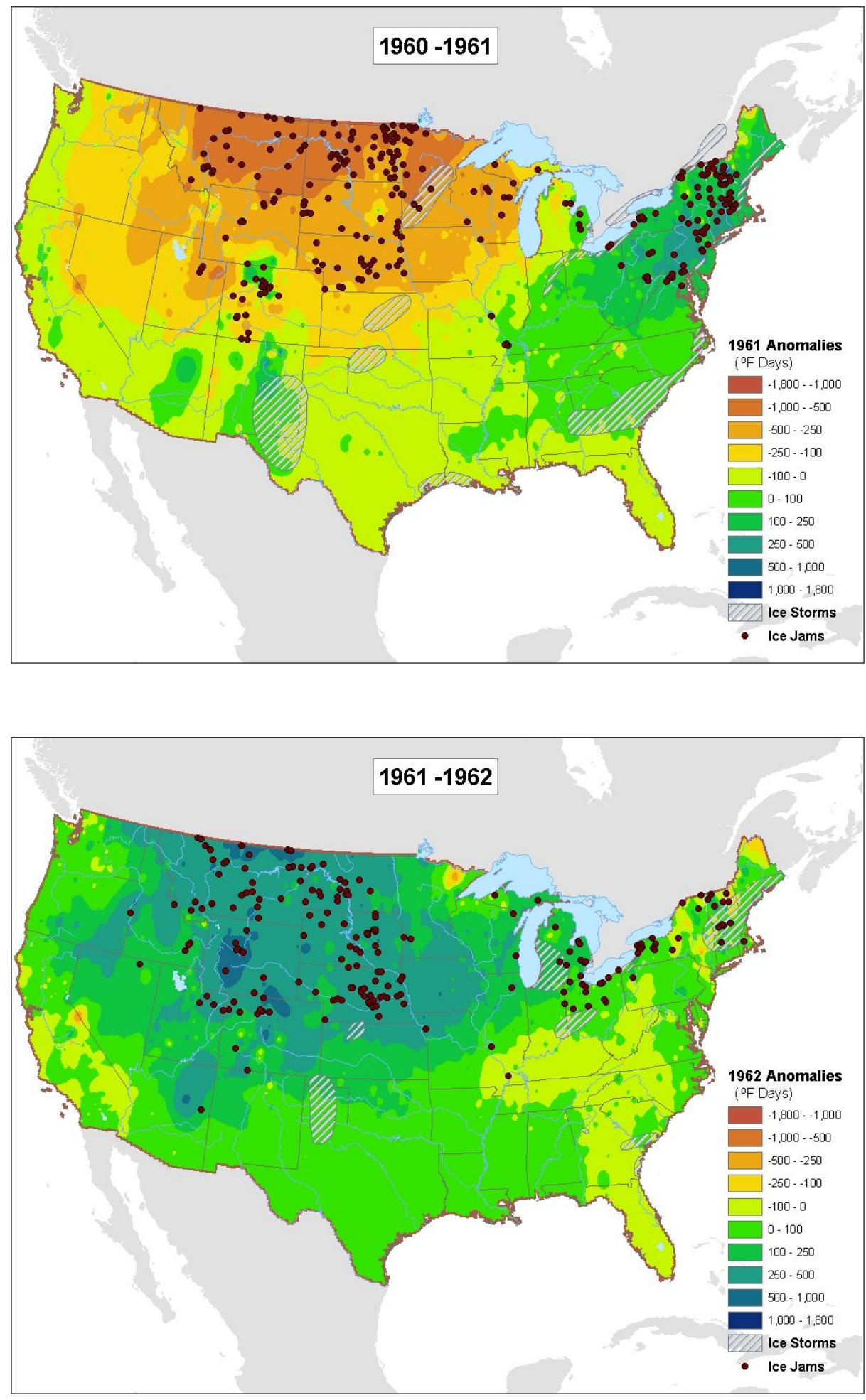

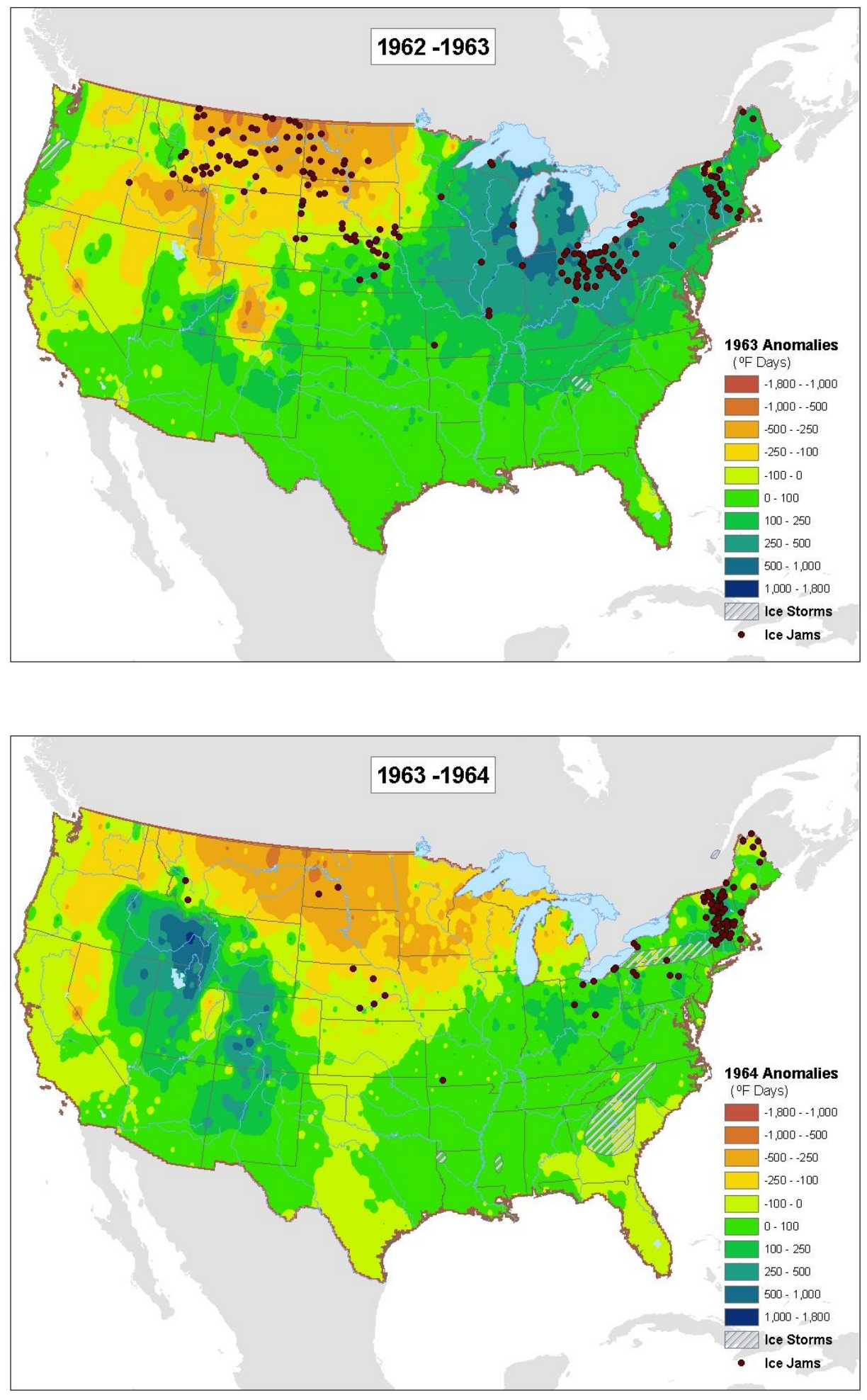

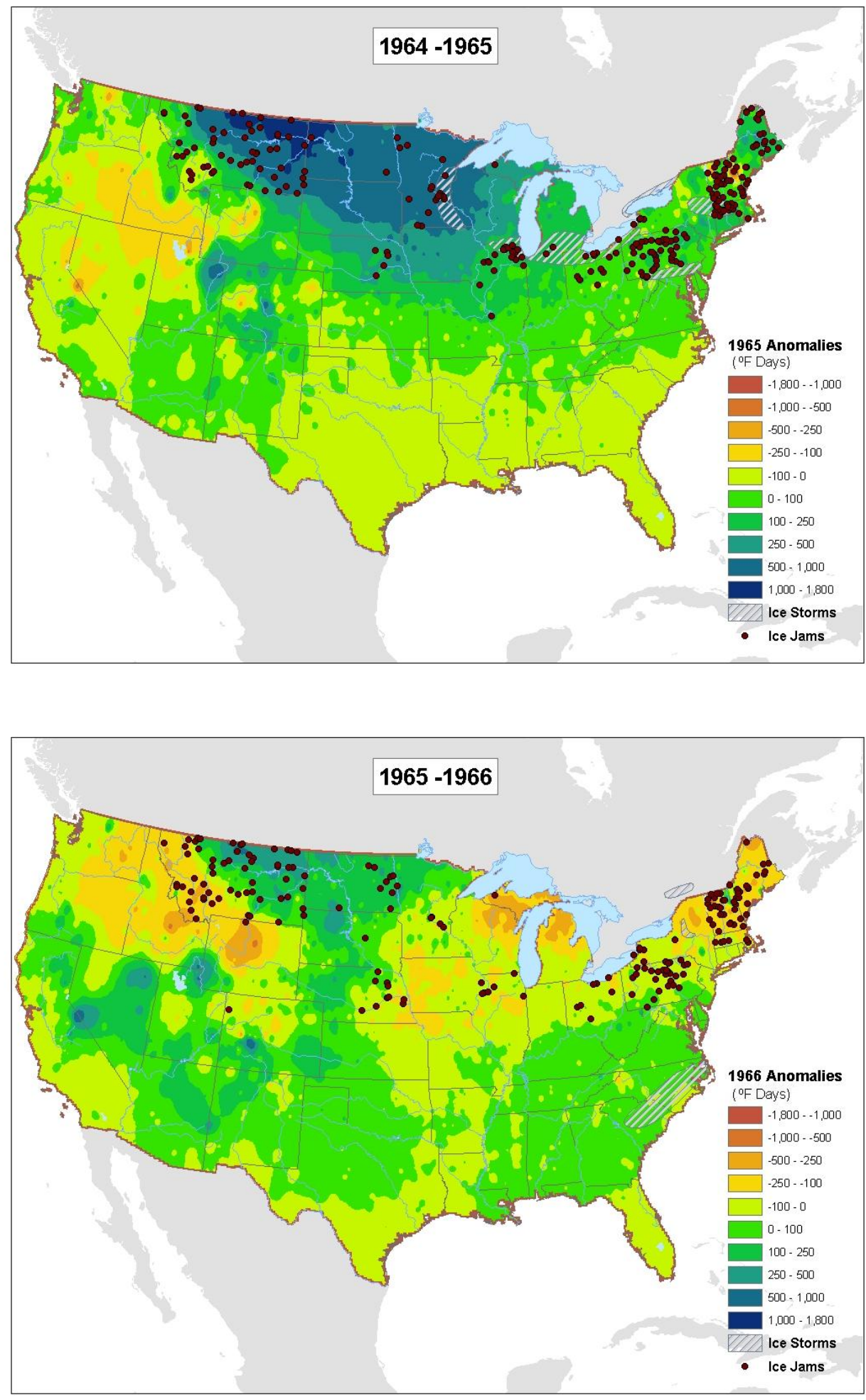

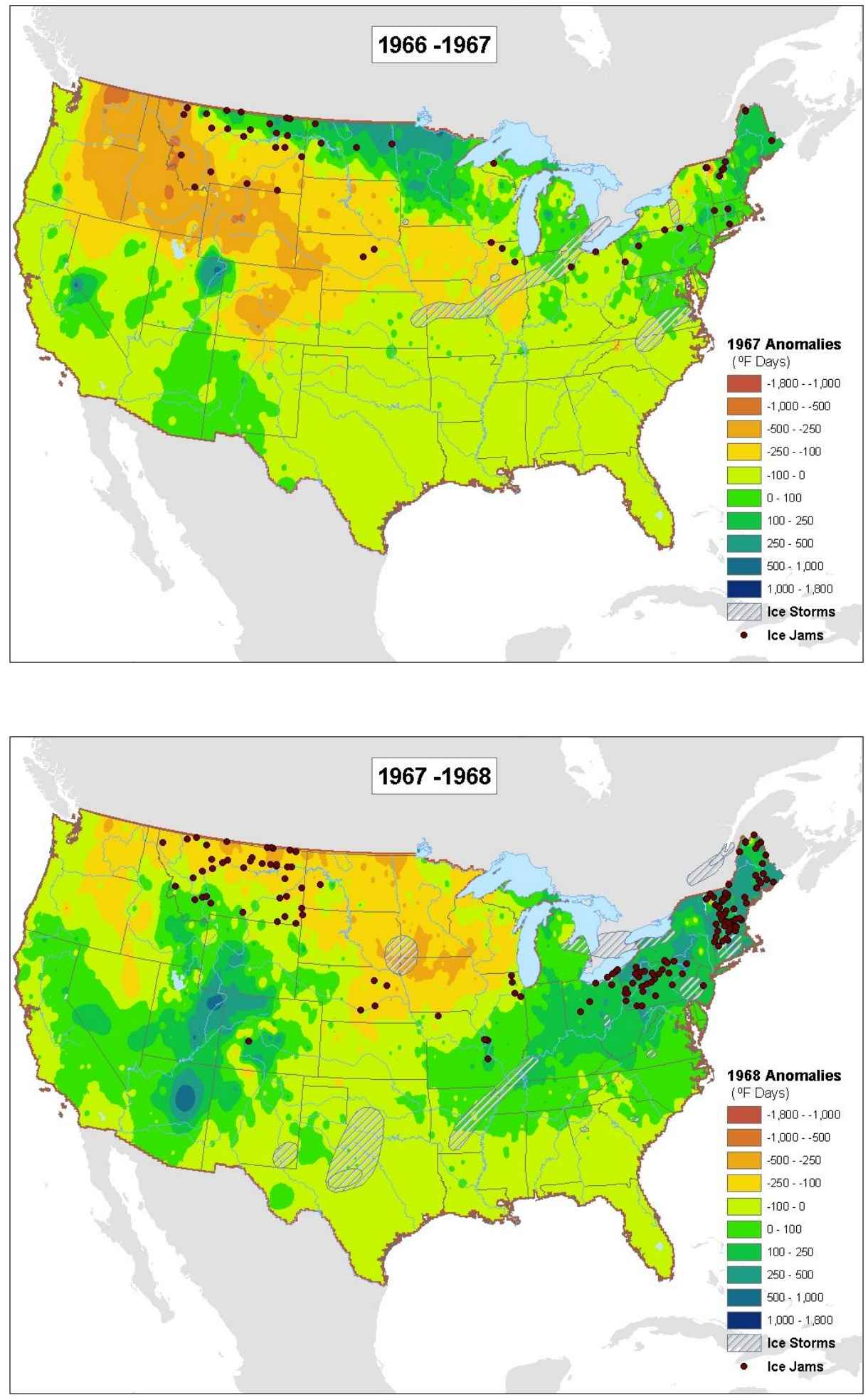

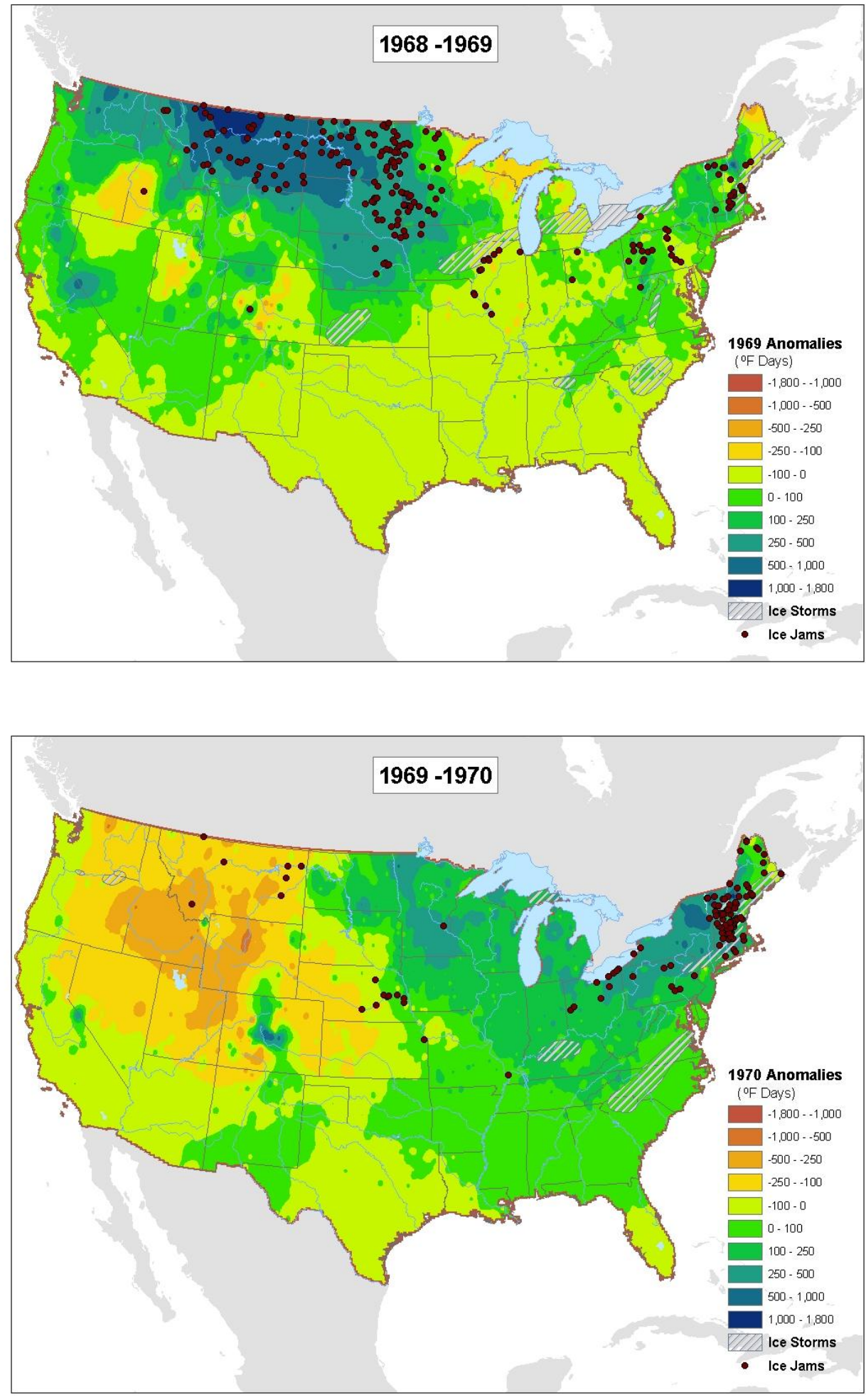

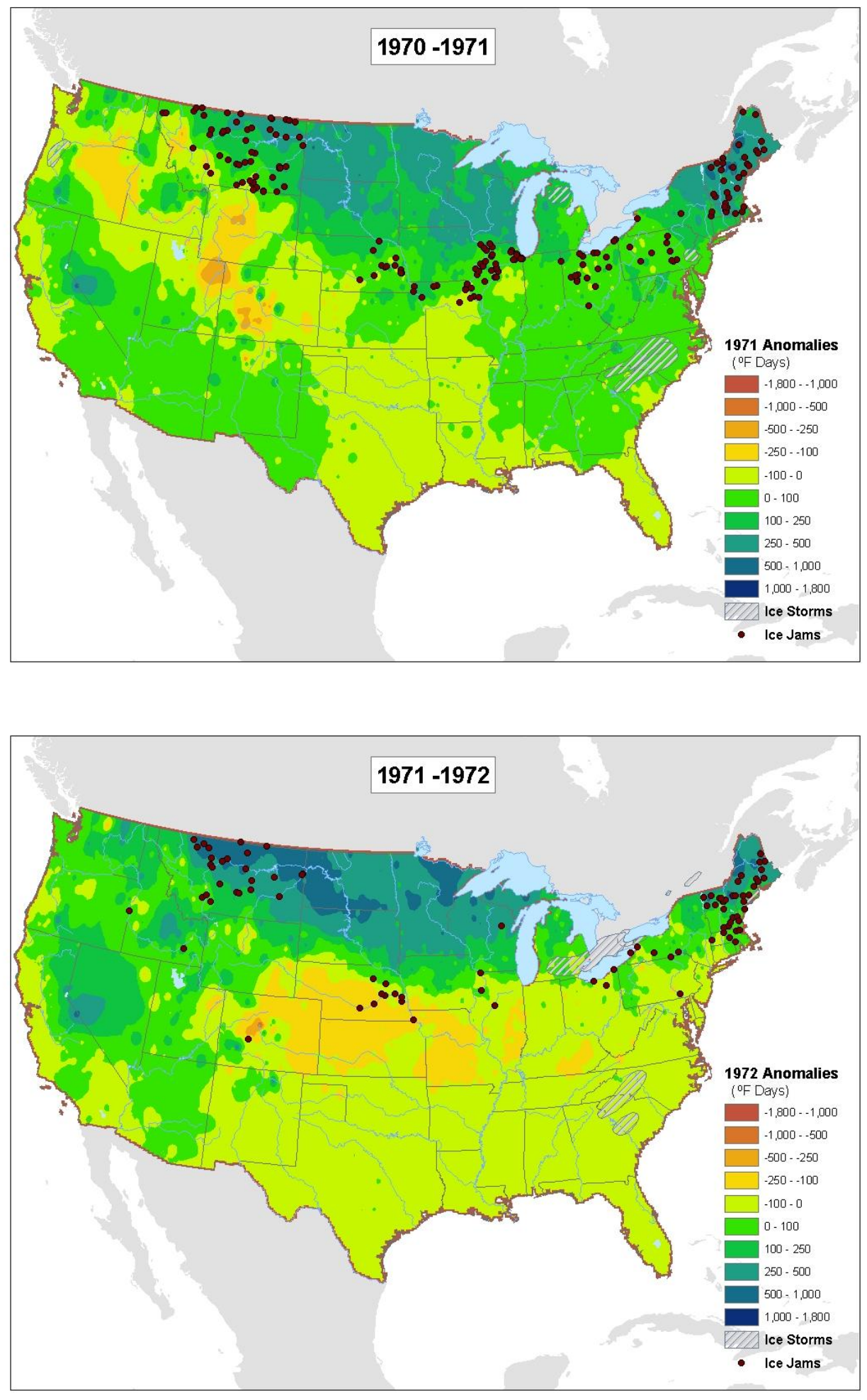

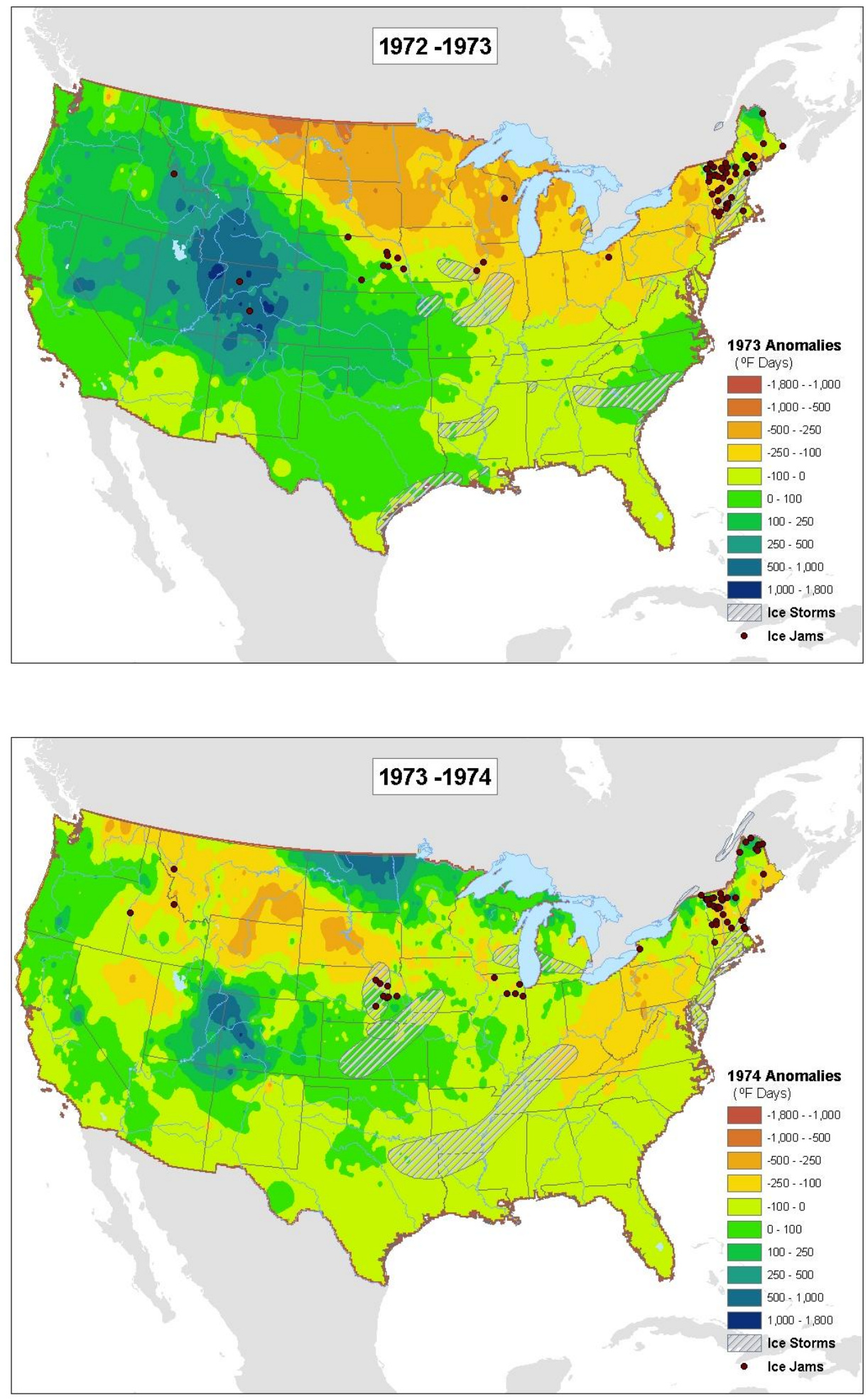

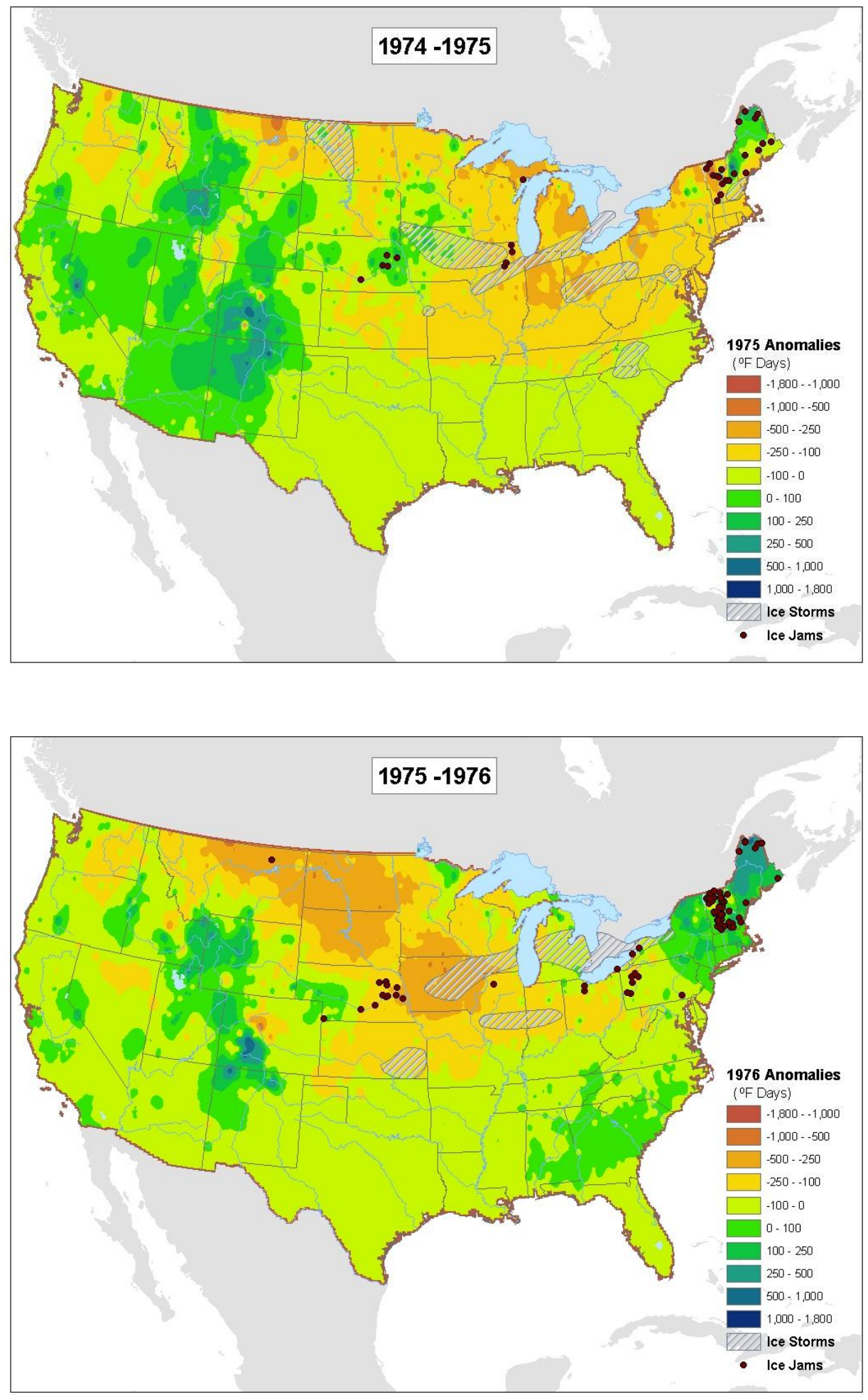

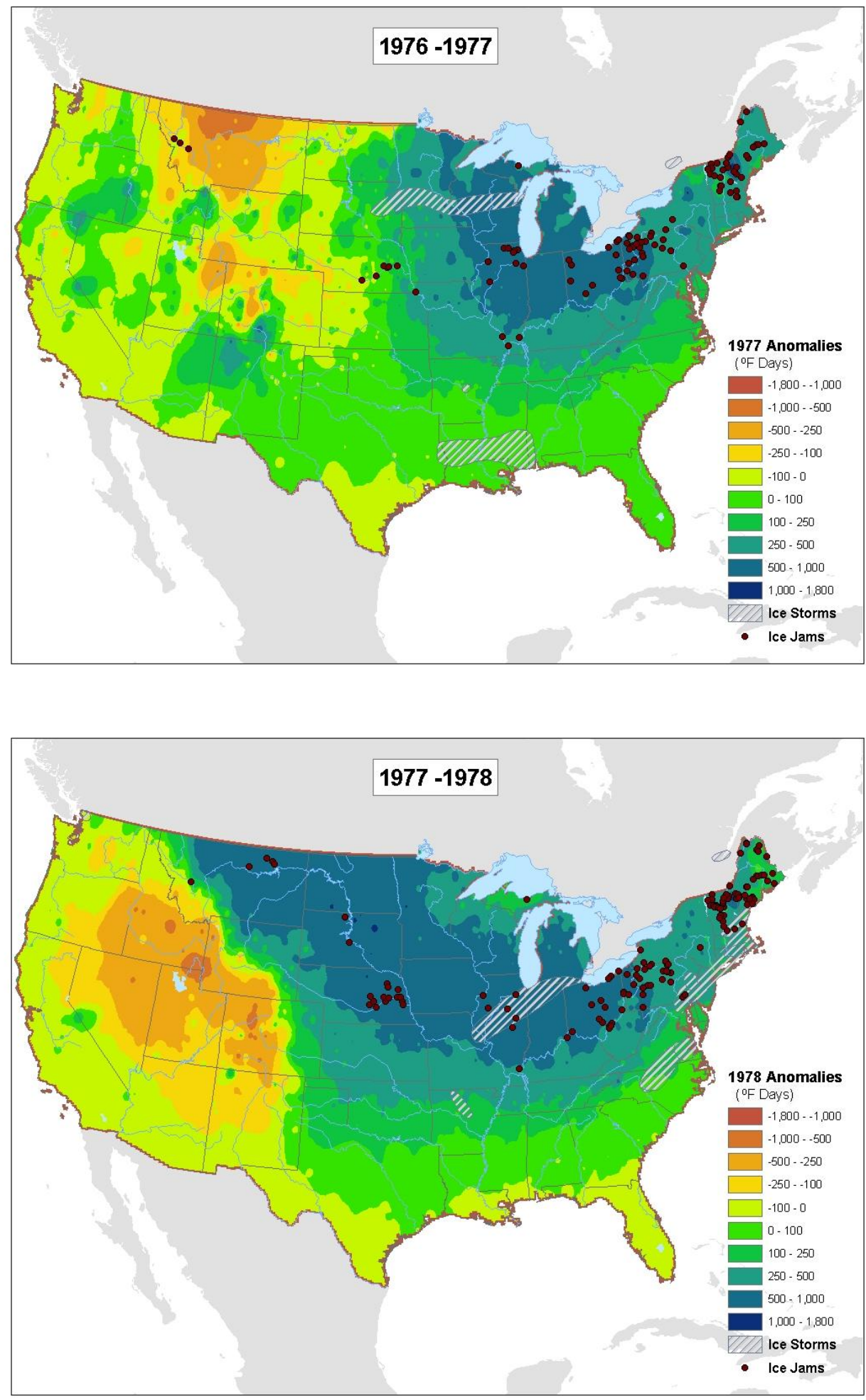

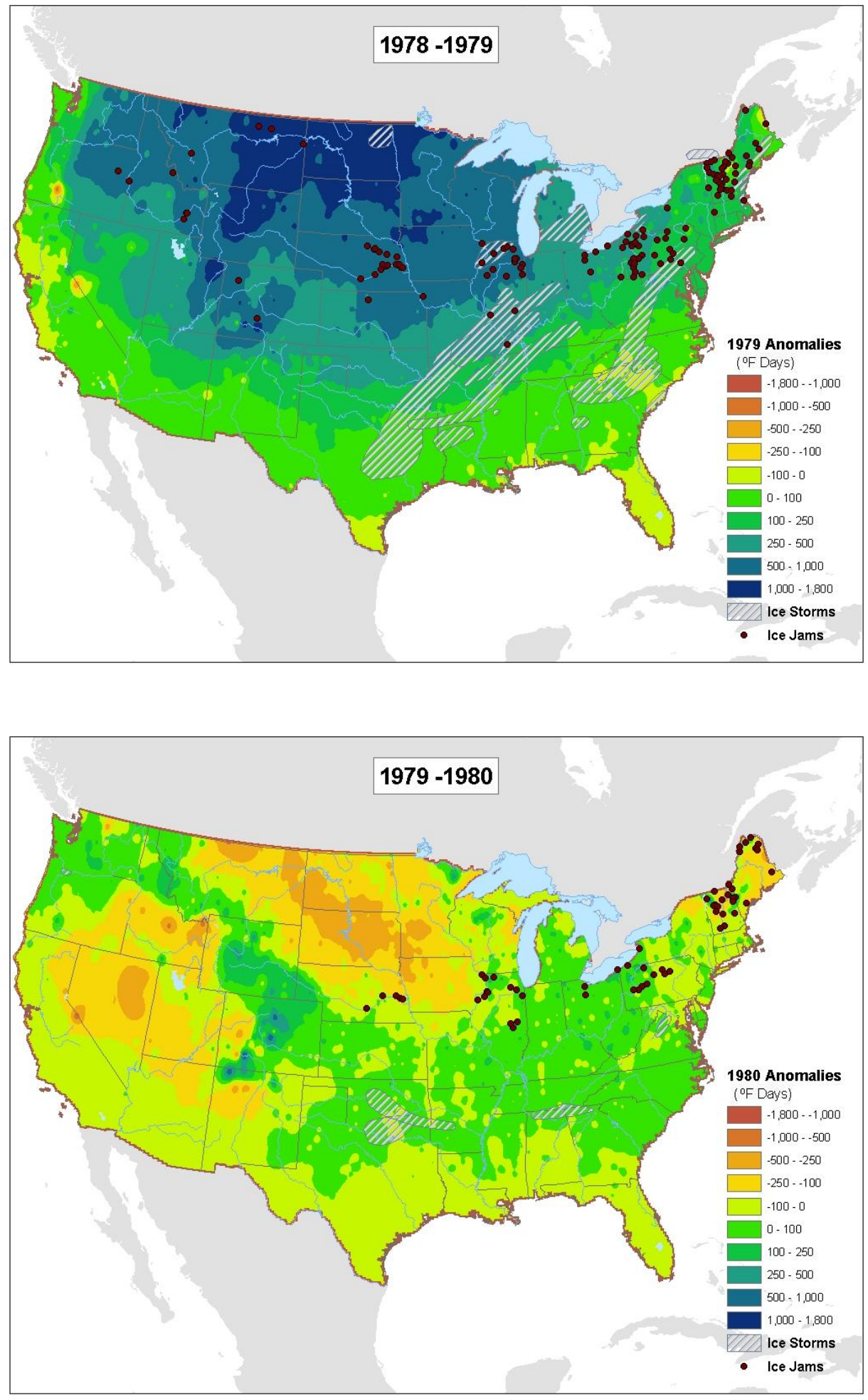

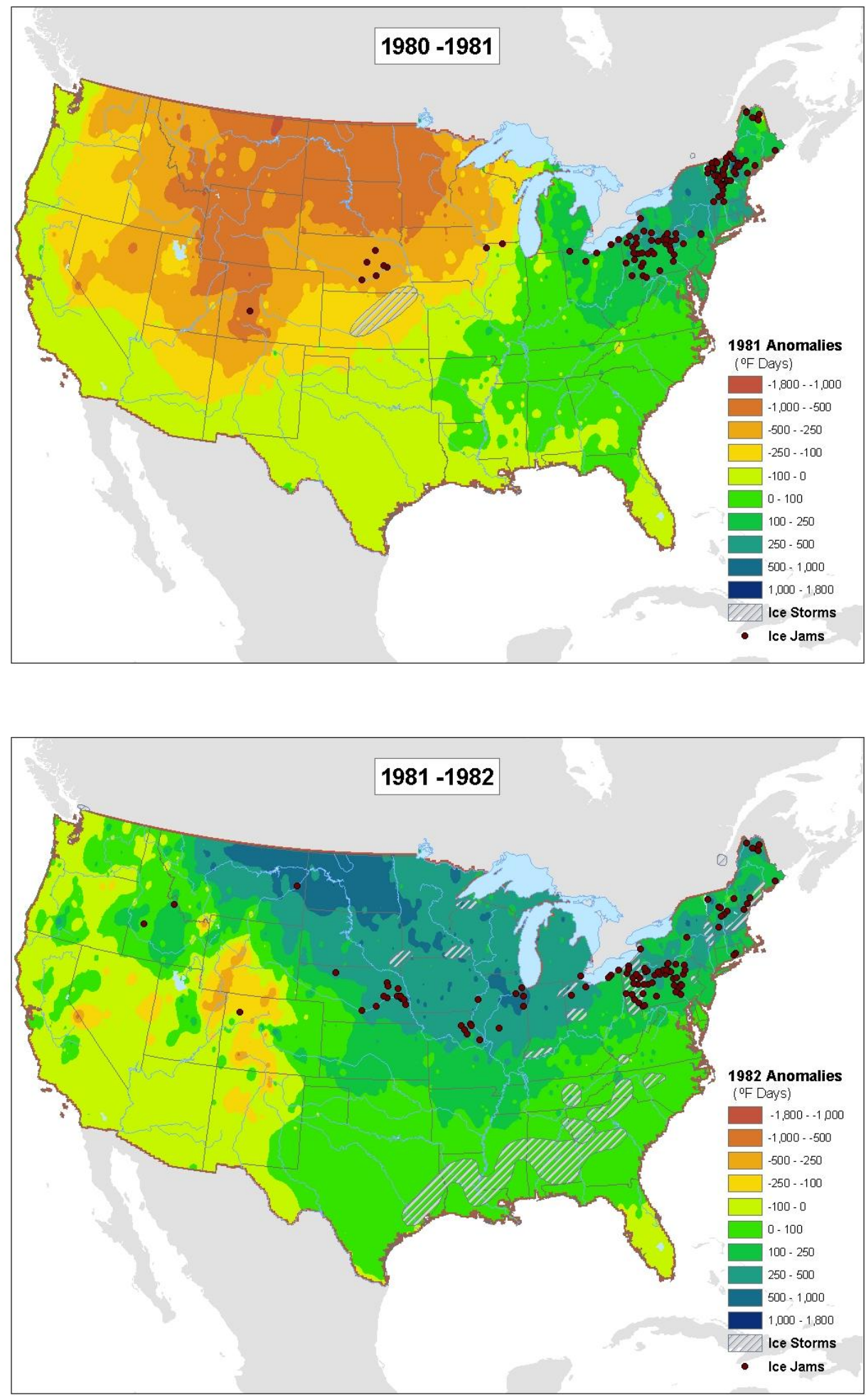

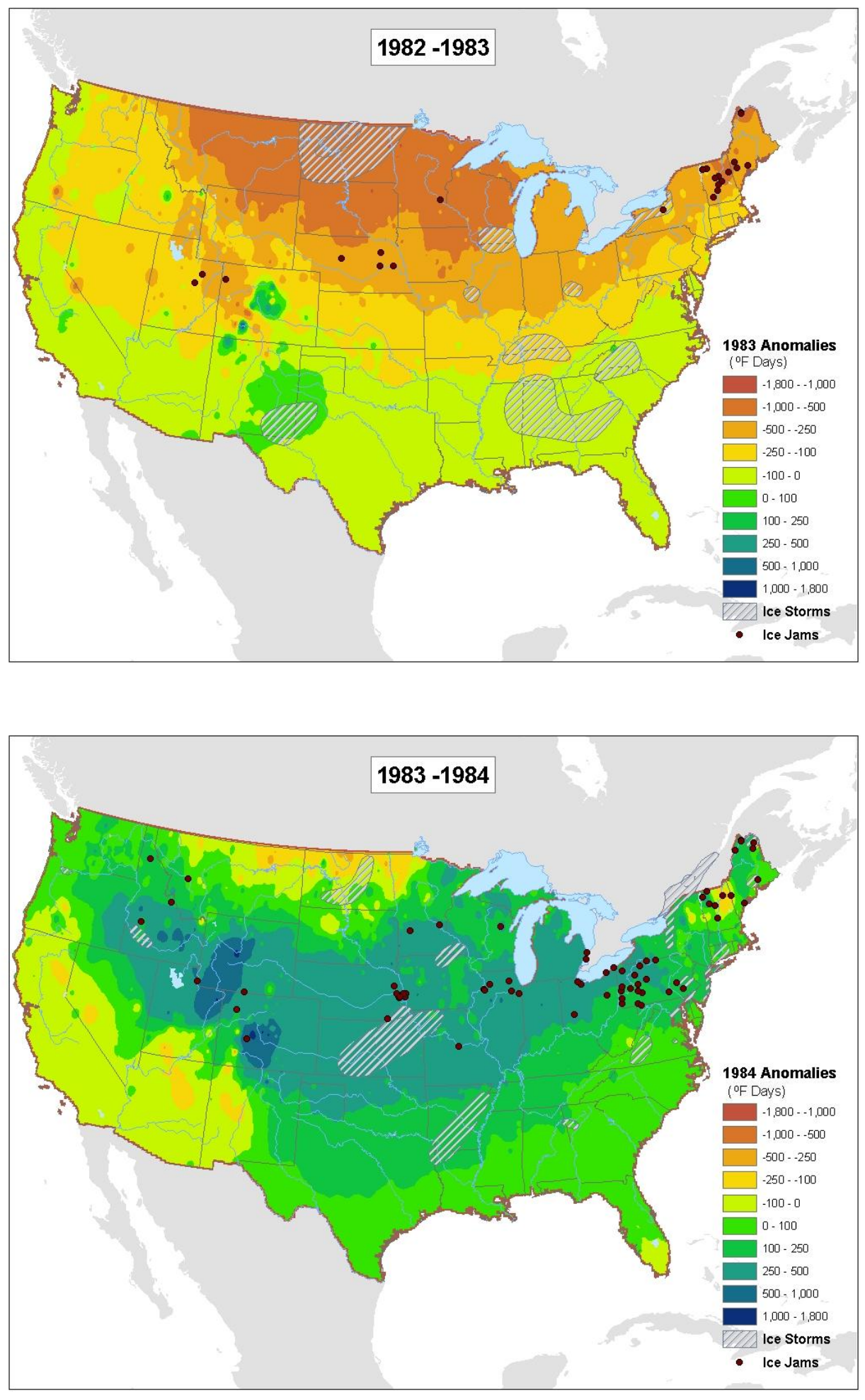

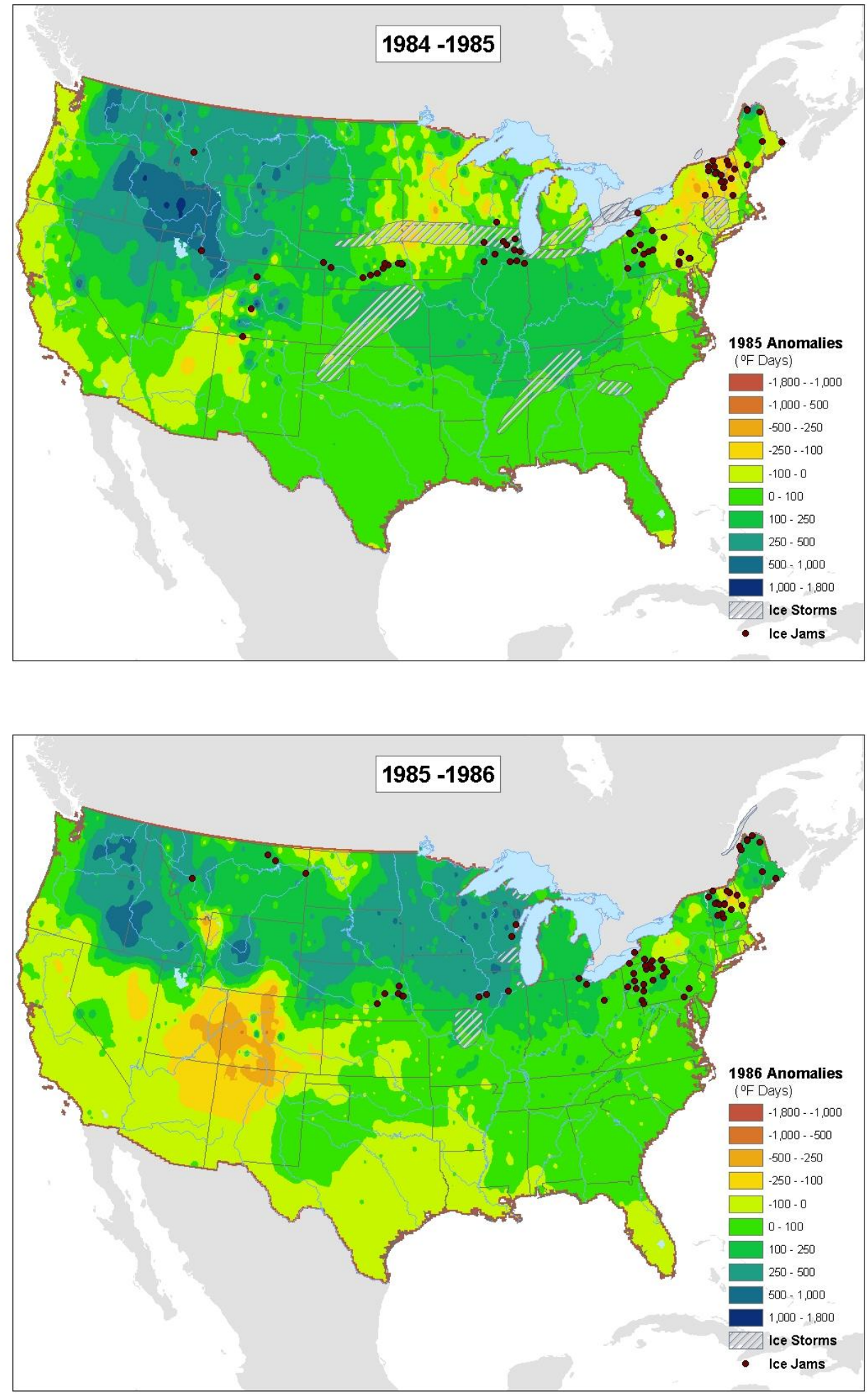

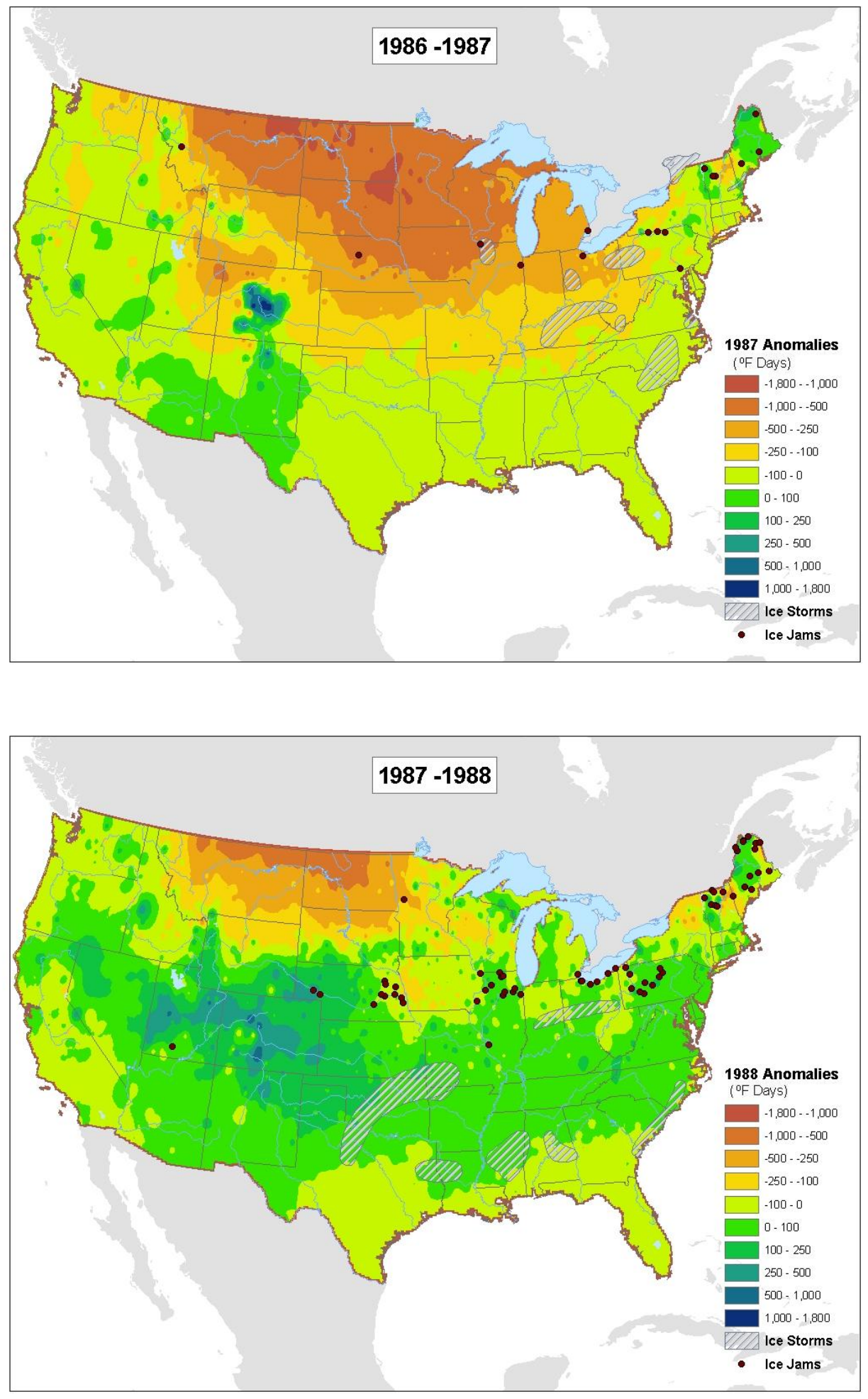

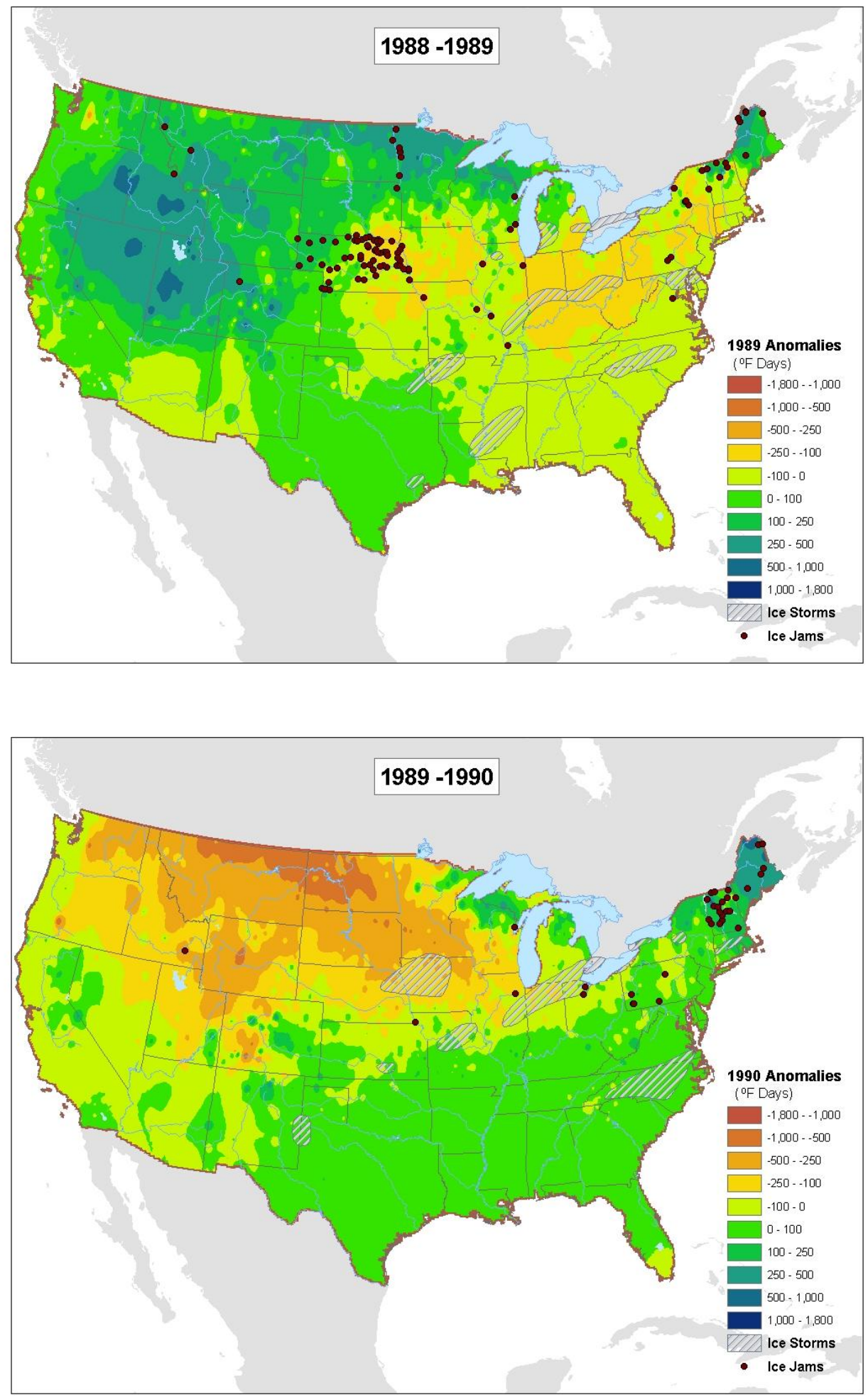

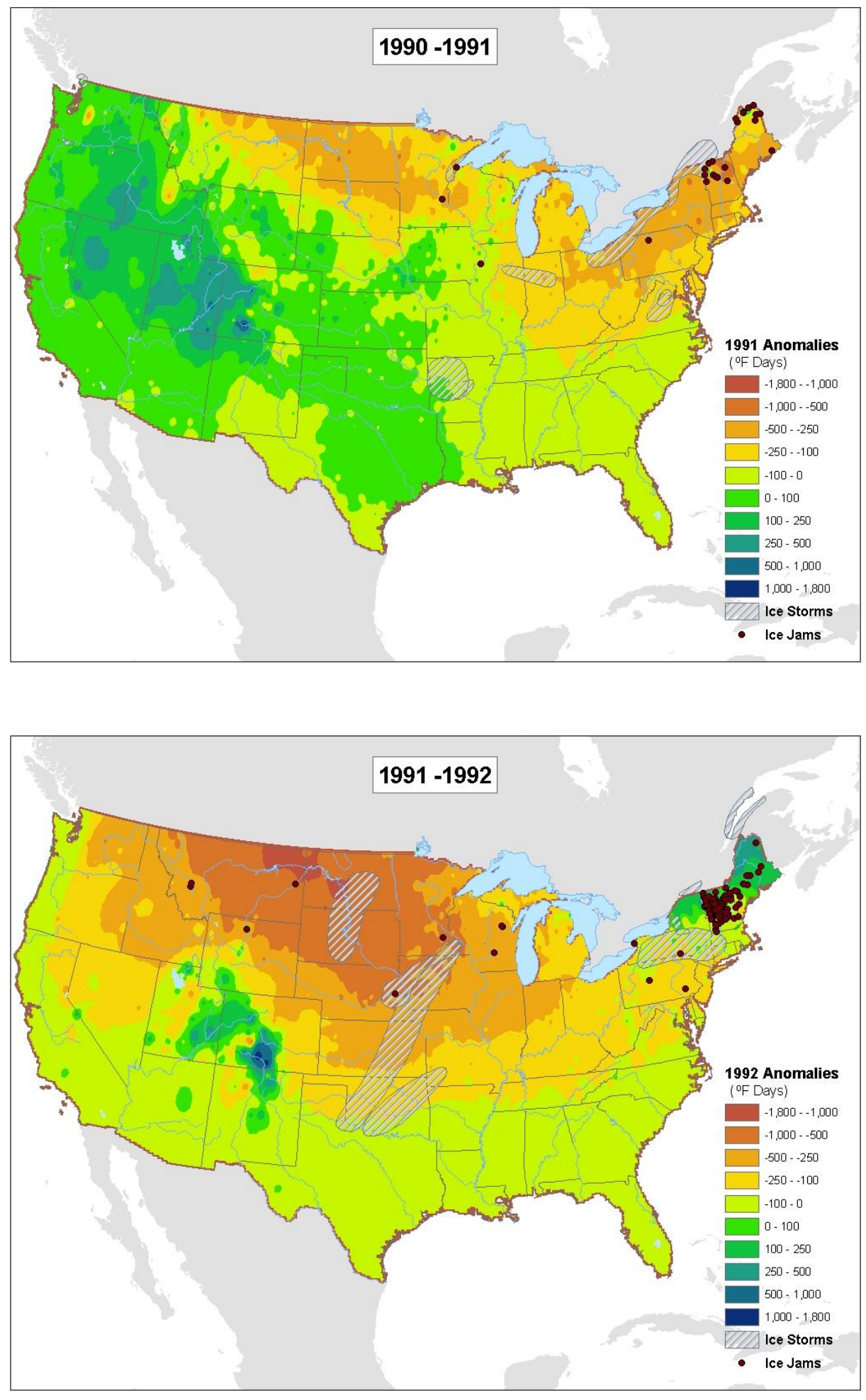

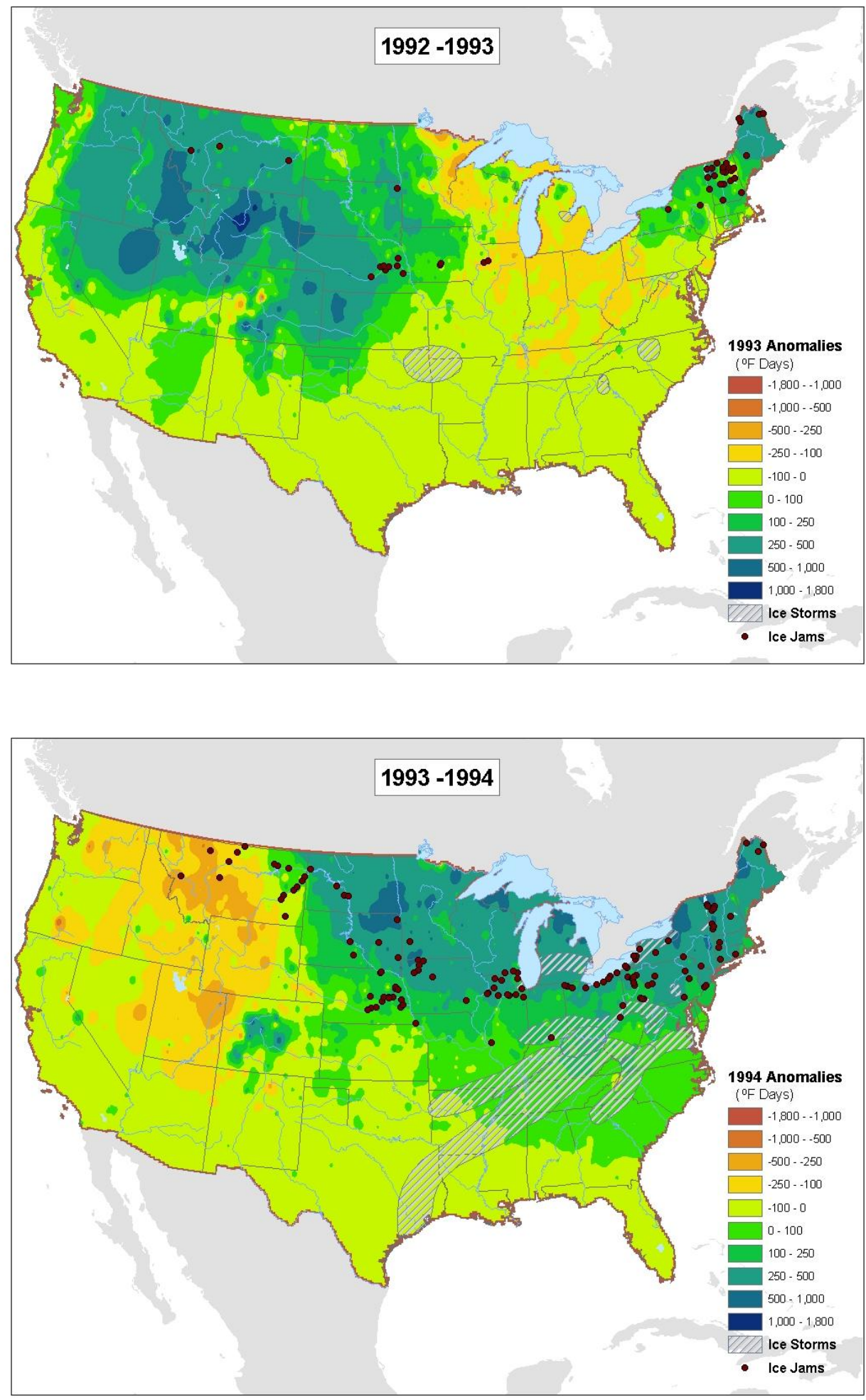

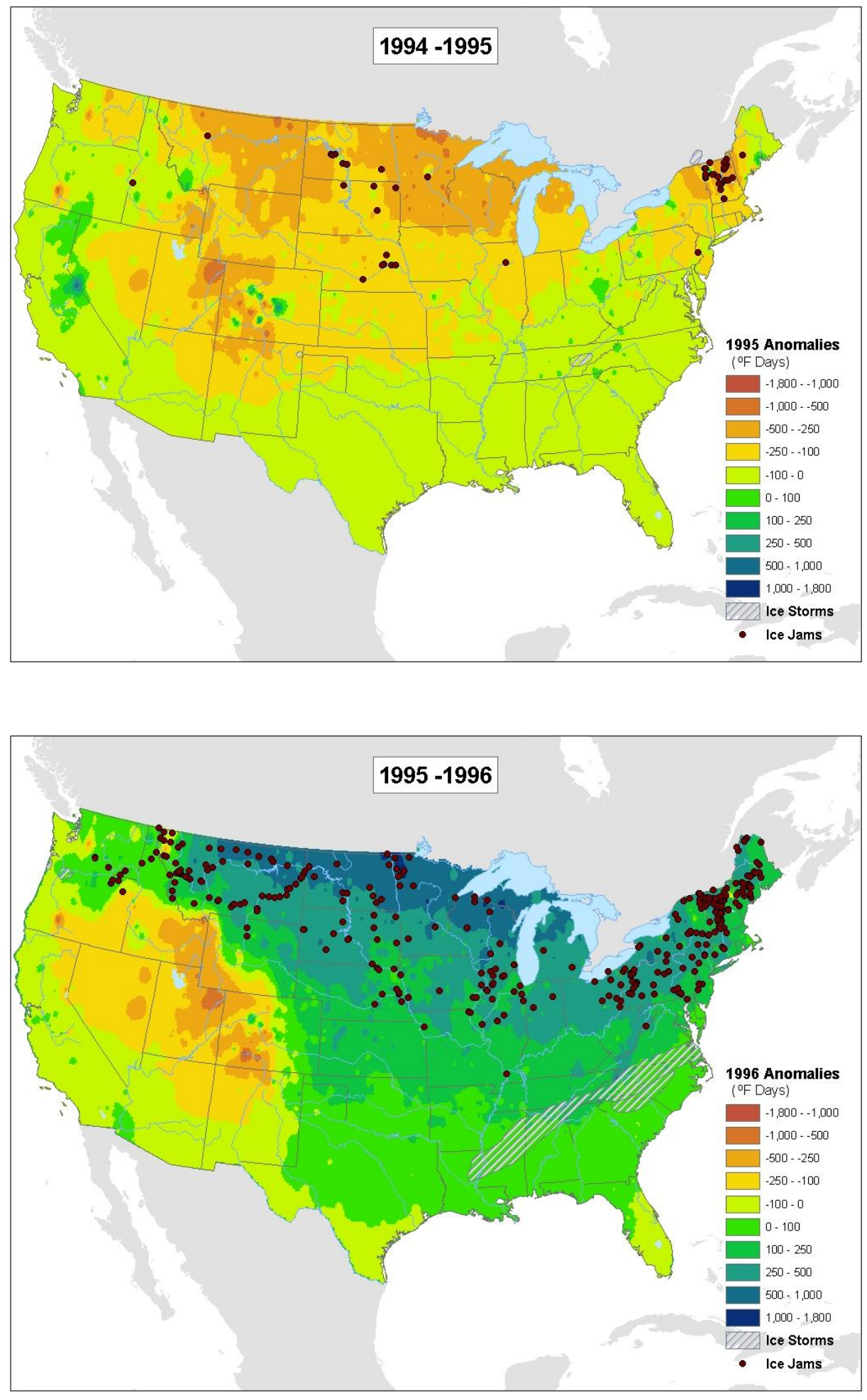

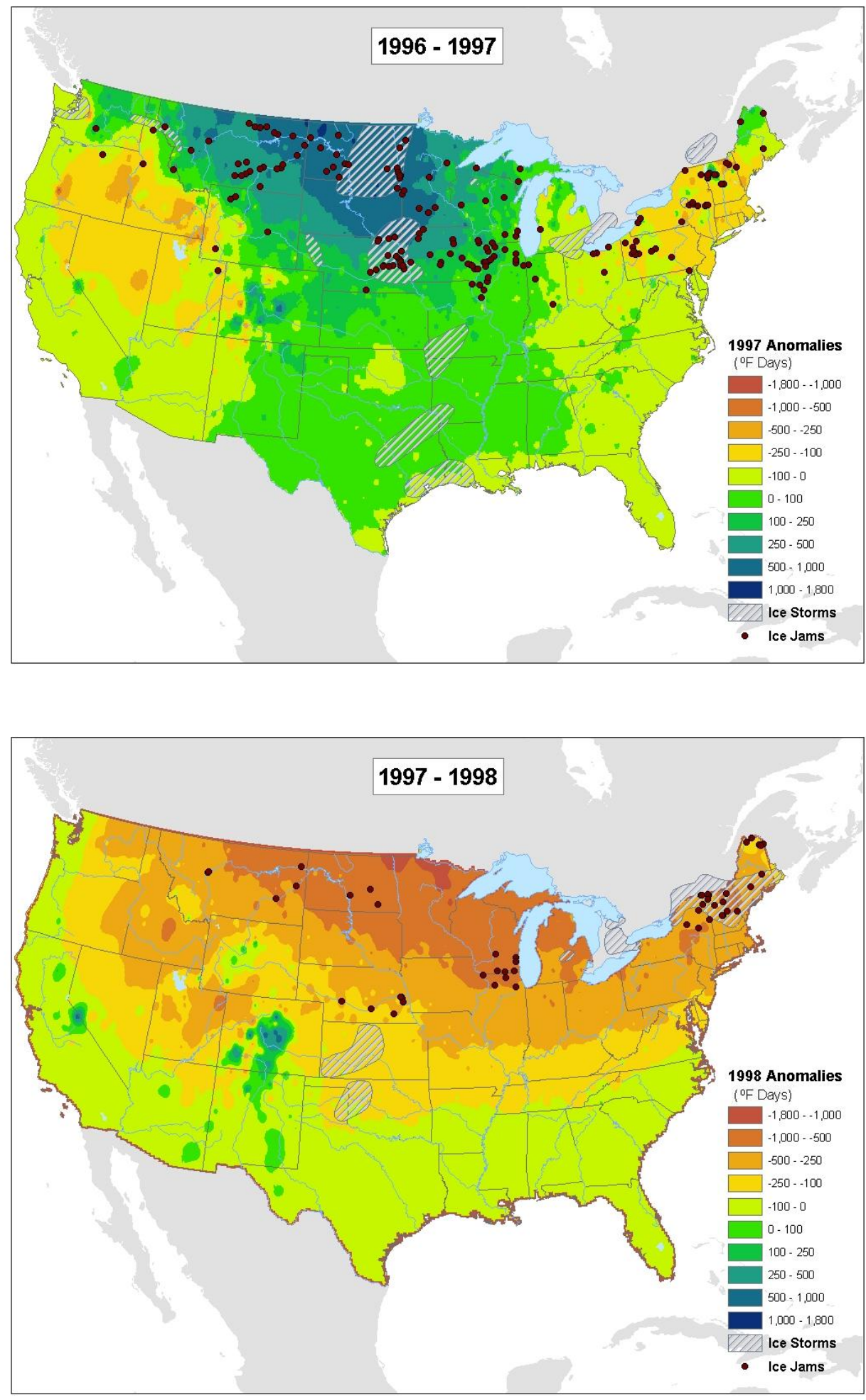

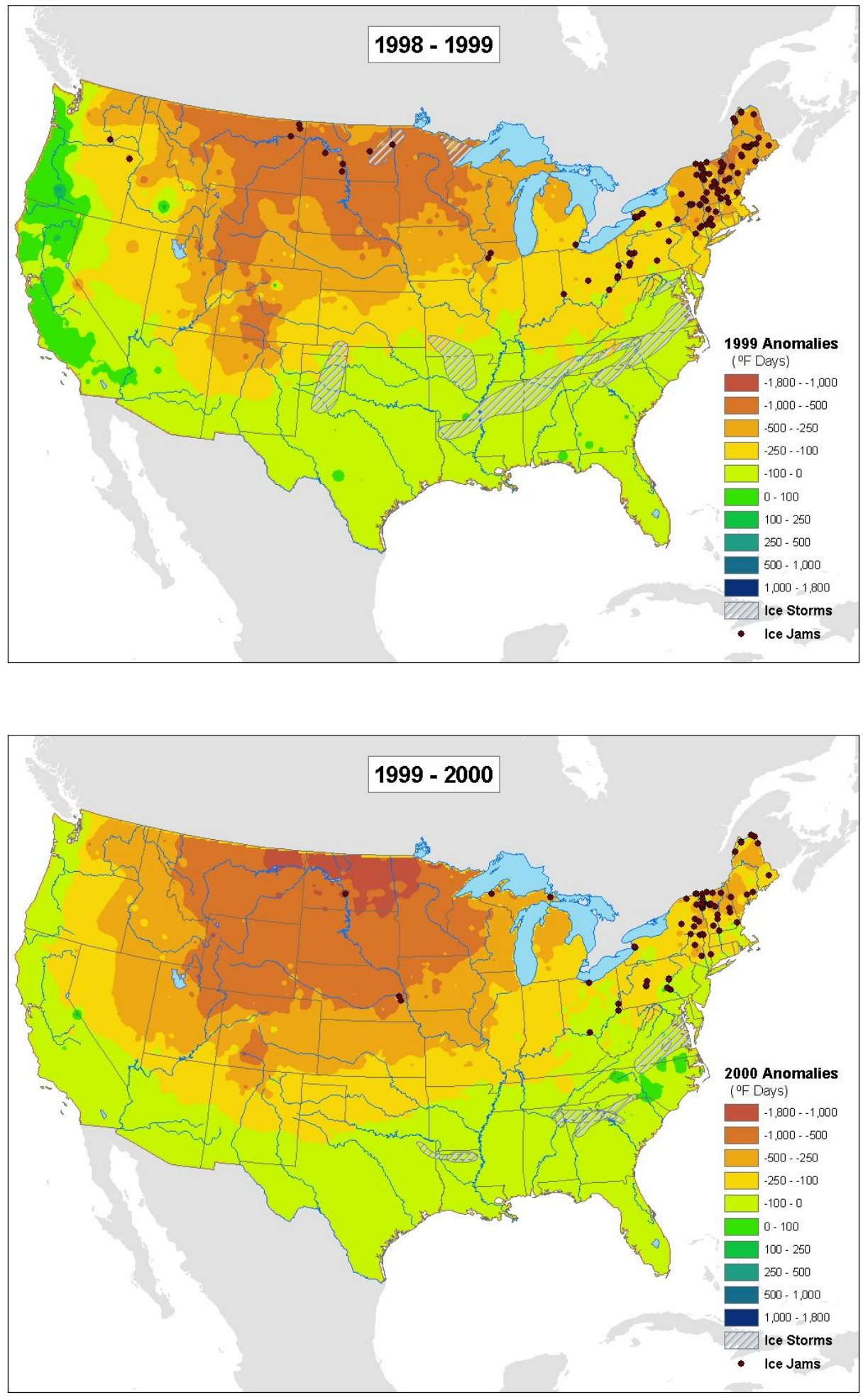


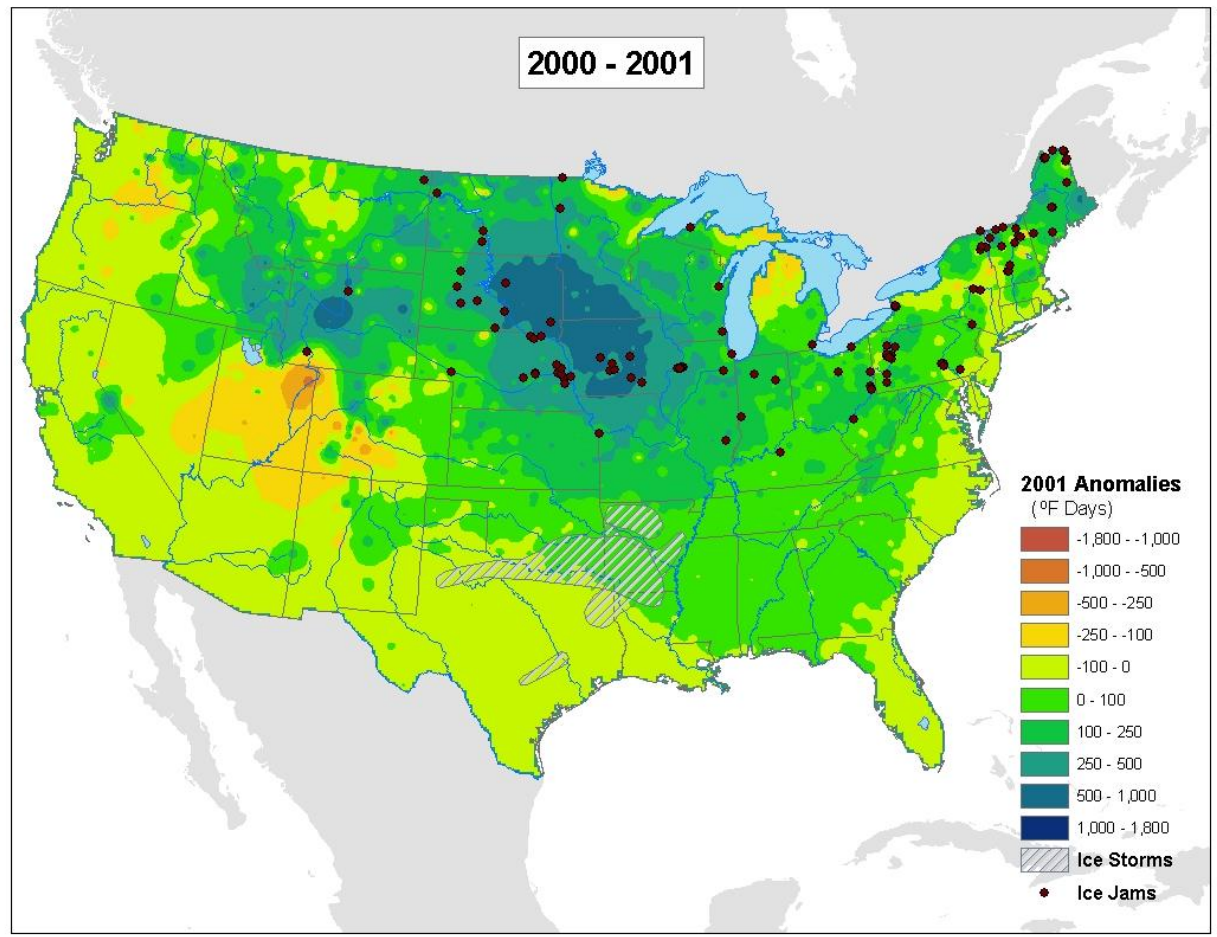




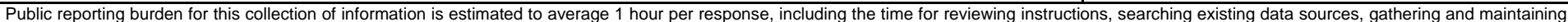

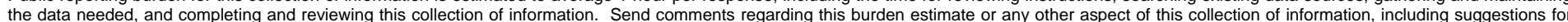

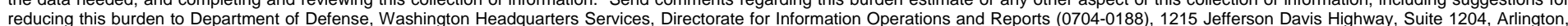

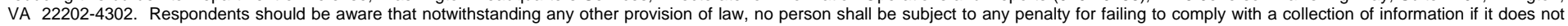
display a currently valid OMB control number. PLEASE DO NOT RETURN YOUR FORM TO THE ABOVE ADDRESS.

\begin{tabular}{l|l}
$\begin{array}{l}\text { 1. REPORT DATE (DD-MM- } Y Y Y Y) \\
\text { October } 2004\end{array}$ & $\begin{array}{l}\text { 2. REPORT TYPE } \\
\text { Technical Report }\end{array}$ \\
\hline
\end{tabular}

\section{TITLE AND SUBTITLE}

Severe Winter Weather in the Continental U.S. and Global Climate Cycles

\section{AUTHOR(S)}

Steven F. Daly, Julie E. Friddell, Kathleen F. Jones, and Carrie M. Vuyovich

3. DATES COVERED (From - To)

5a. CONTRACT NUMBER

5b. GRANT NUMBER

5c. PROGRAM ELEMENT NUMBER

5d. PROJECT NUMBER

5e. TASK NUMBER

5f. WORK UNIT NUMBER

8. PERFORMING ORGANIZATION REPORT NUMBER

ERDC/CRREL TR-04-19

Cold Regions Research and Engineering Laboratory,

72 Lyme Road

Hanover, New Hampshire 03755

9. SPONSORING I MONITORING AGENCY NAME(S) AND ADDRESS(ES)

10. SPONSOR/MONITOR'S ACRONYM(S)

U.S. Army Corps of Engineers

Washington, DC 20314-1000

11. SPONSOR/MONITOR'S REPORT NUMBER(S)

\section{DISTRIBUTION / AVAILABILITY STATEMENT}

Approved for public release; distribution is unlimited

13. SUPPLEMENTARY NOTES

\section{ABSTRACT}

The relationship between severe winter weather in the United States and global climate indices is investigated using data from 1950 to 2002. Winter severity is characterized by accumulated freezing degree-days (AFDD) and damaging freezing rain storms. The first eigenvector of the AFDD anomaly, based on data from 2282 weather stations, shows a pattern in which the entire country tends to be either warmer or colder than average, while the second eigenvector has opposite deviations in the East and West. The relationship between the first three principal component time series and five climate indices, PDO, SOI, PNA, NAO, and Northern Hemisphere temperatures, is investigated using step-wise linear regression. This analysis shows that the most important indices for explaining the annual variation in AFDD are the NAO and PNA. An estimate of the AFDD anomaly for the winter of 2003 using analog years to hindcast the climate indices significantly underestimates the warmth in the West and the cold in the Northeast. The annual variation in the area and path of ice storms is only weakly correlated with the NAO. However, the averages of the SOI and NAO in winter months with ice storms are closer to zero than their averages in winter months without ice storms. This investigation will be extended to other regions of the world to characterize the regional AFDD as well as summer temperature patterns and determine their relationships to global climate cycles

\section{SUBJECT TERMS}

Climatology

Degree-days a. REPORT

Unclassified

\section{SECURITY CLASSIFICATION OF:}

b. ABSTRACT
Unclassified

\section{Freezing}

Ice cover thickness

Ice jams

Ice storms

Weather

Winter

c. THIS PAGE

Unclassified

\begin{tabular}{l|} 
17. LIMITATION \\
OF ABSTRACT \\
Unclassified
\end{tabular}

\section{NUMBER 19 19. NAME OF RESPONSIBLE OF PAGES \\ PERSON}

87 19b. TELEPHONE NUMBER (include area code) 
